\title{
Development of High-Specificity Fluorescent Probes to Enable Cannabinoid Type 2 Receptor Studies in Living Cells
}

Roman C. Sarott, ${ }^{[a]}$ Matthias V. Westphal, ${ }^{[a]}$ Patrick Pfaff, ${ }^{[a]}$ Claudia Korn, ${ }^{[b]}$ David A. Sykes, ${ }^{[c]}$ Thais Gazzi, ${ }^{[d]}$ Benjamin Brennecke, ${ }^{[d]}$ Kenneth Atz, ${ }^{[b]}$ Marie Weise, ${ }^{[d]}$ Yelena Mostinski, ${ }^{[d]}$ Pattarin Hompluem, ${ }^{[c]}$ Eline Koers, ${ }^{[c]}$ Tamara Miljuš, ${ }^{[c]}$ Nicolas J. Roth, ${ }^{[e]}$ Hermon Asmelash, ${ }^{[e]}$ Man C. Vong, ${ }^{[c]}$ Jacopo Piovesan, ${ }^{[c]}$ Wolfgang Guba, ${ }^{[b]}$ Arne C. Rufer, ${ }^{[b]}$ Eric A. Kusznir, ${ }^{[b]}$ Sylwia Huber, ${ }^{[b]}$ Catarina Raposo, ${ }^{[b]}$ Elisabeth A. Zirwes, ${ }^{[b]}$ Anja Osterwald, ${ }^{[b]}$ Anto Pavlovic, ${ }^{[b]}$ Svenja Moes, ${ }^{[b]}$ Jennifer Beck, ${ }^{[b]}$ Irene Benito-Cuesta, ${ }^{[f]}$ Teresa Grande, ${ }^{[f]}$ Samuel Ruiz de Martín Esteban, ${ }^{[f]}$ Alexei Yeliseev, ${ }^{\left[{ }^{[a]}\right.}$ Faye Drawnel, ${ }^{[b]}$ Gabriella Widmer, ${ }^{[b]}$ Daniela Holzer, ${ }^{[b]}$ Tom van der Wel, ${ }^{[h]}$ Harpreet Mandhair, ${ }^{[i]}$ Cheng-Yin Yuan, ${ }^{[j]}$ William R. Drobyski, ${ }^{[k]}$ Yurii Saroz, ${ }^{[1]}$ Natasha Grimsey, ${ }^{[l]}$ Michael Honer, ${ }^{[b]}$ Jürgen Fingerle, ${ }^{[b]}$ Klaus Gawrisch, ${ }^{\left[{ }^{[a]}\right.}$ Julian Romero, ${ }^{[\mathrm{f}]}$ Cecilia J. Hillard, ${ }^{[\mathrm{m}]}$ Zoltan V. Varga, ${ }^{[g, n]}$ Mario van der Stelt, ${ }^{[\mathrm{h}]}$ Pal Pacher, ${ }^{[\mathrm{g}]}$ Jürg Gertsch, ${ }^{[i]}$ Peter J. McCormick, ${ }^{[e]}$ Christoph Ullmer, ${ }^{[b]}$ Sergio Oddi, ${ }^{[0, p]}$ Mauro Maccarrone, ${ }^{[p, q]}$ Dmitry B. Veprintsev, ${ }^{[c]}$ Marc Nazaré, ${ }^{[d]}$ Uwe Grether, ${ }^{*[b]}$ and Erick M. Carreira*[a]

[a]Laboratorium für Organische Chemie, Eidgenössische Technische Hochschule Zürich, Vladimir-Prelog-Weg 3, 8093 Zürich, Switzerland

${ }^{[b]}$ Roche Pharma Research \& Early Development, Roche Innovation Center Basel, F. Hoffmann-La Roche Ltd., 4070 Basel, Switzerland

${ }^{[c]}$ Faculty of Medicine \& Health Sciences, University of Nottingham, Nottingham NG7 2UH, UK; Centre of Membrane Proteins and Receptors (COMPARE), University of Birmingham and University of Nottingham, Midlands, UK

[d]Leibniz-Institut für Molekulare Pharmakologie FMP, Campus Berlin-Buch, 13125 Berlin, Germany

[e]William Harvey Research Institute, Barts and the London School of Medicine, Queen Mary University of London, London EC1M 6BQ, England

[f]Faculty of Experimental Sciences, Universidad Francisco de Vitoria, Pozuelo de Alarcón, 28223, Madrid, Spain

${ }^{[g]}$ National Institute on Alcohol Abuse and Alcoholism, National Institutes of Health, Rockville, MD 20852, USA

${ }^{[h]}$ Department of Molecular Physiology, Leiden Institute of Chemistry, Leiden University, 2333 CC, Leiden, The Netherlands

[i]Institute of Biochemistry and Molecular Medicine, University of Bern, 3012 Bern, Switzerland [i]Department of Microbiology and Immunology, Neuroscience Research Center, Medical College of Wisconsin, Milwaukee, WI 53226, USA 
${ }^{[k]}$ Department of Medicine, Neuroscience Research Center, Medical College of Wisconsin, Milwaukee, WI 53226, USA

["]Department of Pharmacology and Clinical Pharmacology, School of Medical Sciences, Faculty of Medical and Health Sciences, University of Auckland, 1142 Auckland, New Zealand ${ }^{[m]}$ Department of Pharmacology and Clinical Pharmacology, Neuroscience Research Center, Medical College of Wisconsin, Milwaukee, WI 53226, USA

${ }^{[n] H C E M M-S U ~ C a r d i o m e t a b o l i c ~ I m m u n o l o g y ~ R e s e a r c h ~ G r o u p, ~ D e p a r t m e n t ~ o f ~ P h a r m a c o l o g y ~}$ and Pharmacotherapy, Semmelweis University, 1085 Budapest, Hungary ${ }^{[0]}$ Faculty of Veterinary Medicine, University of Teramo, 64100 Teramo, Italy ${ }^{[p]}$ European Center for Brain Research (CERC)/Santa Lucia Foundation, 00179 Rome, Italy ${ }^{[a]}$ Department of Applied Clinical and Biotechnological Sciences, University of L'Aquila, 67100 L'Aquila, Italy 


\section{Supporting Information}

\section{Table of Contents}

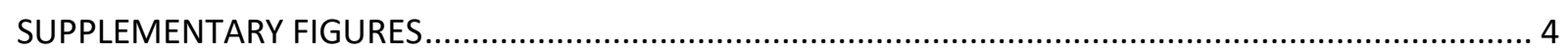

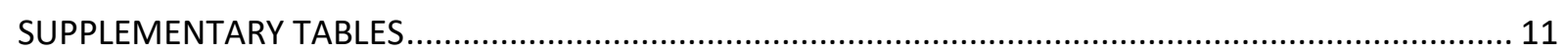

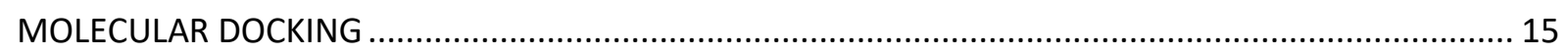

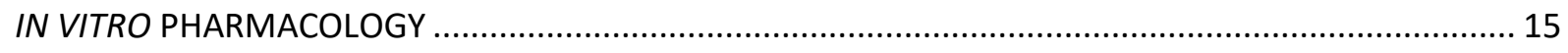

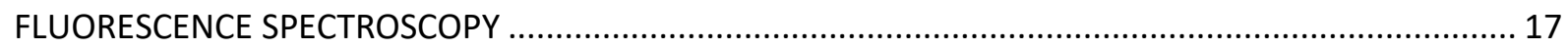

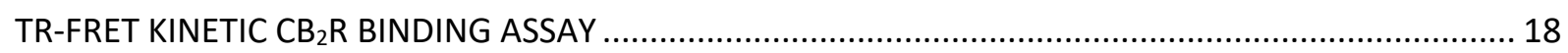

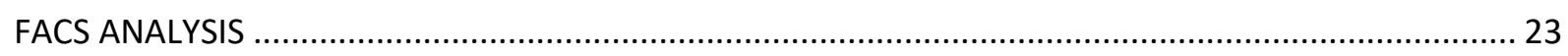

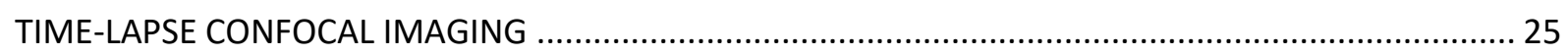

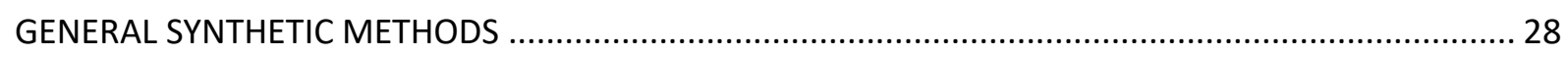

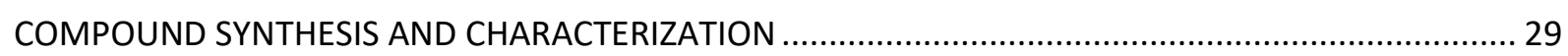

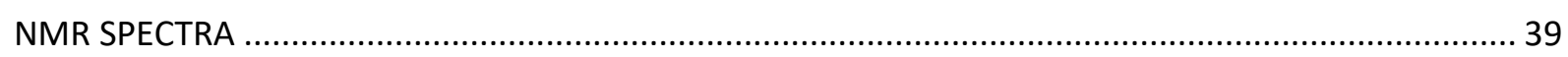

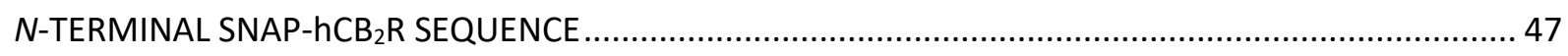

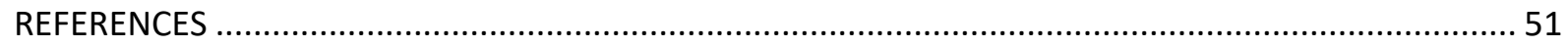




\section{SUPPLEMENTARY FIGURES}

A UV-Vis spectra of $3 b$ (DY-480XL)

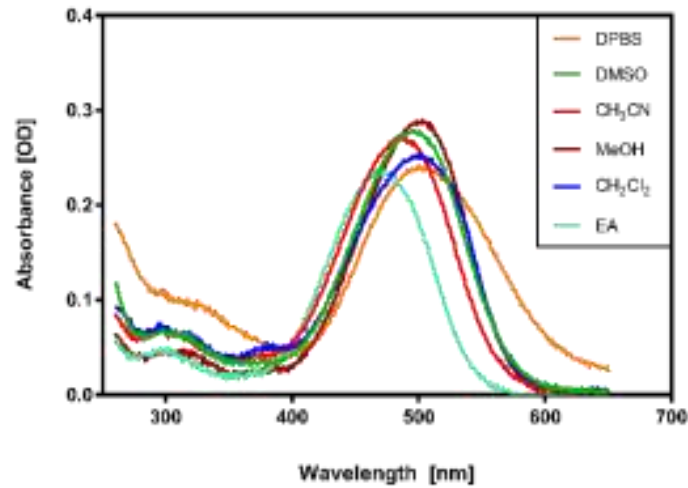

C UV-Vis spectra of 4 (Alexa647)

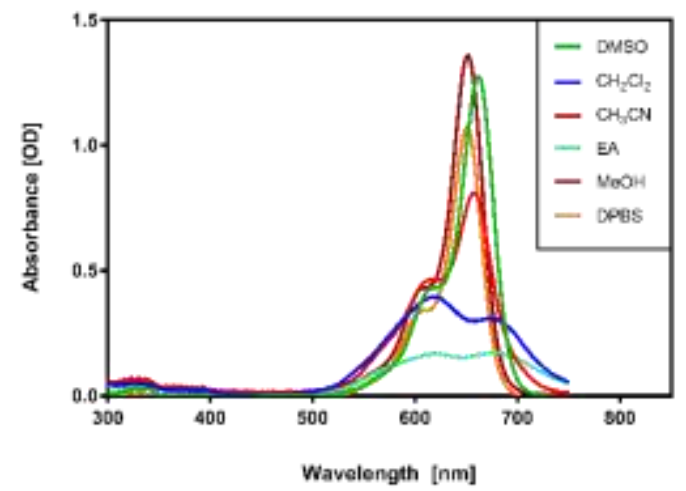

E UV-Vis spectra of 5 (Alexa488)

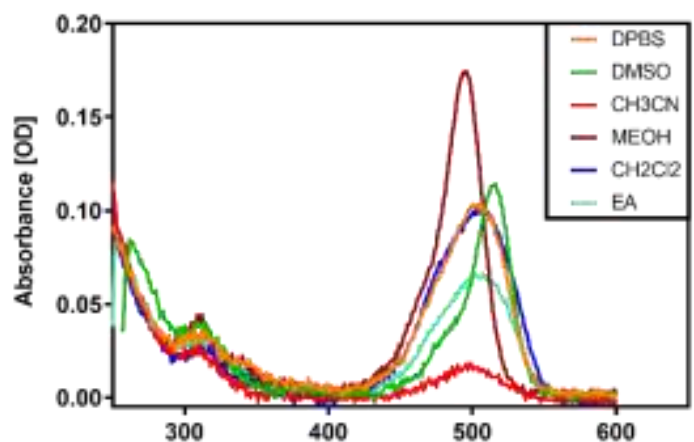

Wavelength [nm]
B Fluorescence spectra of $\mathbf{3 b}$ (DY-480XL)

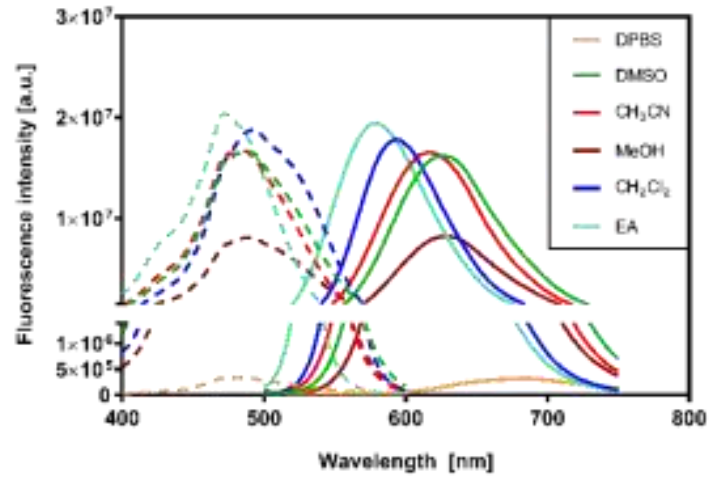

D Fluorescence spectra of 4 (Alexa647)

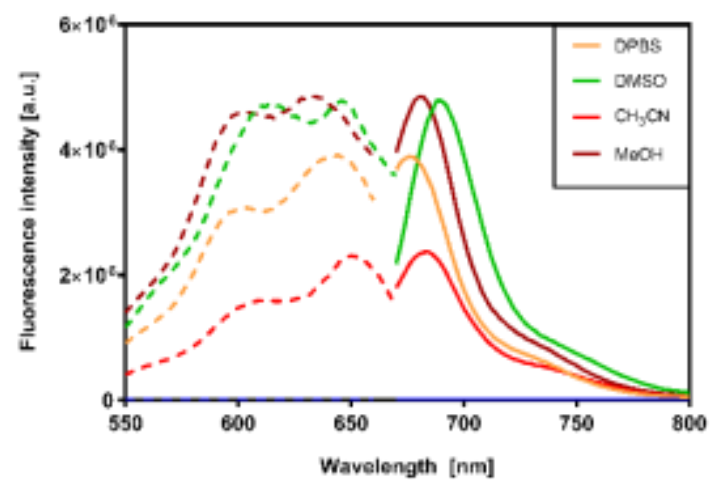

F $\quad$ Fluorescence spectra of $\mathbf{5}$ (Alexa488)

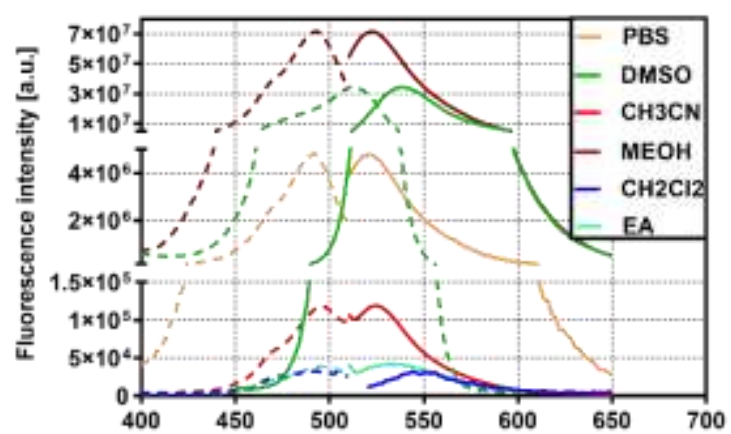

Wavelength [nm] 
G UV-Vis spectra of 6 (AttoThio12)

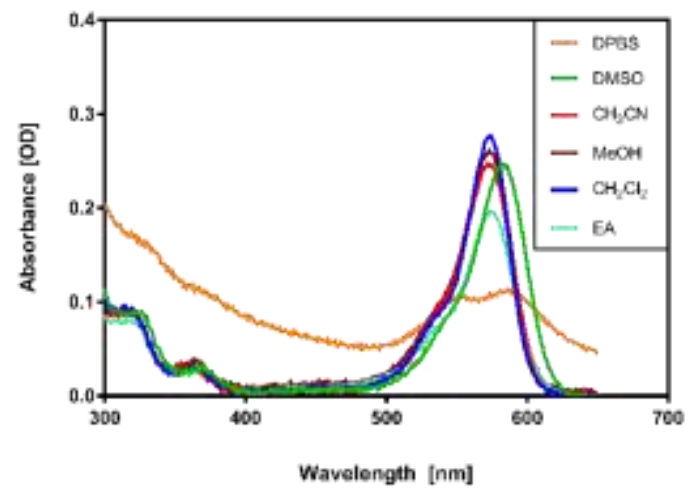

H Fluorescence spectra of 6 (AttoThio12)

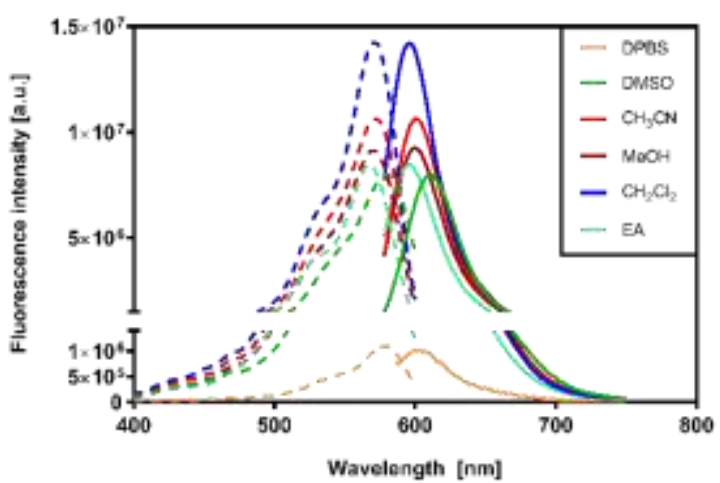

Figure S1. Solution spectra of compound 3b (DY480-XL) (A and B), 4 (Alexa647) (C and D), 5 (Alexa488) (E and F) and 6 (AttoThio12) (G and H). A/C/E/G) UV-Vis spectra (10 $\mu \mathrm{M}$ compound); B/D/F/H) technical excitation and emission fluorescence spectra not corrected for chromatic aberrations (10 $\mu \mathrm{M}$ compound) in indicated organic solvents (DMSO, methylene chloride $\left(\mathrm{CH}_{2} \mathrm{Cl}_{2}\right)$, acetonitrile $\left(\mathrm{CH}_{3} \mathrm{CN}\right)$, ethyl acetate $(\mathrm{EA})$ and methanol $(\mathrm{MeOH})$ and aqueous solution DPBS (Dulbecco's phosphate buffered saline). Excitation and emission spectra are depicted with dashed or solid lines, respectively.

\section{Activation of G protein on E. coli membranes}

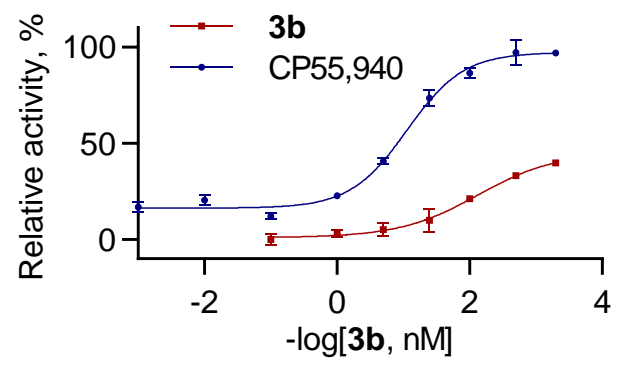

Figure S2. $\left[{ }^{35} \mathrm{~S}\right] \mathrm{GTP}-\gamma-\mathrm{S}$ G protein activation assay employing $\mathrm{CB}_{2} \mathrm{R}$ on $E$. coli membranes. $3 \mathrm{~b} \mathrm{EC}_{50}=133 \mathrm{nM}, \%$ eff $=44$ relative to $\mathrm{CP} 55,940$. 
A

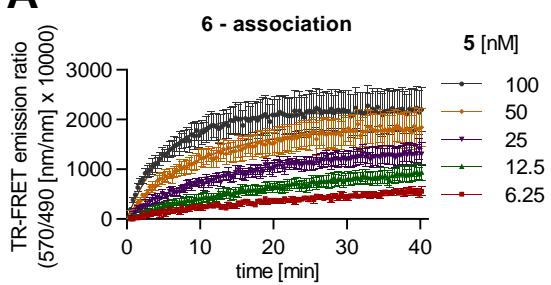

D

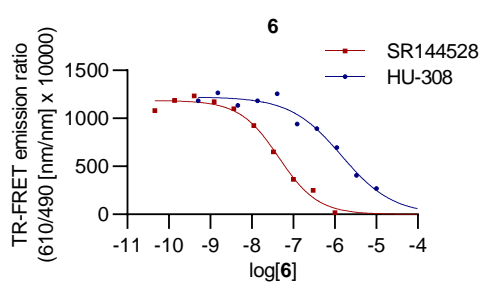

B

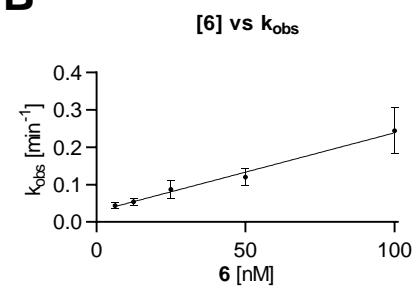

$\mathbf{E}$

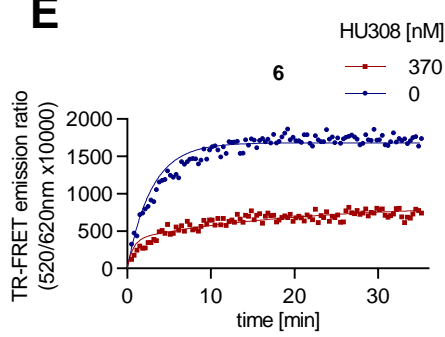

C

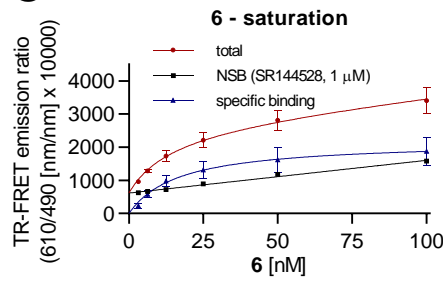

$\mathbf{F}$

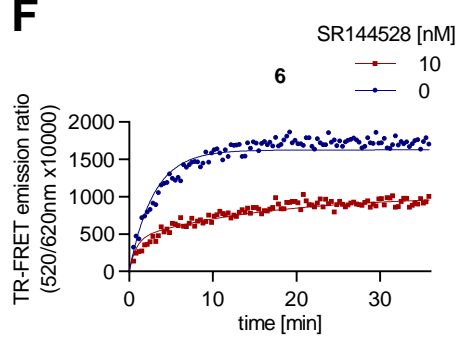

Figure S3. FRET-based fluorescent probe characterization with determination of affinities and binding kinetics of $\mathrm{CB}_{2} \mathbf{R}$ compounds. A) Observed association of probe 6 binding to $\mathrm{hCB}_{2} \mathrm{R}$. B) Plot of probe 6 concentration versus observed association rate, $\mathrm{k}_{\text {obs }}$ increased linearly with fluorescent ligand concentration. C) Saturation analysis showing the binding of probe 6 to $\mathrm{hCB}_{2} \mathrm{R}$. D) Competition association between probe 6 (100 nM) and increasing concentrations of $\mathrm{CB}_{2} \mathrm{R}$ specific ligands $\mathrm{HU}-308$ and $\mathrm{SR} 144528$ for $\mathrm{hCB}_{2} \mathrm{R}$. Competition association curves of 6 in the presence of E) HU-308 and F) SR144528. All binding reactions were performed in the presence of GppNHp $(100 \mu \mathrm{M})$ to prevent receptor $\mathrm{G}$ protein coupling and the formation of the artificial high-affinity state. Nonspecific-binding levels were determined by inclusion of SR144528 $(1 \mu \mathrm{M})$. Kinetic and equilibrium data were fitted to the equations described in this Supporting Information to calculate $K_{d}$, and $k_{\text {on }}$ and $k_{\text {off }}$ values for the fluorescent probes; these are summarized in Table 2. Data are presented in mean \pm SEM from a representative of 3-5 experiments. 


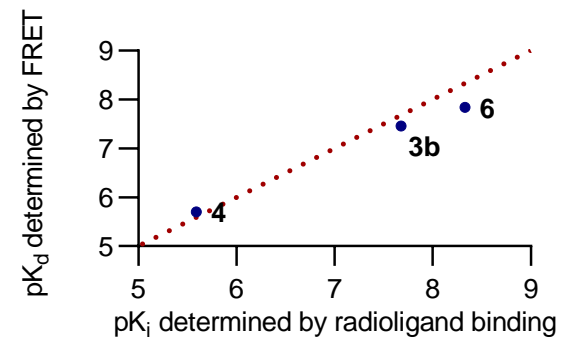

\begin{tabular}{|c|c|}
\hline$R$ squared & 0.9965 \\
\hline & \\
\hline$P$ value & \\
\hline$P$ (two-tailed) & 0.0379 \\
\hline
\end{tabular}

Figure S4. Fluorescent probe binding affinities. Good correlation between $\mathrm{pK}_{\mathrm{d}}$ and $\mathrm{pK}_{\mathrm{i}}$ values obtained by FRET (HEK293T-Rex SNAP-hCB ${ }_{2} \mathrm{R}$ membranes) and by radioligand assays ( $h \mathrm{CB}_{2} \mathrm{R}-\mathrm{CHO}$ cell membrane preparations) was observed. This suggests that addition of a SNAP-tag to the $N$-terminus of the $\mathrm{CB}_{2} \mathrm{R}$ did not affect its pharmacological properties and also validates the FRET binding data showing the usefulness of these probes as fluorescent tracers.
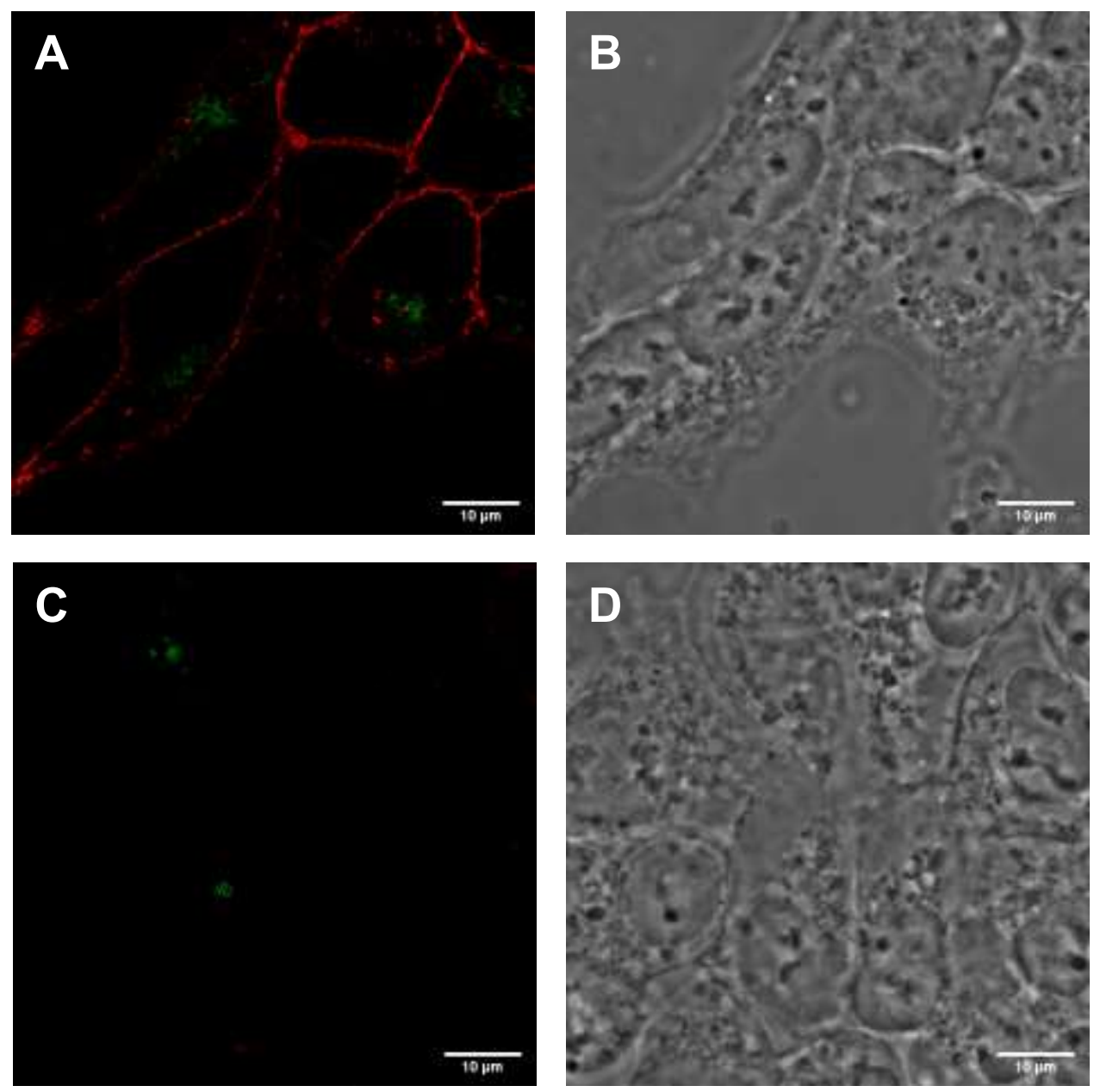
Figure S5. A) Confocal and B) widefield images of N-terminal SNAPtagged-hCB ${ }_{2} R$ expressing T-REx 293 cells labelled with SNAP surface (red) and SNAP cell (green). C) Confocal and D) widefield images of non-expressing T-REx 293 cells depicted processed in the same way. SNAP-hCB ${ }_{2} \mathrm{R}$ is almost exclusively expressed on cell membrane. Signal in green channel is comparable in intensity to background.

A

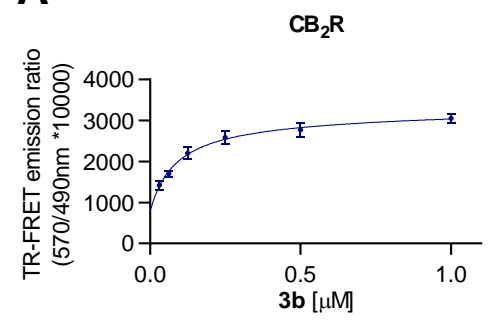

C

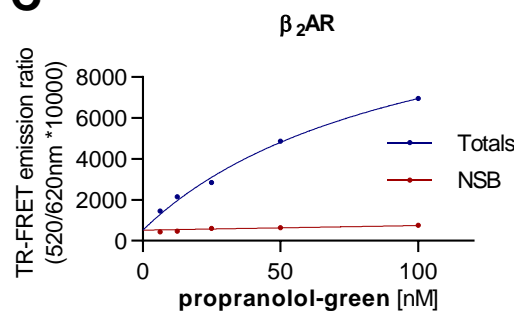

B

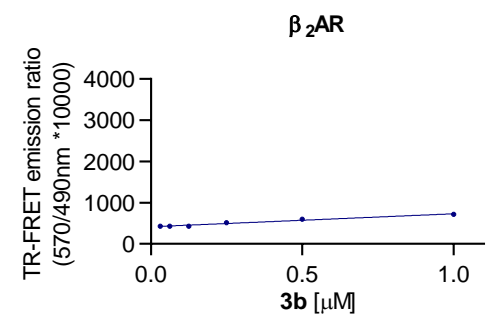

D

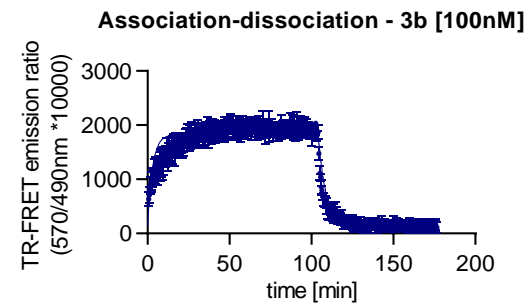

Figure S6. Probe specificity and ligand reversibility demonstrated by TR-FRET binding experiments. A) Total Binding of probe $3 \mathbf{b}$ to $\mathrm{HEK}-\mathrm{CB}_{2} \mathrm{R}$. Saturation is indicative of specific target binding. B) Total binding of probe $\mathbf{3 b}$ to HEK- $\beta_{2} A R$; linear behavior is indicative of nonspecific binding (NSB). C) Binding studies of propranolol green to HEK- $\beta_{2} A R$ membranes. D) Association-dissociation experiments for $\mathbf{3 b}$ in which HU-308 $(10 \mu \mathrm{M})$ added at 100 min results in full dissociation of the probe. 
A

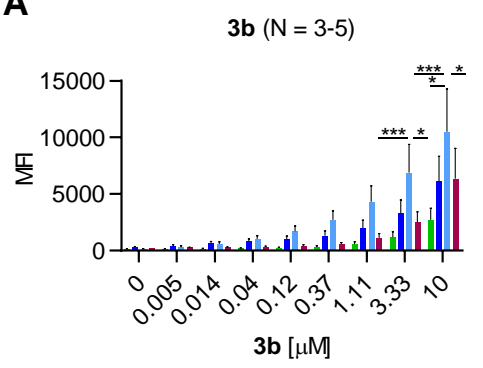

C
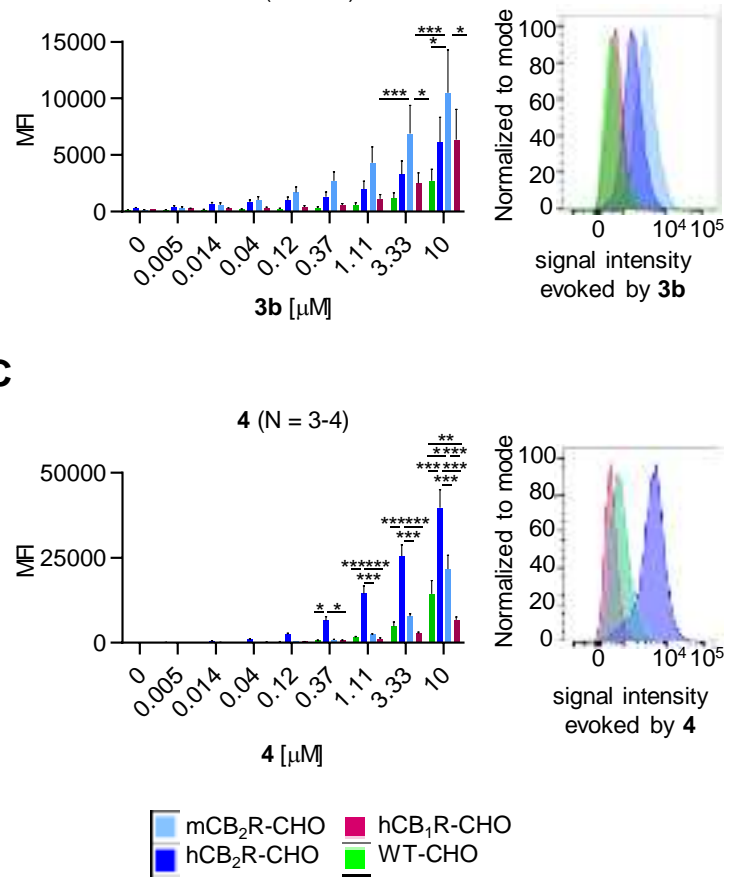

B

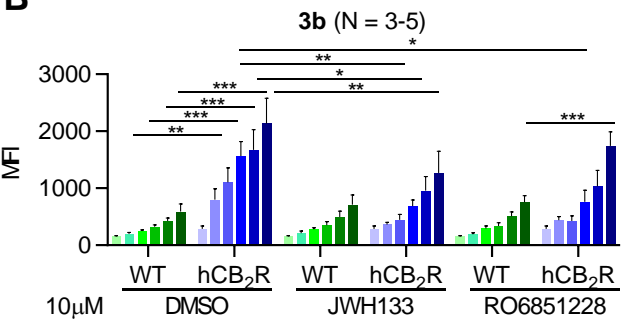

D

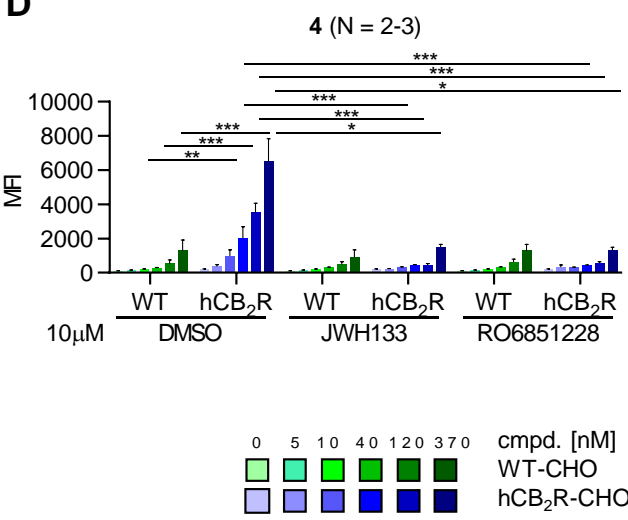

Figure S7. A/C) FACS analysis of cells incubated with fluorescent probes at varying concentrations. Representative fluorescent intensity histograms of cells incubated with $0.37 \mu \mathrm{M}$ fluoroprobe. Mean \pm SEM Two-way ANOVA followed by Bonferroni post hoc analysis, ${ }^{*} p<0.05$; ${ }^{* *} p<0.01$; ${ }^{* *} p<0.005$. B/D) FACS analysis of cells pre-treated with $10 \mu \mathrm{M}$ of competitor ligands and subsequently stained with varying concentrations of fluoroprobe. Mean \pm SEM, Two-way ANOVA followed by Bonferroni post hoc analysis, ${ }^{*} p<0.05 ;{ }^{* *} p<0.01 ;{ }^{* * *} p<$ 0.005 . 

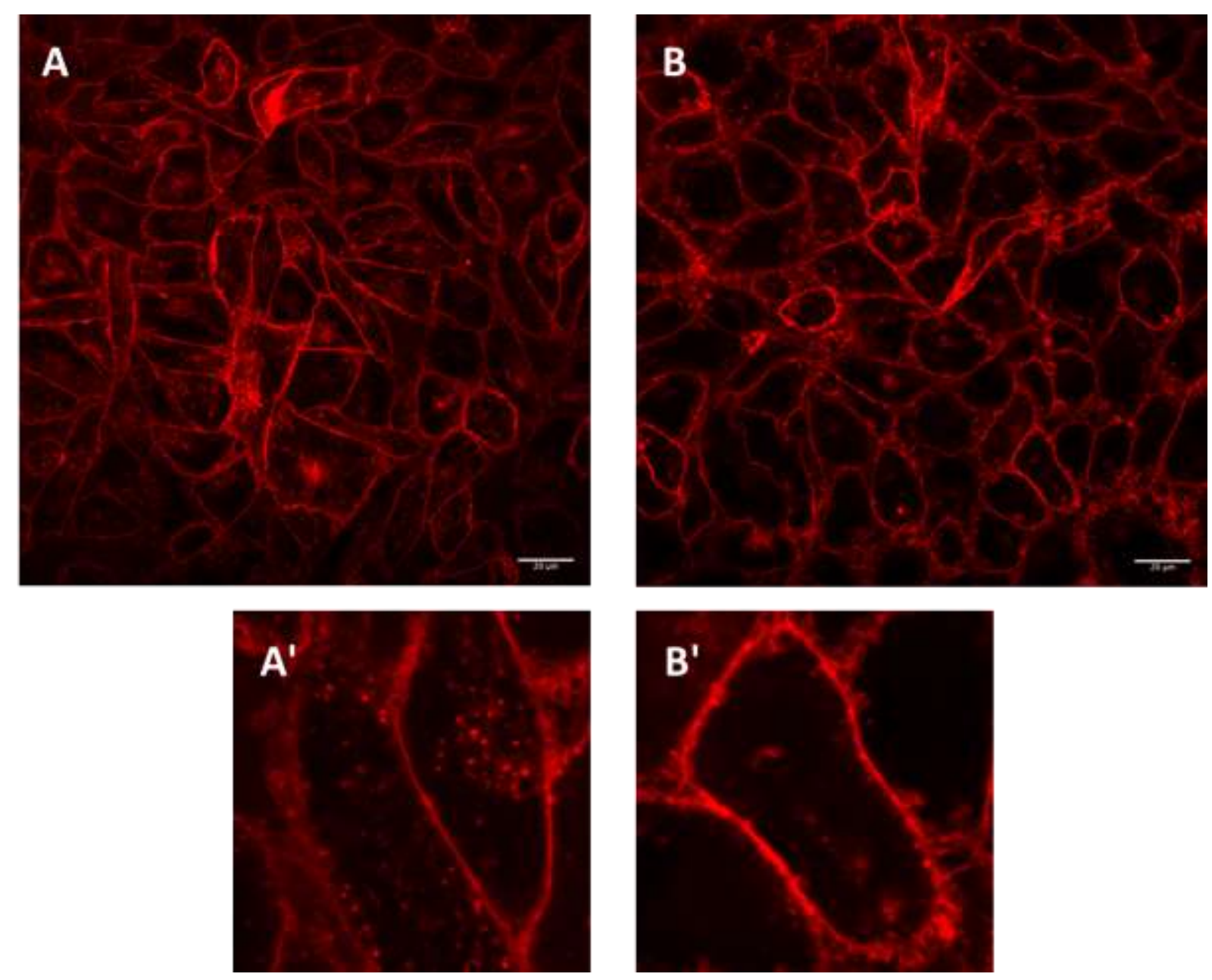

Figure S8. A) Airyscan high-resolution imaging of $\mathrm{CHO}$ cells overexpressing $h \mathrm{CB}_{2} \mathrm{R}$ incubated with $0.2 \mu \mathrm{M}$ 3b. B) Co-incubation with endocytosis inhibitors reduces level of fluorescent probe internalization. Pictures showed cells incubated for $1 \mathrm{~h}$ with $\mathbf{3 b}$ in the absence (A and $\left.A^{\prime}\right)$ and in the presence ( $B$ and $B^{\prime}$ ) of endocytosis inhibitors (i.e. $400 \mathrm{mM}$ sucrose and $5 \mu \mathrm{g} / \mathrm{mL}$ filipin). In the presence of sucrose and filipin, the reduction of $h \mathrm{hCB}_{2} \mathrm{R}$ receptor endocytosis was almost complete, as shown by the robust decrease in punctate vesicles within the cells (see magnified regions shown in panels $\left.A^{\prime} / B^{\prime}\right)$. 


\section{SUPPLEMENTARY TABLES}

Table S1. Fluorescence excitation and emission wavelengths for $\mathrm{CB}_{2} \mathrm{R}$-selective fluorescent ligands $(10 \mu \mathrm{M})$ with corresponding fluorescence intensities and Stokes shifts recorded in various solvents.

\begin{tabular}{|c|c|c|c|c|c|c|c|}
\hline Probe & $\begin{array}{l}\text { Fluorescence } \\
\text { data }\end{array}$ & DPBS & DMSO & $\mathrm{CH}_{3} \mathrm{CN}$ & $\mathrm{MeOH}$ & $\mathrm{CH}_{2} \mathrm{Cl}_{2}$ & EA \\
\hline \multirow{4}{*}{ 3b (DY-480XL) } & Excitation $\lambda[\mathrm{nm}]$ & 486 & 486 & 484 & 490 & 492 & 472 \\
\hline & Emission $\lambda[\mathrm{nm}]$ & 684 & 626 & 616 & 628 & 594 & 578 \\
\hline & Stokes shift [nm] & 198 & 140 & 132 & 138 & 102 & 106 \\
\hline & $\begin{array}{l}\text { Signal intensity } \\
\cdot 10^{6}[\text { a.u. }]^{[a]}\end{array}$ & $0.3^{[b]}$ & 16.7 & 16.7 & 8.1 & 18.8 & 20.4 \\
\hline \multirow{4}{*}{4 (Alexa647) } & Excitation $\lambda[\mathrm{nm}]$ & 648 & 648 & 648 & 632 & $n t$ & $n t$ \\
\hline & Emission $\lambda[\mathrm{nm}]$ & 680 & 689 & 689 & 680 & $n t$ & $n t$ \\
\hline & Stokes shift [nm] & 32 & 41 & 41 & 48 & na & na \\
\hline & $\begin{array}{l}\text { Signal intensity } \\
\cdot 10^{6} \text { [a.u.] }\end{array}$ & 3.8 & 4.7 & 2.3 & 4.9 & $n t$ & $n t$ \\
\hline \multirow{4}{*}{5 (Alexa488) } & Excitation $\lambda[\mathrm{nm}]$ & 492 & 512 & 496 & 492 & 492 & 496 \\
\hline & Emission $\lambda[\mathrm{nm}]$ & 522 & 538 & 524 & 522 & 544 & 532 \\
\hline & Stokes shift [nm] & 30 & 26 & 28 & 30 & 52 & 36 \\
\hline & $\begin{array}{l}\text { Signal intensity } \\
\cdot 10^{6} \text { [a.u.] }\end{array}$ & 4.8 & 34.3 & 1.2 & 71.5 & 0.3 & 0.4 \\
\hline \multirow{4}{*}{6 (AttoThio12) } & Excitation $\lambda[\mathrm{nm}]$ & 576 & 578 & 578 & 570 & 570 & 568 \\
\hline & Emission $\lambda[\mathrm{nm}]$ & 600 & 610 & 600 & 600 & 596 & 596 \\
\hline & Stokes shift [nm] & 24 & 32 & 22 & 30 & 26 & 28 \\
\hline & $\begin{array}{l}\text { Signal intensity } \\
\text { - } 10^{6} \text { [a.u.] }\end{array}$ & 1.0 & 8.0 & 10.6 & 9.1 & 14.2 & 8.5 \\
\hline
\end{tabular}

[a] a.u. - arbitrary units [b] limited solubility in DPBS, measured at $1.0 \mu \mathrm{M}$ in presence of $0.1 \%$ (v/v) DMSO; nt: not tested; na: not applicable

\section{Discussion of Results}

As expected, the fluorescence intensity observed for compounds $3 \mathbf{b}$ (DY-480XL) and for 6 (AttoThio12) increased with decreasing dielectric constant of the solvents: aqueous solution (PBS, $\left.\varepsilon_{25}=79.0\right)<$ dimethyl sulfoxide (DMSO, $\left.\varepsilon_{20}=47\right)<$ acetonitrile $\left(\mathrm{CH}_{3} \mathrm{CN}, \varepsilon_{20}=36.64\right) \leq$ methanol $\left(\mathrm{MeOH}, \varepsilon_{25}=32.6\right)<$ methylene chloride $\left(\mathrm{CH}_{2} \mathrm{Cl}_{2}, \varepsilon_{20}=9.08\right) \leq$ ethyl acetate $\left(\mathrm{EA}, \varepsilon_{25}\right.$ $=6{ }^{[1],[2]}$ Consequently, the fluorescence intensity is expected to increase when in close proximity of the cell membrane $(\varepsilon=3)$ or when bound to the hydrophobic binding site of $C_{2} R$. The lower fluorescence intensity values observed for 3b (DY-480XL) and 6 (AttoThio12) in methanol $(\mathrm{MeOH})$ and ethyl acetate $(\mathrm{EA})$, respectively, may indicate specific solvent effects, but overall the expected trend of increasing of fluorescence signal intensity with decrement of solvent polarity is observed.

3b (DY-480XL). The fluorescence excitation and emission maxima were observed at wavelengths ranging from $472-490 \mathrm{~nm}$ and $594-684 \mathrm{~nm}$, respectively, depending on the applied solvent. The highest fluorescence emission signal was observed in ethyl acetate (Fig. 
S1 and Table S1). The lowest fluorescence signal was observed in aqueous solution (DPBS). An increasing redshift of the fluorescence emission maxima with increasing solvent polarity was observed, with the highest shift $(106 \mathrm{~nm})$ monitored for aqueous solution DPBS when compared to ethyl acetate. The Stokes shift was found to be relatively high with the lowest value of $102 \mathrm{~nm}$ observed in methylene chloride and the highest shift value of $198 \mathrm{~nm}$ observed in DPBS.

4 (Alexa647). The fluorescence excitation and emission maxima were observed at wavelengths ranging from $632-648 \mathrm{~nm}$ and $680-689 \mathrm{~nm}$, respectively, depending on the applied solvent. The highest fluorescence emission signal was observed in methanol and DMSO (Fig. S1 and Table S1). The lowest fluorescence signal was observed in acetonitrile. The Stokes shift was observed to be between $32 \mathrm{~nm}$ in phosphate buffer and $48 \mathrm{~nm}$ in methanol.

5 (Alexa488). The fluorescence excitation and emission maxima were observed at wavelengths ranging from 492 - $512 \mathrm{~nm}$ and 522 - $544 \mathrm{~nm}$, respectively, depending on the applied solvent. The highest fluorescence emission signal was observed in methanol (Fig. S1 and Table S1). The lowest fluorescence signal was observed in methylene chloride. The Stokes shift was observed to be between $26 \mathrm{~nm}$ in DMSO and $52 \mathrm{~nm}$ in methylene chloride.

6 (AttoThio12). The fluorescence excitation and emission maxima were observed at wavelengths ranging from $570-578 \mathrm{~nm}$ and $596-610 \mathrm{~nm}$, respectively, depending on the applied solvent. The highest fluorescence emission signal was observed in methylene chloride (Fig. S1 and Table S1). The lowest fluorescence signal was observed in ethyl acetate. The Stokes shift was observed to be $22 \mathrm{~nm}$ in acetonitrile and $32 \mathrm{~nm}$ in DMSO. 
Table S2. Evaluation of $\mathbf{3 b}$ off-target activity via screening against a representative set of common off-targets (Eurofins)..[3] Data shown is the mean percentage of inhibition for binding assays and the mean percentage of inhibition for enzyme and cell-based assays at a test concentration of $10 \mu \mathrm{M}(\mathrm{n}=2)$.

\begin{tabular}{|c|c|c|}
\hline ASSAY NAME & RESPONSE/READOUT & VALUE \\
\hline MAO-A (h) & Enzymatic activity & -1.5 \\
\hline 5-HT transporter (h) (antagonist radioligand) & Specific binding & -1.0 \\
\hline $5-\mathrm{HT}_{1 \mathrm{~A}}(\mathrm{~h})$ (agonist radioligand) & Specific binding & 7.0 \\
\hline $5-\mathrm{HT}_{2 \mathrm{~A}}(\mathrm{~h})$ (agonist radioligand) & Specific binding & -1.6 \\
\hline $5-\mathrm{HT}_{2 \mathrm{~B}}(\mathrm{~h})$ (agonist radioligand) & Specific binding & 39.0 \\
\hline 5- $\mathrm{HT}_{3}(\mathrm{~h})$ (antagonist radioligand) & Specific binding & 3.9 \\
\hline$A_{1}(h)$ (agonist radioligand) & Specific binding & 6.1 \\
\hline$A_{3}(h)$ (agonist radioligand) & Specific binding & 12.3 \\
\hline Abl kinase (h) & Enzymatic activity & -5.0 \\
\hline ACE (h) & Enzymatic activity & -15.0 \\
\hline acetylcholinesterase (h) & Enzymatic activity & 4.1 \\
\hline$\alpha_{1 \mathrm{~A}}(\mathrm{~h})$ (antagonist radioligand) & Specific binding & 3.5 \\
\hline$\alpha_{2 \mathrm{~A}}(\mathrm{~h})$ (antagonist radioligand) & Specific binding & -5.6 \\
\hline AR (h) (agonist radioligand) & Specific binding & 17.3 \\
\hline $\mathrm{AT}_{1}(\mathrm{~h})$ (antagonist radioligand) & Specific binding & -4.0 \\
\hline$\beta_{1}(\mathrm{~h})$ (agonist radioligand) & Specific binding & 13.0 \\
\hline$\beta_{2}$ (h) (antagonist radioligand) & Specific binding & -6.2 \\
\hline BZD (central) (agonist radioligand) & Specific binding & -8.5 \\
\hline $\begin{array}{l}\mathrm{Ca}^{2+} \text { channel (L, diltiazem site) } \\
\text { (benzothiazepines) (antagonist radioligand) }\end{array}$ & Specific binding & -17.8 \\
\hline $\mathrm{CB}_{1} \mathrm{R}(\mathrm{h})$ (agonist radioligand) & Specific binding & 35.3 \\
\hline $\mathrm{CCK}_{1}\left(\mathrm{CCK}_{\mathrm{A}}\right)(\mathrm{h})$ (agonist radioligand) & Specific binding & 7.5 \\
\hline $\mathrm{CDK}_{2}(\mathrm{~h})(\mathrm{cycA})$ & Enzymatic activity & 7.1 \\
\hline $\begin{array}{l}\mathrm{Cl}^{-} \text {channel (GABA-gated) (antagonist } \\
\text { radioligand) }\end{array}$ & Specific binding & 51.3 \\
\hline $\operatorname{cox} 2(\mathrm{~h})$ & Enzymatic activity & 36.9 \\
\hline $\mathrm{D}_{1}$ (h) (antagonist radioligand) & Specific binding & 12.8 \\
\hline $\mathrm{D}_{2 \mathrm{~S}}(\mathrm{~h})$ (agonist radioligand) & Specific binding & 3.6 \\
\hline $\mathrm{ER} \alpha(\mathrm{h})$ (agonist radioligand) & Specific binding & -1.4 \\
\hline FP $(\mathrm{h})$ (agonist radioligand) & Specific binding & 74.0 \\
\hline $\begin{array}{l}\text { glycine (strychnine-insensitive) (antagonist } \\
\text { radioligand) }\end{array}$ & Specific binding & 33.9 \\
\hline GR (h) (agonist radioligand) & Specific binding & 0.5 \\
\hline GSK3 $\alpha(h)$ & Enzymatic activity & 6.7 \\
\hline GSK3 $\beta(h)$ & Enzymatic activity & 2.8 \\
\hline
\end{tabular}




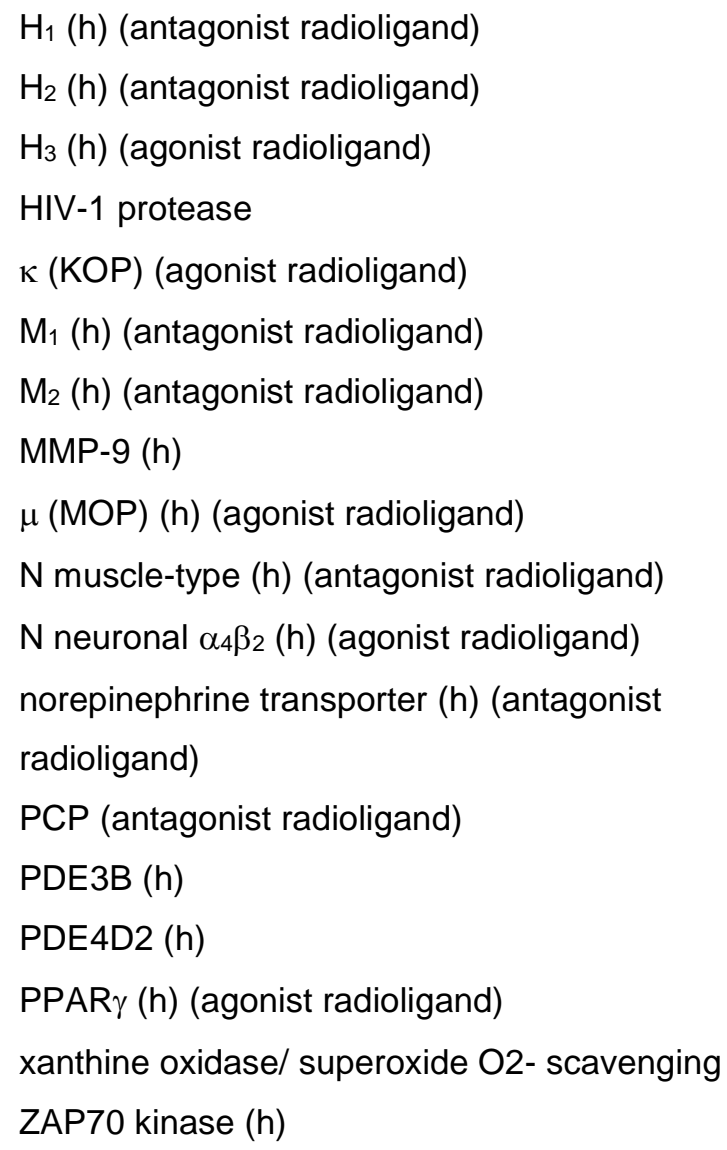

Table S3. Calculated $n$-octanol-water partition coefficients $(\text { AlogP })^{[4]}$ for fluorescent probes $\mathbf{2}-\mathbf{5}$.

\begin{tabular}{cccc}
\hline Compound & MW & AlogP & HAC[a] \\
\hline $\mathbf{2}$ & 885.1 & 8.7 & 64 \\
3a & 910.2 & 11.5 & 65 \\
3b & 951.2 & 11.6 & 68 \\
$\mathbf{4}$ & 1367.8 & 12.0 & 93 \\
$\mathbf{5}$ & 1084.3 & 7.9 & 76 \\
$\mathbf{6}$ & 939.3 & 10.9 & 68 \\
\hline
\end{tabular}

[a] HAC heavy atom count 


\section{MOLECULAR DOCKING}

The X-ray structures of $\mathrm{CB}_{2} \mathrm{R}$ complexed with antagonist AM10257 (5zty) and agonist WIN 55,212-2 (6PT0) were used as template to dock $\mathrm{CB}_{2} \mathrm{R}$ ligands. The docking experiments were performed with the software GOLD ${ }^{[5]}$ (Chemical Computing Group) with default settings. The best 10 docking poses for each compound were energy-minimized within the binding pocket using MOE (CCG, Montreal) ${ }^{[6]}$ and examined visually to select the most reasonable docking mode with respect to molecular interactions and internal conformational strain. The final selection was based on checking consistency with the available structure-activity relationship information.

\section{IN VITRO PHARMACOLOGY}

\section{Radioligand binding assay and cAMP assay}

Radioligand binding assays and forskolin-stimulated cAMP assays were performed as described by Soethoudt et al. ${ }^{[7]}$ The $\mathrm{CB}_{2} \mathrm{R}$-expressing cell lines are clonal and the $\mathrm{B}_{\max }$ of cell lines is indicated in brackets. WT- $\mathrm{CHO}, \mathrm{hCB}_{2} \mathrm{R}-\mathrm{CHO}$ (2.08 pmol/mg protein) and $\mathrm{hCB}_{1} \mathrm{R}-\mathrm{CHO}$ (5.5 pmol/mg protein) were produced in house and $\mathrm{mCB}_{2} \mathrm{R}-\mathrm{CHO}$ cells (11.8 pmol/mg protein) have the following reference (PathHunter®) CHO-K1 mCNR2 $\left(\mathrm{CB}_{2} \mathrm{R}\right)$-Arrestin Cell Line DiscoverX, 93-0472C2). Cells were cultured and membranes for radioligand binding assays prepared in analogy to Soethoudt et al. ${ }^{[7]}$ Reference compounds for binding and cAMP assays were selected in accordance to literature. ${ }^{[7]}$ The corresponding mean $K_{i}$ and $E_{50}$ values, as well as standard error of the mean (SEM), are stated below. Data are means from one or two independent experiments performed in triplicate.

\section{$\underline{\mathrm{hCB}_{2}} \underline{\mathrm{R} \mathrm{K}}$}

The mean $\mathrm{K}_{\mathrm{i}}$ value of the positive control JWH133 used for each run was $34.9 \mathrm{nM}$, with standard error of the mean (SEM) of $\pm 3.4 \mathrm{nM}(\mathrm{n}=128)$.

\section{$\underline{\mathrm{hCB}_{1}} \underline{\mathrm{R} \mathrm{K}}$}

The mean Ki value of the positive control Rimonabant used for each run was $2.8 \mathrm{nM}$, with standard error of the mean (SEM) $\pm 0.2 \mathrm{nM}(\mathrm{n}=105)$.

\section{$\underline{\mathrm{mCB}_{2} R \mathrm{~K}_{\mathrm{i}}}$}

The mean Ki value of the positive control WIN55212-2 used for each run was $5.8 \mathrm{nM}$, with standard error of the mean (SEM) $\pm 1.3 \mathrm{nM}(\mathrm{n}=57)$. 


\section{$\underline{\mathrm{hCB}}_{2} \underline{\mathrm{R}, \mathrm{mCB}} 2 \underline{\mathrm{R} \text { and } \mathrm{hCB}} \underline{\mathrm{R}}_{1} \underline{\mathrm{R} A M P} \mathrm{EC}_{50}$}

The mean $\mathrm{EC}_{50}$ value of the positive control CP55,940 used for each run were $0.08 \mathrm{nM}$, $0.05 \mathrm{nM}$ and $0.11 \mathrm{nM}$, respectively, with respective standard errors of the mean (SEM) \pm 0.011 $\mathrm{nM}(\mathrm{n}=114), \pm 0.007 \mathrm{nM}(\mathrm{n}=94)$ and $\pm 0.013 \mathrm{nM}(\mathrm{n}=95)$.

\section{Passive membrane permeability assay (PAMPA)}

The parallel artificial membrane permeability assay is a method which determines the permeability of substances from a donor compartment, through a lipid-infused artificial membrane into an acceptor compartment. ${ }^{[8]}$ The read-out is a permeation coefficient $P_{\text {eff }}$ drug as well as test compound concentrations in donor, membrane and acceptor compartments. $A$ 96-well microtiter plate completely filled with aqueous buffer solutions ( $\mathrm{pH} 7.4 / 6.5$ ) is covered with a microtiter filterplate in a sandwich construction. The hydrophobic filter material (Durapore/Millipore; pore size $0.22-0.45 \mu \mathrm{m}$ ) of the first 48 wells (sample) of the filterplate is impregnated with a 1-20\% solution of lecithin in an organic solvent (dodecane, hexadecane, 1,9-decadiene). The filter surface of the remaining 48 wells (reference) is wetted with a small volume (4-5 $\mu \mathrm{L})$ of a $50 \%(\mathrm{v} / \mathrm{v})$ methanol/buffer solution. Transport studies were started by the transfer of $100-200 \mu \mathrm{L}$ of a 250 or $500 \mu \mathrm{M}$ stock solution on top of the filter plate in the sample and in the reference section, respectively. In general $0.05 \mathrm{M}$ TRIS, $\mathrm{pH} 7.4$, or $0.05 \mathrm{M}$ phosphate, $\mathrm{pH} 6.5$, buffers were used. The maximum DMSO content of the stock solutions was $5 \%$. 


\section{FLUORESCENCE SPECTROSCOPY}

\section{Material and methods}

UV/Vis absorbance spectra of $50 \mu \mathrm{M}$ solutions of fluorescent probes in various solvents were recorded in a wavelength range of $250-750 \mathrm{~nm}$ to determine $\lambda_{\max }$ used later for compound excitation ( $1 \mathrm{~cm}$ path length, room temperature, scan step $1 \mathrm{~nm}$; Thermo Evolution $600 \mathrm{UV} / \mathrm{Vis}$ spectrophotometer, Thermo Electron Scientific Instruments LLC, Madison, WI, USA). Due to the limited solubility of the probes in DPBS, the spectra in DPBS were measured in a cuvette with $10 \mathrm{~cm}$ path length at $5 \mu \mathrm{M}$ in presence of $0.1 \%(\mathrm{v} / \mathrm{v})$ DMSO.

Technical excitation and emission fluorescence spectra (uncorrected for chromatic aberrations) of fluorescent probes were measured at $10 \mu \mathrm{M}$ compound concentration $\left(20^{\circ} \mathrm{C}\right.$, integration time 1s, scan step $2 \mathrm{~nm}$, slits $2.4 \mathrm{~mm}$ and $2 \mathrm{~mm}$ in excitation and emission, respectively; ISS Inc. PC1 fluorometer, Champaign, IL, USA) in organic (dimethyl sulfoxide (DMSO), methylene chloride $\left(\mathrm{CH}_{2} \mathrm{Cl}_{2}\right)$, acetonitrile $\left(\mathrm{CH}_{3} \mathrm{CN}\right)$, ethyl acetate $(\mathrm{EA})$ and methanol $(\mathrm{MeOH})$ and aqueous solvent (Dulbecco's phosphate buffered saline, DPBS). Due to the limited solubility of the HU-308-based probes in DPBS, the spectra in DPBS were measured at $1.0 \mu \mathrm{M}$ in the presence of $0.1 \%(\mathrm{v} / \mathrm{v}) \mathrm{DMSO}$ and then scaled to expected fluorescence signal intensity at concentration of $10 \mu \mathrm{M}$ by multiplication of the signal intensity by factor of 10 . 


\section{TR-FRET KINETIC CB ${ }_{2}$ R BINDING ASSAY}

\section{Cell Culture}

Cells were maintained in a humidified environment at $37{ }^{\circ} \mathrm{C}$ and $5 \% \mathrm{CO}_{2}$ in Dulbecco's modified Eagle's medium (DMEM) with 10\% fetal bovine serum (FBS) containing blasticidin (5 $\mu \mathrm{g} / \mathrm{ml}$; Invitrogen) and (Zeocin; $20 \mu \mathrm{g} / \mathrm{mL}$; Invitrogen). For inducible expression, SNAP-tagged human $\mathrm{CB}_{2} \mathrm{R}$ receptor cDNAs, in pcDNA4/TO were introduced through transfection, using PEI into HEK293T-Rex cells (Invitrogen, which express Tetracyclin repressor protein to allow inducible expression). A mixed population stable line was selected by resistance to blasticidin (TR vector, $5 \mu \mathrm{g} / \mathrm{mL}$ ) and Zeocin; (receptor plasmid, $20 \mu \mathrm{g} / \mathrm{mL}$ ). For receptor-inducible expression, cells were seeded into $175 \mathrm{~cm}^{2}$ flasks, grown to $70 \%$ confluence and DMEM containing $1 \mu \mathrm{g} / \mathrm{mL}$ tetracycline added. 24h later cells were labelled with SNAP-Lumi4-Tb (CisBio) and membranes prepared as described in detail below.

\section{Terbium labeling of SNAP-tagged $\mathrm{CB}_{2} \mathrm{R}$ HEK293-TR cells}

Cell culture medium was removed from the $175 \mathrm{~cm}^{2}$ flasks containing confluent adherent $\mathrm{CB}_{2} \mathrm{R}$ HEK293T-Rex cells. Cells were washed 1x in PBS (GIBCO Carlsbad, CA) followed by 1x Taglite labeling medium (LABMED, CisBio) to remove the excess cell culture media, then ten milliliter of LABMED containing $100 \mathrm{nM}$ of SNAP-Lumi4-Tb was added to the flask and incubated for $1 \mathrm{~h}$ at $37^{\circ} \mathrm{C}$ under $5 \% \mathrm{CO}_{2}$. Cells were washed $1 \times$ in PBS (GIBCO Carlsbad, $\mathrm{CA})$ to remove the excess of SNAP-Lumi4-Tb then detached using $5 \mathrm{ml}$ of GIBCO enzymefree Hank's-based cell dissociation buffer (GIBCO, Carlsbad, CA) and collected in a vial containing $5 \mathrm{~mL}$ of DMEM (Sigma-Aldrich) supplemented with $10 \%$ fetal calf serum. Cells were pelleted by centrifugation ( $5 \mathrm{~min}$ at $1500 \mathrm{rpm}$ ) and the pellets were frozen to $-80^{\circ} \mathrm{C}$. To prepare membranes, homogenization steps were conducted at $4{ }^{\circ} \mathrm{C}$ (to avoid receptor degradation) as described in Klein-Herenbrink et al., 2016..$^{[9]}$ Total protein concentration of the membrane preparation was measured using BCA assay (Pierce).

\section{Fluorescent ligand-binding assays}

All fluorescent ligand binding experiments were conducted in white 384-well Optiplate plates (PerkinElmer), in assay binding buffer, LABMED containing $5 \mathrm{mM} \mathrm{HEPES,} \mathrm{0.5 \%} \mathrm{BSA,} \mathrm{0.02 \%}$ pluronic acid $\mathrm{pH} 7.4$, and $100 \mu \mathrm{M}$ GppNHp.

The stable GTP analogue, GppNHp was included to promote a single population of receptors (free of $G$ protein) since the original Motulsky-Mahan model ${ }^{[10]}$ can only be applied under such stringent conditions with probe and compounds competing for a single receptor species. Previous radioligand binding data has suggested the presence of a high affinity population of 
effector bound receptors. ${ }^{[11]}$ The resulting model fits obtained with the fluorescent probes are consistent with the presence of a single population of low affinity receptors. In all cases, nonspecific binding was determined by the presence of $1 \mu \mathrm{M}$ SR 144528 .

\section{Determination of fluorescent ligand binding kinetics and equilibrium affinity}

To accurately determine association rate $\left(k_{\mathrm{on}}\right)$ and dissociation rate $\left(k_{\text {off }}\right)$ values, the observed rate of association $\left(k_{\mathrm{ob}}\right)$ was calculated using at least five different concentrations fluorescent ligand. The appropriate concentration of fluorescent ligand binding was incubated with human $\mathrm{CB}_{2} \mathrm{R}$ cell membranes ( $4 \mu \mathrm{g}$ total protein per well) in assay binding buffer (final assay volume, $40 \mu \mathrm{L}$ ). The degree of fluorescent ligand bound to the receptor was assessed at multiple time points by HTRF detection to allow construction of association kinetic curves. The resulting data were globally fitted to the association kinetic model (Eq. 1) to derive a single best-fit estimate for $k_{\text {on }}$ and $k_{\text {off }}$ as described under data analysis. Saturation analysis was performed at equilibrium, by simultaneously fitting total and Nonspecific (NSB) binding data (Eq. 3) allowed the determination of fluorescent ligand binding affinity.

\section{Determination of ligand binding kinetics}

To determine the association and dissociation rates of $\mathrm{CB}_{2} \mathrm{R}$ specific ligands, we used a competition-association binding assay. ${ }^{[10]}$ This approach involves the simultaneous addition of both fluorescent ligand and competitor to the receptor preparation so that at $t=0$ all receptors are unoccupied. To achieve this aim HEK293 cell membranes containing the human $\mathrm{CB}_{2} \mathrm{R}$ (4 $\mu \mathrm{g}$ per well) were added to wells containing $100 \mathrm{nM} 3 \mathbf{b}$ or $\mathbf{6}$, a concentration which avoids ligand depletion in this assay volume, and a fixed concentration of the antagonist SR144528 or the agonist $\mathrm{HU}-308$, designed to produce approximately $50 \%$ inhibition of probe binding, in a total assay volume of $40 \mu \mathrm{L}$. The degree of fluorescent ligand bound to the receptor was assessed at multiple time points by HTRF detection.

The kinetic parameters of the fluorescent ligands $\mathbf{3 b}$ and $\mathbf{6}$ plus those of unlabeled compounds were determined using a start time of $\sim 30 \mathrm{sec}$ and an interval time of $20 \mathrm{sec}$. Non-specific binding was determined as the amount of TR-FRET signal detected in the presence of SR144528 $(1 \mu \mathrm{M})$ and was subtracted from each time point, meaning that $t=0$ was always equal to zero. Each time point was conducted on the same 384-well plate incubated at room temperature with orbital mixing ( $1 \mathrm{sec}$ of $100 \mathrm{RPM} / \mathrm{cycle}$ ). Data were globally fitted using (Eq. 2) to simultaneously calculate $k_{\text {on }}$ and $k_{\text {off }}$ of unlabeled compounds. 


\section{Competition binding}

To determine the affinity of $\mathrm{CB}_{2} \mathrm{R}$ specific ligands, we used a simple competition kinetic binding assay. This approach involves the simultaneous addition of both fluorescent ligand and competitor to the $\mathrm{CB}_{2} \mathrm{R}$ preparation. $100 \mathrm{nM} \mathbf{3 b}$ and $\mathbf{6}$, concentrations which avoid ligand depletion in this assay volume, were added simultaneously with increasing concentrations of the unlabeled compound to $\mathrm{CB}_{2} \mathrm{R}$ cell membranes ( $4 \mu \mathrm{g}$ total protein per well) in $40 \mu \mathrm{l}$ of assay buffer in a 384-well plate incubated at ambient temperature with orbital mixing. The degree of fluorescent ligand bound to the receptor was assessed at equilibrium by HTRF detection. Nonspecific binding was determined as the amount of HTRF signal detected in the presence of SR144528 $(1 \mu \mathrm{M})$ and was subtracted from total binding, to calculate specific binding for construction of $\mathrm{IC}_{50}$ curves and calculation of affinity values (Eq. 4 and 5).

\section{Signal detection and data analysis}

Signal detection was performed on a Pherastar FSX (BMG Labtech, Offenburg, Germany). The terbium donor was always excited with eight laser flashes at a wavelength of $337 \mathrm{~nm}$. TRFRET signals were collected at both at 570 (acceptor) and $490 \mathrm{~nm}$ (donor), when using the DY480XL-based fluorescent ligand $3 \mathbf{b}$ and at 665 (acceptor) and $620 \mathrm{~nm}$ (donor), when using the red acceptor fluorescent ligand 4. The AttoThio12-based fluorescent ligand, 6 required production of a custom manufactured modules with emissions measured at 610 (acceptor) and 490nm (donor) respectively. HTRF ratios were obtained by dividing the acceptor signal by the donor signal and multiplying this value by 10 '000. All experiments were analyzed by non-linear regression using Prism 8.0 (GraphPad Software, San Diego, USA).

Fluorescent ligand association data were fitted as follows to a global fitting model using GraphPad Prism 8.0 to simultaneously calculate $k_{\text {on }}$ and $k_{\text {off }}$ using the following equation,

$$
\begin{array}{r}
k_{\mathrm{ob}}=[\mathrm{L}]^{*} k_{\mathrm{on}}+k_{\mathrm{off}} \\
Y=Y_{\max }{ }^{*}\left(1-\exp \left(-1^{*} k_{\mathrm{ob}}{ }^{*} \mathrm{X}\right)\right)
\end{array}
$$

Where, $k_{\mathrm{ob}}$ equals the observed rate of ligand association and $k_{\mathrm{on}}$ and $k_{\mathrm{off}}$ are the association and dissociation-rate constants respectively of the fluorescent ligand. In this globally fitted model of tracer binding, tracer concentrations [L] are fixed, $k_{\text {on }}$ and $k_{\text {off }}$ are shared parameters whilst $k_{\text {obs }}$ is allowed to vary. Here, $Y$ is the level of receptor-bound tracer, $Y_{\max }$ is the level of tracer binding at equilibrium, $X$ is in units of time (eg. min) and $k_{\text {obs }}$ is the rate in which equilibrium is approached (eg. $\min ^{-1}$ ). 
Association and dissociation rates for unlabeled antagonists were calculated using the following equations first described by Motulsky and Mahan. ${ }^{[10]}$

$$
\begin{gathered}
K_{A}=k_{1}[L]+k_{2} \\
K_{B}=k_{3}[I]+k_{4} \\
S=\sqrt{\left(\left(K_{A}-K_{A}\right)^{2}+4 \cdot k_{1} \cdot k_{3} \cdot L \cdot I \cdot 10^{-18}\right)} \\
K_{F}=0.5 *\left(K_{A}+K_{B}+S\right) \\
K_{S}=0.5 *\left(K_{A}+K_{B}-S\right) \\
Q=\frac{B_{\max } * K_{1} * L * 10^{-9}}{K_{F}-K_{S}} \\
\mathrm{Y}=Q \cdot\left(\frac{k_{4} \cdot\left(K_{F}-K_{S}\right)}{K_{F} \cdot K_{S}}+\frac{k_{4}-K_{F}}{K_{F}} \exp ^{\left(-K_{F} \cdot X\right)}-\frac{k_{4} K_{S}}{K_{S}} \exp ^{\left(-K_{S} \cdot X\right)}\right)
\end{gathered}
$$

Where: $X=$ Time $(\min ), Y=$ Specific binding (eg. CPM or HTRF units eg. HTRF ratio $\left.520 \mathrm{~nm} / 620 \mathrm{~nm} \times 10^{\prime} 000\right), k_{1}=k_{\text {on }} \operatorname{tracer}\left(\mathrm{M}^{-1} \mathrm{~min}^{-1}\right), k_{2}=\mathrm{k}_{\text {off }}$ tracer $\left(\mathrm{min}^{-1}\right), \mathrm{L}=$ Concentration of tracer used $(\mathrm{nM}), \mathrm{I}=$ Concentration unlabeled ligand $(\mathrm{nM})$. Fixing the above parameters allows the following to be calculated: $k_{3}=$ Association-rate constant of unlabeled ligand $\left(\mathrm{M}^{-1} \mathrm{~min}^{-1}\right), k_{4}$ $=$ Dissociation-rate constant of unlabeled ligand $\left(\min ^{-1}\right), B_{\max }=$ Maximal specific binding of the system at equilibrium binding (eg. CPM or HTRF units, eg. HTRF ratio $520 \mathrm{~nm} / 620 \mathrm{~nm} x$ 10’000).

Saturation binding data were analysed by non-linear regression according to a one-site equation by globally fitting total and NSB. Individual estimates for the fluorescent ligand dissociation constant $\left(K_{d}\right)$ were calculated using the following equations where $L$ is the fluorescent ligand concentration:

$$
\begin{gathered}
\text { Total binding }=\text { Specific }+N S B=\frac{B m a x *[\mathrm{~L}]}{K d+[L]}+\text { slope } *[\mathrm{~L}]+\text { Background } \\
\text { NSB }=\text { slope } *[\mathrm{~L}]+\text { Background }
\end{gathered}
$$

Fitting the total and NSB data sets globally (simultaneously), sharing the value of slope, provides one best-fit value for both the $K_{\mathrm{d}}$ and the $B_{\max }$. 
Competition displacement binding data were fitted to sigmoidal (variable slope) curves using a 'four-parameter logistic equation':

$$
Y=\text { Bottom }+(\text { Top-Bottom }) /\left(1+10^{\text {(loglC50-X). Hill coefficient })}\right.
$$

$\mathrm{IC}_{50}$ values obtained from the inhibition curves were converted to $K_{\mathrm{i}}$ values using the method of Cheng and Prusoff. ${ }^{[12]}$

$$
K_{\mathrm{i}}=\mathrm{IC}_{50} /\left(1+[\text { fluorescent tracer concentration }] / K_{\mathrm{d}}\right)
$$

\section{SNAP-hCB ${ }_{2}$ R Construct: Localization Studies}

A 6-well Costar cell culture plate (Corning) containing $18 \mathrm{~mm}$ square no 1.0 coverslips was poly-D-lysine coated. T-REx 293 cells, containing SNAP-tagged $h_{C B} R$ on a pcDNA4/TO vector, were seeded at a density of 600 000/well in growth medium (DMEM high glucose (Sigma-Aldrich) with 10\% FBS, $20 \mathrm{ug} / \mathrm{mL}$ Zeocin, $15 \mathrm{ug} / \mathrm{mL}$ Blasticidin). After $7 \mathrm{~h}, \mathrm{CB}_{2}$ expression was induced using $1 \mu \mathrm{g} / \mathrm{mL}$ tetracycline. The cells were stained with SNAP dyes $24 \mathrm{~h}$ after induction: First, cells were incubated for $30 \mathrm{~min}$ with $200 \mathrm{nM}$ SNAP-surface 647 (New England Biolabs), washed 3x 5 min in growth medium to remove non-reacted dye. Secondly, the cells were stained with 200 nM SNAP-cell Oregon Green (New England Biolabs) for $30 \mathrm{~min}$ and washed $3 \times 5 \mathrm{~min}$ in growth medium to remove non-reacted dye. The cells were incubated for $30 \mathrm{~min}$ in growth medium to enable non-reacted dye to diffuse out of the cells. Lastly, they were washed for $3 \times 5$ min washes in PBS and fixed with 3\% PFA. The coverslip was mounted in vectashield anti-fade mounting medium (Vector Laboratories).

Cells were imaged using a Zeiss LSM 710 laser scanning confocal microscope fitted with a Zeiss Plan-Apochromat 63x/1.40 NA oil immersion objective. A Helium Neon $633 \mathrm{~nm}$ laser and Argon laser at 488 were used to excite the Alexafluor 647 and Alexafluor 488 fluorophores respectively and emission was collected using a 488/561/633 multi beam splitting filter. Images were taken at $512 \times 512$ pixels per frame with line average of 4 and a slice of 53.36 um for confocal images. Laser power and gain were kept constant between experiments. 


\section{FACS ANALYSIS}

\section{CHO cells}

For validation of $\mathrm{CB}_{2} \mathrm{R}$-fluoroprobes via FACS analysis, 50'000 WT-CHO, or $\mathrm{CHO}$ cells overexpressing $h \mathrm{hCB}_{2} \mathrm{R}, \mathrm{mCB} 2 \mathrm{R}$ or $\mathrm{hCB}{ }_{1} \mathrm{R}$ were incubated with different concentrations of $\mathrm{CB}_{2}$ R-fluoroprobes $(0.005 \mu \mathrm{M}-10 \mu \mathrm{M})$ in PBS/0.5\%BSA/2 mM EDTA for $30 \mathrm{~min}$ at $4{ }^{\circ} \mathrm{C}$. For cold ligand replacement experiments, 50'000 WT-CHO cells or $\mathrm{CHO}$ cells overexpressing $\mathrm{hCB}_{2} \mathrm{R}$ were pre-incubated with $10 \mu \mathrm{M} \mathrm{JWH} 133$ or R06851228 in PBS/0.5\%BSA/2 mM EDTA at room temperature. After $30 \mathrm{~min}$, different concentrations of $\mathrm{CB}_{2} \mathrm{R}$-fluoroprobes were added to the cell suspensions ( $5 \mathrm{nM}-370 \mathrm{nM})$ and cells were incubated for another $30 \mathrm{~min}$ at $4{ }^{\circ} \mathrm{C}$. After $\mathrm{CB}_{2} \mathrm{R}$-fluoroprobe incubation, cells in both experiments were washed 3 times with $\mathrm{PBS} / 0.5 \% \mathrm{BSA} / 2 \mathrm{mM}$ EDTA and resuspended in PBS/0.5\%BSA/2 mM EDTA containing 1:1000 AquaZombie (Biolegend 423102). FACS analysis was performed on BD Fortessa. After exclusion of dead cells, mean fluorescent intensity of viable cells was determined. 


\section{Mouse Microglia Cells}

Microglial isolation: After perfusion with ice-cold PBS, brains of male mice (5XFAD or $\left.5 \mathrm{xFAD} / \mathrm{CB}_{2} \mathrm{KO}\right)^{13}$ were dissected and enzymatically digested using trypsin-EDTA for 40 min at $37^{\circ} \mathrm{C}$ and re-suspended in DMEM, and then filtered with a $70 \mu \mathrm{m}$ cell strainer. Microglia and infiltrating mononuclear cells were isolated at the interface of $70 \%$ and $30 \%$ Percoll (after centrifugation $2800 \mathrm{~g}$ for 20 minutes).

After isolation of microglial cells, BSA 1\%/PBS was used as blocking solution by incubation at $4{ }^{\circ} \mathrm{C}$ for $30 \mathrm{~min}$. Cells were then stained with $\mathbf{3 b}$ (DY-480XL) probe at 1.5, 3, 4.5 and $6 \mu \mathrm{M}$ and labeled with anti-CD11b-phycoerythrin (PE) and anti-CD45-allophycocyanin-Vio770 (APCVio770) at $4{ }^{\circ} \mathrm{C}$ for $30 \mathrm{~min}$. Cells were washed with PBS and re-suspended in $400 \mu \mathrm{L}$ of PBS.

Cytometry analysis: Isolated microglia and infiltrating mononuclear cells were stained and analyzed by flow cytometry (MACS-Quant) after gating live cells based on FSC and SSC. Cell doublets were excluded in FSC-A/FSC-W panel. The expression of CD45 and CD11b was measured to distinguish CNS-resident CD45lo microglia from infiltrating CD45hi leukocytes, in conjunction with their expression of CD11b (macrophages) or lack thereof (lymphocytes). Quantification of 3b (DY-480XL)-positive microglia was then performed. 


\section{TIME-LAPSE CONFOCAL IMAGING}

In order to minimize receptor internalization and thus to maximize the fluorescence signal on the plasma membrane, these experiments were performed at $22{ }^{\circ} \mathrm{C}$. For real-time labeling studies, cells were plated onto 8-well chamber slides (Ibidi, Milan, Italy), at a density of 50'000 cells/well and cultured for $24 \mathrm{~h}$. For a nuclear staining, the medium was replaced by $1 \mu \mathrm{g} / \mathrm{mL}$ Hoechst 33342 in RPMI (Sigma-Aldrich, Milan, Italy) and the cells were incubated for 10 minutes at $37^{\circ} \mathrm{C}$, then washed with PBS twice. A small volume of the $3 \mathbf{b}$, dissolved at $10 \mathrm{mM}$ in DMSO, was mixed with the $20 \%$ (w/v) Pluronic F-127 in DMSO (Sigma-Aldrich) at a ratio of 1:1, immediately before use. To inhibit clathrin- and caveolae-dependent endocytosis, we pretreated the cells for $30 \mathrm{~min}$ with $400 \mathrm{mM}$ sucrose and $5 \mu \mathrm{g} / \mathrm{mL}$ filipin. ${ }^{14}$ Prior to imaging, the solution of compound $\mathbf{3 b}$ and Pluronic F-127 was diluted at $0.2 \mu \mathrm{M}$ in HEPES-buffered RPMI and quickly added to the cells without any washing step during the time-lapse experiments. Imaging was performed by using confocal laser scanning microscope ZEISS LSM 800 equipped with an Airyscan detection unit (Zeiss, Oberkochen, Germany). To maximize the resolution enhancement, a high numerical aperture oil immersion alpha Plan-Apochromat $63 X / 1.40$ oil DIC M27 objective was used. 3b was excited using a $488 \mathrm{~nm}$ laser line and the corresponding fluorescence emission was detected using a $655 \mathrm{~nm}$ long-pass filter, whereas Hoechst 33342 was excited with a dedicated $405 \mathrm{~nm}$ UV diode, and the corresponding fluorescence emission was detected using a 490/40 nm band-pass filter. Images within each experiment were collected by using identical laser-power, offset, and gain setting that was adjusted to minimize the level of auto-fluorescence. Live imaging was performed at $22 \pm 2^{\circ} \mathrm{C}$ by recording one frame every $15 \mathrm{sec}$ for $10 \mathrm{~min}$. At the end of recording session, living cells were imaged with Airyscan mode. Each image was taken at the equatorial plan of the cells, using the ZEN Blue 2.3 software (Zeiss). Super-resolution image processing was performed using the Airyscan processing toolbox in the ZEN software. The data were exported as TIFF files and analyzed using the Fiji software (National Institutes of Health; https://imagej.net/Fiji). A Gaussian kernel filter was applied to the images using a standard deviation of 0.8 pixels. All intensity profiles were background subtracted and normalized to the frame taken at the end of registration. For presentation purposes, images were exported in Artstudio Pro version 2.0.13 (Lucky Clan, Lodz, Poland; http://www.luckyclan.com) for adjustments of brightness and contrast. 


\section{Video Files}

Time-lapse image sequences were converted from the czi file format to audio-video interleave (AVI) movies using Fiji software (National Institutes of Health; https://imagej.net/Fiji).

Video 1. Time-lapse video of $\mathrm{CHO}-\mathrm{hCB}_{1} \mathrm{R}$ cells labeled with $0.2 \mu \mathrm{M} 3 \mathbf{b}$ for $10 \mathrm{~min}$. Time-lapse image sequences were converted from the czi file format to audio-video interleave (AVI) movies using Fiji.

Video 2. Time-lapse video of $\mathrm{CHO}-\mathrm{hCB}_{2} \mathrm{R}$ cells labeled with $0.2 \mu \mathrm{M} 3 \mathbf{b}$ for 10 min. Time-lapse image sequences were converted from the czi file format to audio-video interleave (AVI) movies using Fiji.

Video 3. Time-lapse video of murine splenocytes incubated with $0.05 \%$ DMSO (vehicle) for 10 min to assess video background.

Video 4. Time-lapse video of murine splenocytes labeled with $0.4 \mu \mathrm{M} 3 \mathbf{b}$ for 10 min.

Video 5. Time-lapse video of murine splenocytes labeled with $0.4 \mu \mathrm{M} 3 \mathrm{~b}$ in presence of $4 \mu \mathrm{M}$ of $\mathrm{JWH}-133$ for $10 \mathrm{~min}$.

Video 6. Time-lapse video of human macrophages labeled with $0.6 \mu \mathrm{M} 3 \mathrm{~b}$ for $10 \mathrm{~min}$.

Video 7. Time-lapse video of human macrophages labeled with $0.6 \mu \mathrm{M} 3 \mathbf{b}$ in presence of $4 \mu \mathrm{M}$ of JWH-133 for $10 \mathrm{~min}$.

\section{Spleen cell extraction and culturing}

Two-month-old male mice (C57BL6/j6) were sacrificed by decapitation according to institutional guidelines, spleen was extracted and washed in complete medium (RPMI 1640 medium without $\mathrm{Ca}^{2+}$ and $\mathrm{Mg}^{2+}$, supplemented with $10 \%$ heat inactivated FBS (HyClone, Logan, UT, USA), $10 \mathrm{U} / \mathrm{mL}$ penicillin/streptomycin and $2 \mathrm{mM} \mathrm{L-glutamine).} \mathrm{The} \mathrm{spleen} \mathrm{was} \mathrm{cut}$ in small cubes of approximately $1 \mathrm{~mm}^{3}$ of volume by using a sterile scalpel. Spleen samples were then placed in a $27 \mathrm{~mm}$ Nunc Glass Base dish (Thermo Fisher Scientific, Monza, Italy) with $5 \mathrm{~mL}$ of complete medium and incubated for 1 hour at $37^{\circ} \mathrm{C}$ and $5 \% \mathrm{CO}_{2}$. Splenocytes were separated by passing the spleen cubes in serial pipette tips of different size. The cells were counted using a counting chamber, Imp. Neubauer, 25×75 mm (NanoEntek, Seoul, South Korea) and $5 \times 10^{5}$ cells were seeded in each well of a 8-well sterile Lab-Tek chambered 1.0 borosilicate coverglass (Thermo Fisher Scientific) with $400 \mu \mathrm{L}$ complete medium and incubated at $37^{\circ} \mathrm{C}$ and $5 \% \mathrm{CO}_{2}$ until imaging experiments. Mice were handled according to ethical 
regulations on the use and welfare of experimental animals of the European Union (EU Directive 2010/63/EU) and the Italian Ministry of Health (art. 31, D.lgs. 26/2014), and the procedures were approved by the bioethical committee of Fondazione Santa Lucia of Rome (protocol n. 421/2019-PR).

\section{Human primary macrophages}

To obtain human macrophages, peripheral blood mononuclear cells from 40-50 years old healthy male donors were isolated by Ficoll density gradient centrifugation. CD14+ human monocytes were further isolated by leukocytes by means of immunomagnetic sorting, plated onto 24-well plates, and were differentiated into monocyte-derived macrophages in $1640 \mathrm{RPMI}$ medium, containing $10 \%$ heat-inactivated fetal bovine serum, $5 \%$ heat-inactivated human serum, $100 \mathrm{U} / \mathrm{mL}$ penicillin/streptomycin and supplemented with $25 \mathrm{ng} / \mathrm{ml}$ premium grade macrophage colony-stimulating factor (Miltenyi Biotec, Bologna, Italy), and were incubated in a humidified atmosphere containing $5 \% \mathrm{CO}_{2}$ at $37^{\circ} \mathrm{C}$. Cell cultures were periodically washed every $48 \mathrm{~h}$ in order to eliminate non adherent cells (i.e., undifferentiated monocytes). After 6-8 days, adherent cells were considered as naïve M0 (M2-like) macrophages and were used for further experiments. ${ }^{15}$ All donors gave informed consent, and the study protocol was approved the bioethical committee of Fondazione Santa Lucia of Rome (CE/Prog. 589). 


\section{GENERAL SYNTHETIC METHODS}

Unless otherwise noted, all reactions were carried out under $\mathrm{N}_{2}$ atmosphere, and all reagents were purchased from commercial suppliers and used without further purification. Fluorescent dyes were purchased from Dyomics $\mathrm{GmbH}$ and ATTO-TEC $\mathrm{GmbH}$. Analytical thin layer chromatography (TLC) was performed on Merck silica gel $60 \mathrm{~F}_{254}$ TLC glass plates and analytes were visualized by fluorescence quenching (using $254 \mathrm{~nm}$ light); and stained by potassium permanganate solution $\left(\mathrm{KMnO}_{4}(3 \mathrm{~g}), \mathrm{K}_{2} \mathrm{CO}_{3}(20 \mathrm{~g}), 5 \%\right.$ aq. $\mathrm{NaOH}(5 \mathrm{~mL})$, water $(300 \mathrm{~mL}))$ or "Seebach's magic stain" (Phosphomolybdic acid $(2.5 \mathrm{~g}), \mathrm{Ce}\left(\mathrm{SO}_{4}\right)_{2}(1 \mathrm{~g})$, conc. $\left.\mathrm{H}_{2} \mathrm{SO}_{4}(6 \mathrm{~mL}), \mathrm{H}_{2} \mathrm{O}(94 \mathrm{~mL})\right)$ followed by heating. Purification of reaction products was carried out by flash chromatography using Sigma Aldrich silica 230-400 mesh particle size, $60 \AA$ under 0.3-0.5 bar overpressure or by preparative HPLC (Waters Auto Purification System, Reprosil Gold 120 C18 125 x 20 mm column). NMR spectra were acquired on Bruker AVIII HD 600 $\mathrm{MHz}, 500 \mathrm{MHz}$ and $400 \mathrm{MHz}$ spectrometers, Bruker Neo $500 \mathrm{MHz}$ and $400 \mathrm{MHz}$ spectrometers, operating at the denoted spectrometer frequency given in $\mathrm{MHz}$ for the specified nucleus. All experiments were acquired at $298.0 \mathrm{~K}$ with a calibrated Bruker Variable Temperature Controller unless otherwise noted. The chemical shifts are reported in parts per million (ppm) and coupling constants $\left(\mathcal{J}\right.$ ) are given in Hertz $(\mathrm{Hz}) .{ }^{1} \mathrm{H}$ NMR spectra are reported with the solvent resonance as the reference unless noted otherwise $\left(\mathrm{CDCl}_{3}\right.$ at $7.26 \mathrm{ppm}$, $\mathrm{CD}_{3} \mathrm{OD}$ at $3.31 \mathrm{ppm}, \mathrm{CD}_{2} \mathrm{Cl}_{2}$ at $5.32 \mathrm{ppm}$ ). Peaks are reported as $(\mathrm{s}=$ singlet, $\mathrm{d}=$ doublet, $\mathrm{t}=$ triplet, $\mathrm{q}=$ quartet, $\mathrm{m}=$ multiplet or unresolved, $\mathrm{br}=$ broad signal, coupling constant(s) in $\mathrm{Hz}$, integration). ${ }^{13} \mathrm{C}$ NMR spectra were recorded with ${ }^{1} \mathrm{H}$-decoupling and are reported with the solvent resonance as the reference unless noted otherwise $\left(\mathrm{CDCl}_{3}\right.$ at $77.16 \mathrm{ppm}, \mathrm{CD}_{3} \mathrm{OD}$ at $49.00 \mathrm{ppm}, \mathrm{CD}_{2} \mathrm{Cl}_{2}$ at $54.00 \mathrm{ppm}$ ). Service measurements were performed by the NMR service team of the Laboratorium für Organische Chemie at ETH Zürich. Infrared (IR) spectra were measured neat on a Perkin-Elmer UATR Two Spectrometer. Band maxima are reported in wavenumbers $\left(\mathrm{cm}^{-1}\right)$. High-resolution mass spectrometric data were obtained the mass spectrometry service operated by the Laboratory of Organic Chemistry at the ETHZ on VGTRIBRID for electron impact ionization (EI), Varian IonSpec Spectrometer for electrospray ionization (ESI) or IonSpec Ultima Fourier Transform Mass Spectrometer for matrix-assisted laser desorption/ionization (MALDI), and are reported as $(\mathrm{m} / \mathrm{z})$. Optical rotations were measured with a Jasco P-2000 Polarimeter (10 cm, $1.5 \mathrm{~mL}$ cell). 


\section{COMPOUND SYNTHESIS AND CHARACTERIZATION}

\section{Synthesis of $2^{16}$}

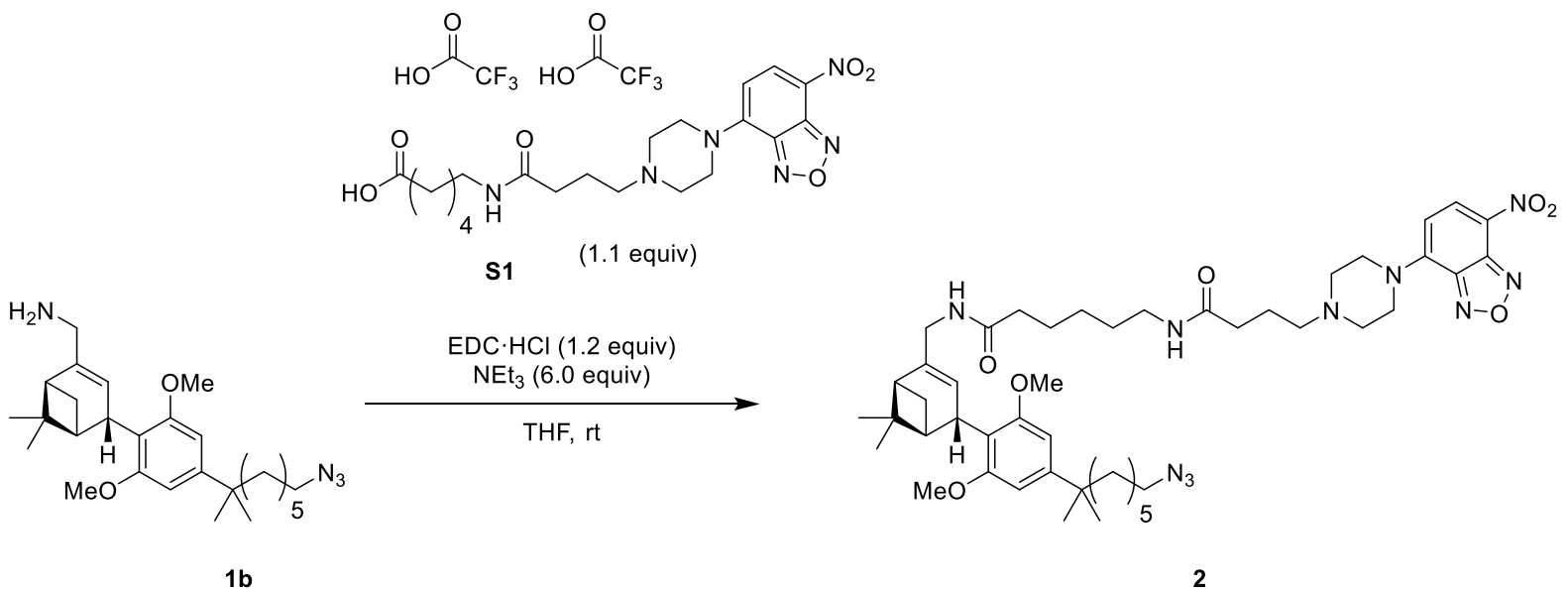

Furazane-dye S1 (19 mg, $0.028 \mathrm{mmol}, 1.1$ equiv) was dissolved in THF (0.3 mL) and combined with $\mathrm{NEt}_{3}(20 \mu \mathrm{L}, 0.14 \mathrm{mmol}, 5.4$ equiv). EDC. $\mathrm{HCl}(6.2 \mathrm{mg}, 0.032 \mathrm{mmol}, 1.2$ equiv) was added and it was stirred for 5 minutes at ambient temperature, before a solution of amine 1b (12 mg, $0.026 \mathrm{mmol}, 1.0$ equiv) in THF $(0.3 \mathrm{~mL})$ was added. The mixture was concentrated under a stream of nitrogen to a volume of about $0.3 \mathrm{~mL}$ and stirred at ambient temperature. After $3 \mathrm{~h}$, the mixture was diluted with EtOAc $(100 \mathrm{~mL})$, washed with water $(10 \mathrm{~mL})$ and brine $(2 \times 10 \mathrm{~mL})$, dried over $\mathrm{MgSO}_{4}$, filtered and concentrated. The residue was purified by preparative TLC $\left(\mathrm{CH}_{2} \mathrm{Cl}_{2}\right.$ :hexanes:MeOH 10:3:1) to afford the title compound as orange oil (13 mg, $0.015 \mathrm{mmol}, 56 \%)$.

$\mathbf{R}_{\mathbf{f}}=0.37\left(\mathrm{CH}_{2} \mathrm{Cl}_{2}\right.$ :hexanes:MeOH 10:3:1; orange spot, $\left.\mathrm{KMnO}_{4}, \mathrm{UV}\right) .{ }^{1} \mathbf{H} \mathbf{~ N M R}(400 \mathrm{MHz}$, $\left.\mathrm{CDCl}_{3}\right) \delta=8.41(\mathrm{~d}, J=8.9 \mathrm{~Hz}, 1 \mathrm{H}), 6.47(\mathrm{~s}, 2 \mathrm{H}), 6.29(\mathrm{~d}, J=9.0 \mathrm{~Hz}, 1 \mathrm{H}), 5.86(\mathrm{~s}, 1 \mathrm{H}), 5.60$ (dt, $J=2.9,1.5 \mathrm{~Hz}, 1 \mathrm{H}), 5.37(\mathrm{t}, J=5.7 \mathrm{~Hz}, 1 \mathrm{H}), 4.11(\mathrm{t}, J=4.9 \mathrm{~Hz}, 4 \mathrm{H}), 3.99-3.93(\mathrm{~m}, 1 \mathrm{H})$, $3.93-3.77(\mathrm{~m}, 2 \mathrm{H}), 3.73(\mathrm{~s}, 6 \mathrm{H}), 3.26(\operatorname{app~q}, J=6.7 \mathrm{~Hz}, 2 \mathrm{H}), 3.21(\mathrm{t}, J=6.9 \mathrm{~Hz}, 2 \mathrm{H}), 2.70$ (t, $J=4.9 \mathrm{~Hz}, 4 \mathrm{H}), 2.47(\mathrm{t}, J=7.1 \mathrm{~Hz}, 2 \mathrm{H}), 2.25(\mathrm{t}, J=7.3 \mathrm{~Hz}, 2 \mathrm{H}), 2.22-2.13(\mathrm{~m}, 3 \mathrm{H}), 2.10-$ $2.03(\mathrm{~m}, 2 \mathrm{H}), 1.89$ (q, J = 7.1 Hz, 2H), 1.67 (t, J=8.4 Hz, 3H), $1.59-1.49(\mathrm{~m}, 4 \mathrm{H}), 1.43-1.28$ $(\mathrm{m}, 6 \mathrm{H}), 1.27(\mathrm{~s}, 3 \mathrm{H}), 1.26(\mathrm{~d}, J=4.9 \mathrm{~Hz}, 6 \mathrm{H}), 1.21$ (dd, $J=9.2,7.3 \mathrm{~Hz}, 2 \mathrm{H}), 1.15-1.06(\mathrm{~m}$, $2 \mathrm{H}), 0.94(\mathrm{~s}, 3 \mathrm{H}) .{ }^{13} \mathrm{C}$ NMR (101 MHz, $\left.\mathrm{CDCl}_{3}\right) \delta=172.7,172.6,158.5,149.5,145.3,145.0$, 144.9, 138.5, 135.3, 124.1, 123.7, 117.6, 102.8, 102.7, 57.4, 55.9, 52.7, 51.6, 49.5, 47.4, 44.6, $44.5,44.5,40.9,39.3,38.1,37.6,36.6,34.3,30.0,29.3,29.0,29.0,28.0,26.7,26.5,26.4$, 25.2, 24.7, 22.6, 21.2. IR (neat) 3301, 3094, 2931, 2861, 2095, 1644, 1609, 1543, 1294, 1247, 1121, 997, 912, 733. ESI-HRMS calcd for $\mathrm{C}_{47} \mathrm{H}_{69} \mathrm{~N}_{10} \mathrm{O}_{7}[\mathrm{M}+\mathrm{H}]^{+} 885.5345$, found 885.5345. 


\section{Synthesis of 3a}

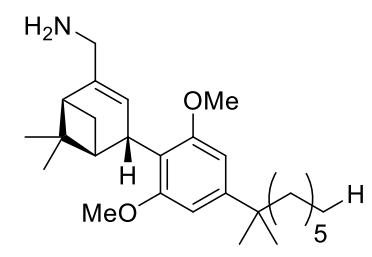

$1 \mathbf{a}$

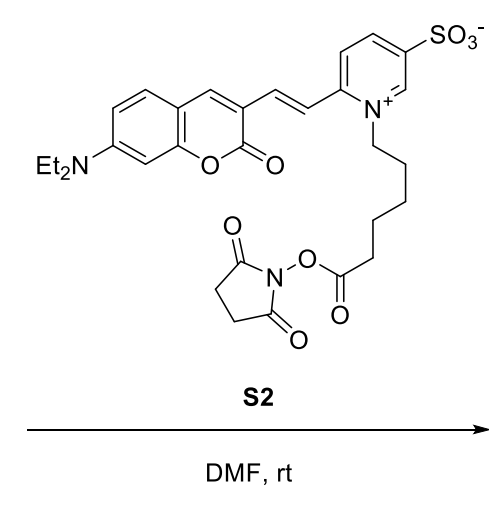

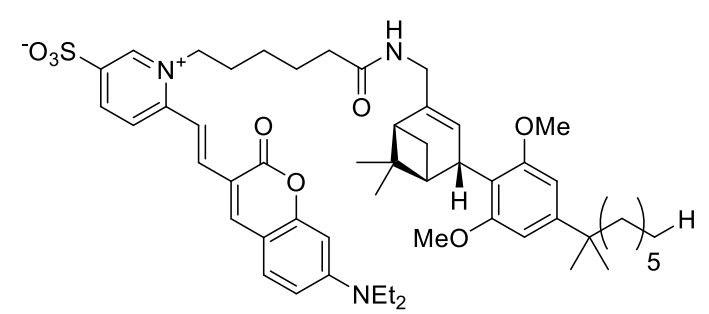

$3 \mathbf{a}$

The NHS ester of DY480XL S2 (2.0 mg, $0.0033 \mathrm{mmol}, 1.0$ equiv) was combined with a solution of amine 1a (2.0 mg, $0.0049 \mathrm{mmol}, 1.5$ equiv) in DMF $(0.13 \mathrm{~mL})$ and stirred at ambient temperature until LCMS analysis indicated full consumption of the active ester $(<10 \mathrm{~h})$. The product was isolated by pipette column $\left(2 \% \mathrm{MeOH}\right.$ in $\left.\mathrm{CH}_{2} \mathrm{Cl}_{2}\right)$ as dark-red oil $(2.5 \mathrm{mg}$, $0.0028 \mathrm{mmol}, 84 \%)$.

$\mathbf{R}_{\mathbf{f}}=0.43\left(10 \% \mathrm{MeOH}\right.$ in $\mathrm{CH}_{2} \mathrm{Cl}_{2}$; red spot, UV, Seebach). ${ }^{1} \mathbf{H}$ NMR $\left(500 \mathrm{MHz}, \mathrm{CD}_{3} \mathrm{OD}\right)$ $\delta=9.02(\mathrm{~d}, J=1.9 \mathrm{~Hz}, 1 \mathrm{H}$ ), 8.58 (ddd, $J=8.6,1.8,0.6 \mathrm{~Hz}, 1 \mathrm{H}), 8.42(\mathrm{~d}, J=8.7 \mathrm{~Hz}, 1 \mathrm{H}$ ), 8.15 (s, $1 \mathrm{H}), 8.10(\mathrm{~d}, J=15.4 \mathrm{~Hz}, 1 \mathrm{H}), 7.79(\mathrm{~d}, J=15.4 \mathrm{~Hz}, 1 \mathrm{H}), 7.52(\mathrm{~d}, J=9.1 \mathrm{~Hz}, 1 \mathrm{H}), 6.83$ (dd, $J=9.0,2.5 \mathrm{~Hz}, 1 \mathrm{H}), 6.56(\mathrm{dd}, J=2.4,0.6 \mathrm{~Hz}, 1 \mathrm{H}), 6.48(\mathrm{~s}, 2 \mathrm{H}), 5.60-5.56(\mathrm{~m}, 1 \mathrm{H}), 4.71-$ $4.60(\mathrm{~m}, 2 \mathrm{H}), 3.93(\mathrm{t}, J=2.4 \mathrm{~Hz}, 1 \mathrm{H}), 3.86-3.80(\mathrm{~m}, 1 \mathrm{H}), 3.73-3.71(\mathrm{~m}, 1 \mathrm{H}), 3.69(\mathrm{~s}, 6 \mathrm{H})$, $3.56-3.48(\mathrm{~m}, 4 \mathrm{H}), 2.34-2.27(\mathrm{~m}, 2 \mathrm{H}), 2.16-2.12(\mathrm{~m}, 1 \mathrm{H}), 2.09-2.00(\mathrm{~m}, 3 \mathrm{H}), 1.97-1.93$ $(\mathrm{m}, 1 \mathrm{H}), 1.81-1.74(\mathrm{~m}, 2 \mathrm{H}), 1.72(\mathrm{~d}, J=8.4 \mathrm{~Hz}, 1 \mathrm{H}), 1.57(\mathrm{dd}, J=7.7,4.7 \mathrm{~Hz}, 4 \mathrm{H}), 1.25-$ $1.19(\mathrm{~m}, 21 \mathrm{H}), 1.06(\mathrm{~m}, 2 \mathrm{H}), 0.92(\mathrm{~s}, 3 \mathrm{H}), 0.86-0.83(\mathrm{~m}, 3 \mathrm{H}) .{ }^{13} \mathrm{C}$ NMR $\left(126 \mathrm{MHz}, \mathrm{CD}_{3} \mathrm{OD}\right)$ $\delta=175.4,162.1,159.8,158.4,155.3,154.5,150.5,149.4,143.9,143.5,142.7,142.0,139.7$, 132.3, 126.0, 123.9, 118.6, 116.7, 114.6, 111.8, 110.5, 103.8, 97.6, 56.2, 48.5, 46.1, 45.5, 45.4 , 44.9, 41.8, 39.0, 38.7, 36.7, 32.9, 31.1, 30.8, 30.4, 29.6, 29.5, 28.4, 26.8, 26.8, 26.3, 25.8, 23.7, 21.4, 14.4, 12.8.IR 2928, 2859, 1713, 1618, 1579, 1504, 1453, 1417, 1355, 1278, 1238, 1133, 1042, 671. ESI-HRMS calcd for $\mathrm{C}_{53} \mathrm{H}_{72} \mathrm{~N}_{3} \mathrm{NaO}_{8} \mathrm{~S}[\mathrm{M}+\mathrm{H}]^{+} 910.5035$, found 910.5008 . 


\section{Synthesis of $3 b$}
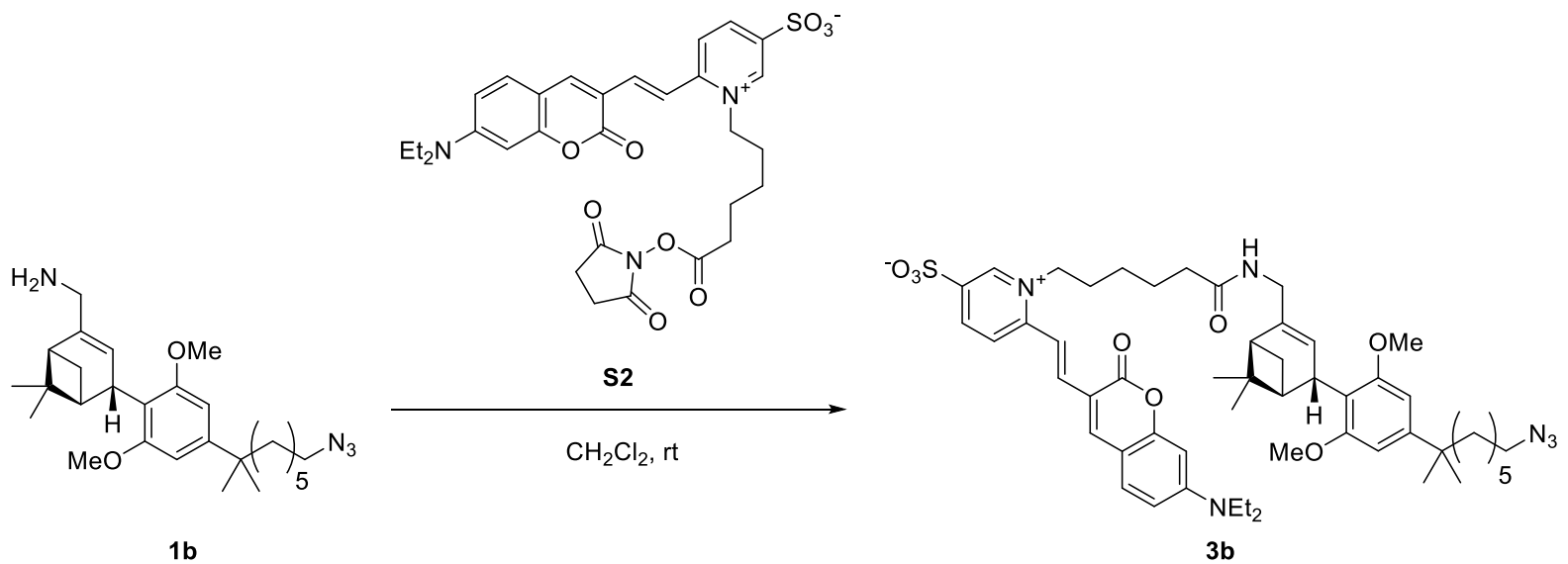

3b

The NHS ester of DY480XL S2 $(5.0 \mathrm{mg}, 0.0082 \mathrm{mmol}, 1.0$ equiv) was combined with a solution of amine $\mathbf{1 b}\left(5.0 \mathrm{mg}, 0.011 \mathrm{mmol}, 1.3\right.$ equiv) in $\mathrm{CH}_{2} \mathrm{Cl}_{2}(0.3 \mathrm{~mL})$ and stirred at ambient temperature until LCMS analysis indicated full consumption of the active ester $(<2 \mathrm{~h})$. The product was isolated by preparative TLC $\left(10 \% \mathrm{MeOH}\right.$ in $\left.\mathrm{CH}_{2} \mathrm{Cl}_{2}\right)$ as dark-red oil $(7.0 \mathrm{mg}$, $0.0074 \mathrm{mmol}, 90 \%)$.

$\mathbf{R}_{\mathbf{f}}=0.26\left(10 \% \mathrm{MeOH}\right.$ in $\mathrm{CH}_{2} \mathrm{Cl}_{2}$; red spot, UV, Seebach). ${ }^{1} \mathbf{H}$ NMR $\left(500 \mathrm{MHz}, \mathrm{CD}_{2} \mathrm{Cl}_{2}\right) \delta=9.02$ (d, $J=1.6 \mathrm{~Hz}, 1 \mathrm{H}), 8.68(\mathrm{~d}, J=8.4 \mathrm{~Hz}, 1 \mathrm{H}), 8.18-8.12(\mathrm{~m}, 2 \mathrm{H}), 7.95(\mathrm{~s}, 1 \mathrm{H}), 7.52(\mathrm{~d}, J=15.3$ $\mathrm{Hz}, 1 \mathrm{H}), 7.47$ (d, $J=9.0 \mathrm{~Hz}, 1 \mathrm{H}), 6.73(\mathrm{dd}, J=9.0,2.5 \mathrm{~Hz}, 1 \mathrm{H}), 6.54(\mathrm{~d}, J=2.4 \mathrm{~Hz}, 1 \mathrm{H}), 6.51$ (s, $1 \mathrm{H}), 6.00$ (t, J=5.8 Hz, 1H), $5.63(\mathrm{dt}, J=2.9,1.5 \mathrm{~Hz}, 1 \mathrm{H}), 4.61$ (t, $J=8.2 \mathrm{~Hz}, 2 \mathrm{H}$ ), $3.99-$ $3.96(\mathrm{~m}, 1 \mathrm{H}), 3.92-3.82(\mathrm{~m}, 2 \mathrm{H}), 3.75(\mathrm{~d}, J=6.3 \mathrm{~Hz}, 6 \mathrm{H}), 3.50(\mathrm{q}, J=7.2 \mathrm{~Hz}, 4 \mathrm{H}), 3.25(\mathrm{t}, J$ $=7.0 \mathrm{~Hz}, 2 \mathrm{H}), 2.29(\mathrm{t}, J=7.5 \mathrm{~Hz}, 2 \mathrm{H}), 2.21-2.16(\mathrm{~m}, 1 \mathrm{H}), 2.16-2.12(\mathrm{~m}, 1 \mathrm{H}), 2.12-2.06$ (m, 2H), 2.03 (tt, $J=5.9,1.9 \mathrm{~Hz}, 1 \mathrm{H}), 1.78(\mathrm{q}, J=7.5 \mathrm{~Hz}, 2 \mathrm{H}), 1.72(\mathrm{~d}, J=8.3 \mathrm{~Hz}, 1 \mathrm{H}), 1.65-$ $1.53(\mathrm{~m}, 6 \mathrm{H}), 1.37-1.32(\mathrm{~m}, 2 \mathrm{H}), 1.31-1.24(\mathrm{~m}, 17 \mathrm{H}), 1.15(\mathrm{qd}, J=8.1,4.8 \mathrm{~Hz}, 2 \mathrm{H}), 0.98$ (s, 3H). ${ }^{13} \mathrm{C}$ NMR $\left(126 \mathrm{MHz}, \mathrm{CD}_{2} \mathrm{Cl}_{2}\right) \delta=172.3,160.6,158.9,157.4,153.4,153.0,149.8$, $147.8,145.5,142.8,142.3,141.2,139.1,131.2$, 124.7, 123.6, 117.9, 115.8, 113.7, 110.7, 109.3, 103.1, 97.1, 59.2, 56.1, 56.1, 51.9, 47.9, 45.6, 44.7, 44.6, 44.6, 41.1, 38.3, 37.9, 36.3, $30.2,29.8,29.2,29.1,27.9,27.0,26.5,26.2,25.0,25.0,21.2,12.6$. IR 3332, 3059, 2932, 2863, 2096, 1713, 1618, 1580, 1505, 1417, 1355, 1272, 1238, 1134, 1042, 671. ESI-HRMS calcd for $\mathrm{C}_{53} \mathrm{H}_{70} \mathrm{~N}_{6} \mathrm{NaO}_{8} \mathrm{~S}[\mathrm{M}+\mathrm{Na}]^{+}$973.4868, found 973.4857 . 


\section{Synthesis of S3}

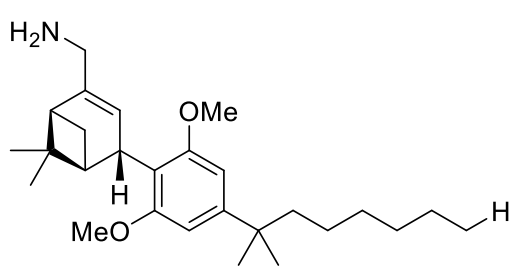

$1 \mathrm{a}$

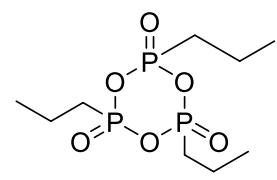

(1.2 equiv)

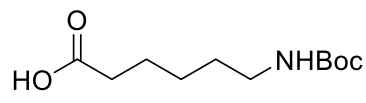

(1.2 equiv)

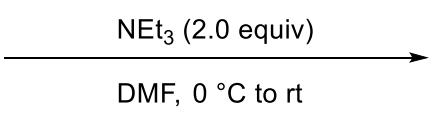

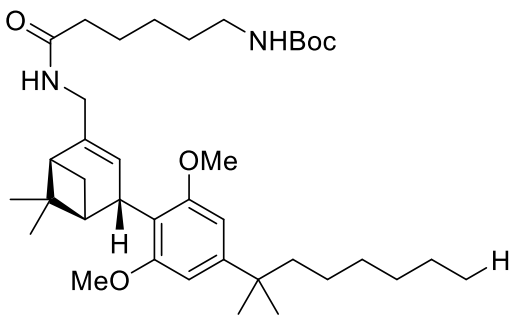

S3

To a solution of 6-(Boc-amino)hexanoic acid (33.5 mg, $0.145 \mathrm{mmol}, 1.20$ equiv) and 1a (50 mg, $0.12 \mathrm{mmol}, 1.0$ equiv) in DMF $(0.6 \mathrm{~mL})$ at $0^{\circ} \mathrm{C}$ was added propylphosphonic anhydride (50 wt\% in DMF, $0.85 \mu \mathrm{L}, 0.15 \mathrm{mmol}, 1.2$ equiv) and $\mathrm{NEt}_{3}$ (34 $\mu \mathrm{L}, 0.24$ mmol, 2.0 equiv). The resulting yellow solution was allowed to warm to ambient temperature and was stirred for $20 \mathrm{~h}$. The reaction was then stopped by addition of water. After dilution with EtOAc $(20 \mathrm{~mL})$ and separation of the organic phase, the aqueous layer was extracted with EtOAc (3 $x 10 \mathrm{~mL}$ ). The combined organic layers were washed with water, sat. aq. $\mathrm{NaHCO}_{3}, 5 \mathrm{wt} \%$ aq. $\mathrm{LiCl}$ and brine, dried over $\mathrm{Na}_{2} \mathrm{SO}_{4}$ and concentrated under reduced pressure. Purification by flash chromatography (hexanes/EtOAc 9:1, then 1:1) afforded the product as yellow oil (45 mg, $0.0072 \mathrm{mmol}, 59 \%$ yield).

${ }^{1} \mathrm{H}$ NMR $\left(400 \mathrm{MHz}, \mathrm{CDCl}_{3}\right) \delta=6.48(\mathrm{~s}, 2 \mathrm{H}), 5.62-5.59(\mathrm{~m}, 1 \mathrm{H}), 5.33(\mathrm{~s}, 1 \mathrm{H}), 4.52(\mathrm{~s}, 1 \mathrm{H})$, $3.96(\mathrm{t}, J=2.3 \mathrm{~Hz}, 1 \mathrm{H}), 3.92-3.79(\mathrm{~m}, 2 \mathrm{H}), 3.73(\mathrm{~s}, 6 \mathrm{H}), 3.14-3.07(\mathrm{~m}, 2 \mathrm{H}), 2.23-2.14(\mathrm{~m}$, $3 \mathrm{H}), 2.11-2.04(\mathrm{~m}, 2 \mathrm{H}), 1.72-1.62(\mathrm{~m}, 3 \mathrm{H}), 1.58-1.53(\mathrm{~m}, 2 \mathrm{H}), 1.52-1.46(\mathrm{~m}, 2 \mathrm{H}), 1.43$ $(\mathrm{s}, 9 \mathrm{H}), 1.40-1.33(\mathrm{~m}, 2 \mathrm{H}), 1.28(\mathrm{~s}, 3 \mathrm{H}), 1.26(\mathrm{~s}, 6 \mathrm{H}), 1.24-1.19(\mathrm{~m}, 6 \mathrm{H}), 1.14-1.06(\mathrm{~m}$, $2 \mathrm{H}), 0.95(\mathrm{~s}, 3 \mathrm{H}), 0.87-0.83(\mathrm{~m}, 3 \mathrm{H}) .{ }^{13} \mathrm{C}$ NMR $\left(101 \mathrm{MHz}, \mathrm{CDCl}_{3}\right) \delta=172.7,158.5,156.1$, 149.7, 138.5, 124.0, 117.5, 102.9, 79.2, 56.0, 47.4, 44.7, 44.6, 44.5, 40.9, 40.5, 38.1, 37.6, 37.0, 32.0, 30.2, 30.0, 29.1, 28.6, 28.0, 26.6, 26.4, 25.6, 24.8, 22.8, 21.2, 14.2 IR 3320, 2929, 2861, 1695, 1648, 1606, 1572, 1533, 1453, 1411, 1365, 1238, 1173, 1123. ESI-HRMS calcd for $\mathrm{C}_{38} \mathrm{H}_{63} \mathrm{~N}_{2} \mathrm{O}_{5}[\mathrm{M}+\mathrm{H}]^{+} 627.4731$; found 627.4723. $[\alpha]_{\mathbf{D}}^{25}=+62.4\left(\mathrm{c}=1.0, \mathrm{CHCl}_{3}\right)$. 


\section{Synthesis of 4}
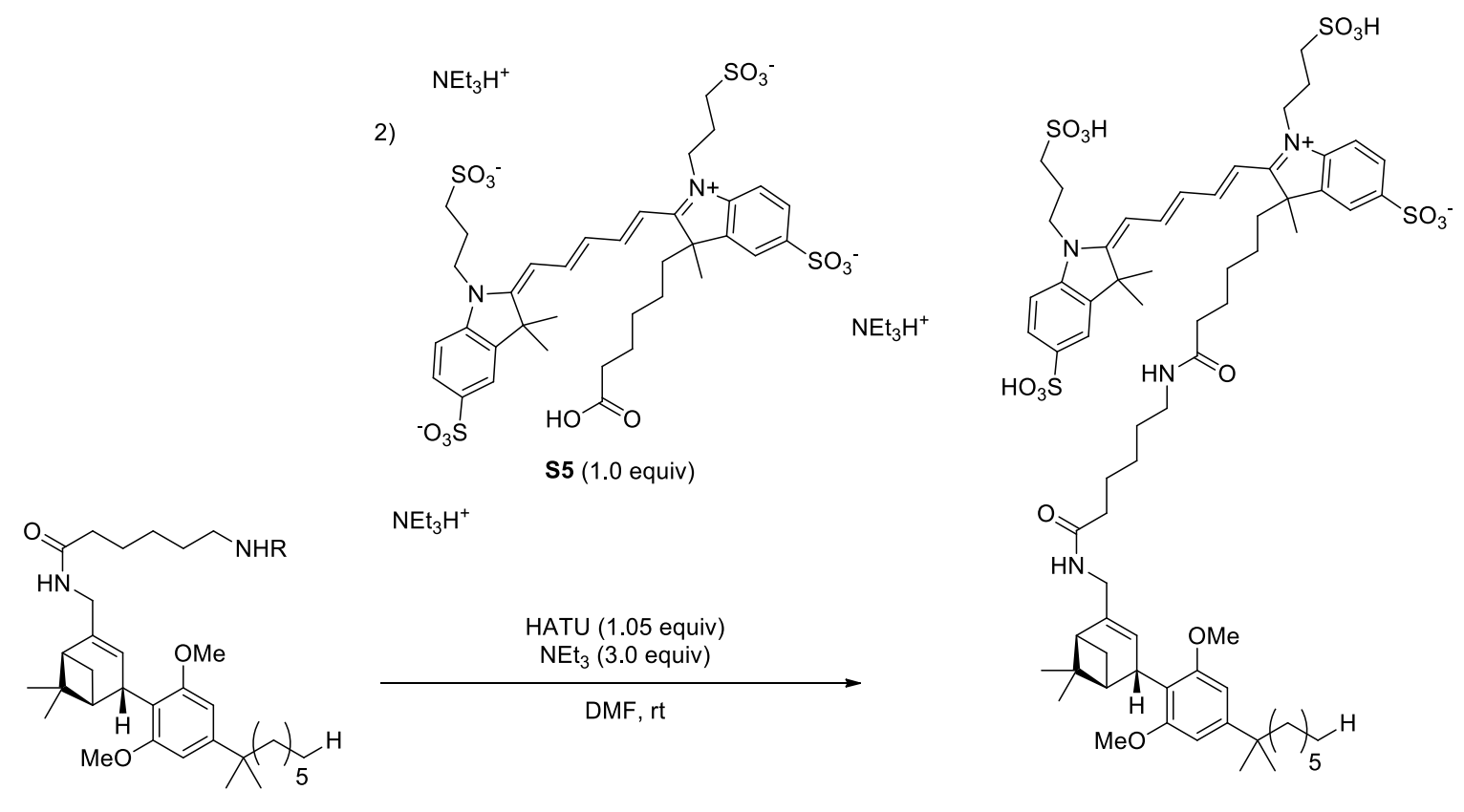

S3 $\mathrm{R}=\mathrm{Boc} \longrightarrow$ 1) $\mathrm{HCl}, 1$,4-dioxane, quant.
S4 $\mathrm{R}=\mathrm{H}_{2} \mathrm{Cl} \longleftarrow$

To a solution of $\mathbf{S 3}(4.3 \mathrm{mg}, 0.0064 \mathrm{mmol}, 1.5$ equiv) in dioxane $(0.032 \mathrm{~mL})$ was added $4.0 \mathrm{M}$ $\mathrm{HCl}$ in dioxane $(0.0081 \mathrm{~mL}, 0.032 \mathrm{mmol}, 7.5$ equiv) and it was stirred for 1 hour at ambient temperature. The solvent was removed under a stream of nitrogen followed by high vacuum. The obtained hydrochloride was used as is in the subsequent step.

The (tris)triethylammonium salt $\mathbf{S} 5$ of Alexa647 carboxylic acid $(5.0 \mathrm{mg}, 0.0043 \mathrm{mmol}, 1.0$ equiv) was combined with a solution of hydrochloride $\mathbf{S 4}$ (3.6 $\mathrm{mg}, 0.0064 \mathrm{mmol}, 1.5$ equiv) in DMF (0.043 mL). Then, $\mathrm{NEt}_{3}(1.8 \mu \mathrm{L}, 0.013 \mathrm{mmol}, 3.0$ equiv) and HATU $(1.7 \mathrm{mg}, 0.0045 \mathrm{mmol}$, 1.0 equiv) were added to the reaction mixture and it was left to stir for $15 \mathrm{~h}$. Since conversion was observed to be incomplete, HATU $(0.8 \mathrm{mg}, 0.002 \mathrm{mmol}, 0.5$ equiv) was re-added to the reaction mixture and the mixture was left to stir for another 2 hours upon which full conversion was monitored by TLC. The mixture was diluted with $\mathrm{H}_{2} \mathrm{O}$ and $\mathrm{MeOH}$ and lyophilized to remove the solvent. The crude product was further purified by flash chromatography (superneutral silica, dry loading, $20 \% \mathrm{MeOH}$ in $\mathrm{CH}_{2} \mathrm{Cl}_{2}$ to $10 \%$ water/20\% isopropyl alcohol in ethyl acetate to $20 \%$ water/40\% isopropyl alcohol in ethyl acetate) to remove co-eluting HOAt contaminant. Further purification by preparative TLC (20\% water/40\% isopropyl alcohol in ethyl acetate) furnished the product ( $1.8 \mathrm{mg}, 0.0011 \mathrm{mmol}, 26 \%$ ) as deep blue oil.

$\mathbf{R}_{\mathbf{f}}=0.42$ (20\% water/40\% isopropyl alcohol in ethyl acetate; blue spot, UV). ${ }^{1} \mathbf{H}$ NMR (600 $\left.\mathrm{MHz}, \mathrm{CD}_{3} \mathrm{OD}\right) \delta=8.35(\mathrm{q}, J=12.5 \mathrm{~Hz}, 2 \mathrm{H}), 7.92-7.89(\mathrm{~m}, 3 \mathrm{H}), 7.86(\mathrm{~d}, J=1.7 \mathrm{~Hz}, 1 \mathrm{H}), 7.46$ 
(d, $J=8.6 \mathrm{~Hz}, 1 \mathrm{H}), 7.43(\mathrm{dd}, J=8.4,2.9 \mathrm{~Hz}, 1 \mathrm{H}), 6.75(\mathrm{t}, J=12.4 \mathrm{~Hz}, 1 \mathrm{H}), 6.53-6.46(\mathrm{~m}$, $2 \mathrm{H}), 6.51(\mathrm{~s}, 2 \mathrm{H}), 5.57-5.55(\mathrm{~m}, 1 \mathrm{H}), 4.38-4.33(\mathrm{~m}, 4 \mathrm{H}), 3.97-3.95(\mathrm{~m}, 1 \mathrm{H}), 3.79(\mathrm{dt}, J=$ $15.2,1.8 \mathrm{~Hz}, 1 \mathrm{H}$ ), $3.72(\mathrm{dt}, J=15.2,1.8 \mathrm{~Hz}, 1 \mathrm{H}), 3.71(\mathrm{~d}, J=1.0 \mathrm{~Hz}, 6 \mathrm{H}), 3.06(\mathrm{tt}, J=7.1,1.7$ $\mathrm{Hz}, 2 \mathrm{H}), 2.98(\mathrm{q}, J=6.8 \mathrm{~Hz}, 4 \mathrm{H}), 2.46(\mathrm{t}, J=13 \mathrm{~Hz}, 1 \mathrm{H}), 2.28-2.19(\mathrm{~m}, 7 \mathrm{H}), 2.15-2.13(\mathrm{~m}$, $1 \mathrm{H}), 2.08(\mathrm{td}, J=5.7,1.4 \mathrm{~Hz}, 1 \mathrm{H}), 2.00-1.96(\mathrm{~m}, 3 \mathrm{H}), 1.77-1.72(\mathrm{~m}, 10 \mathrm{H}), 1.62-1.58(\mathrm{~m}$, $4 \mathrm{H}), 1.47-1.43(\mathrm{~m}, 4 \mathrm{H}), 1.33-1.31(\mathrm{~m}, 2 \mathrm{H}), 1.27(\mathrm{~s}, 3 \mathrm{H}), 1.26(\mathrm{~s}, 6 \mathrm{H}), 1.24-1.19(\mathrm{~m}, 8 \mathrm{H})$, $1.10-1.05(\mathrm{~m}, 2 \mathrm{H}), 0.95-0.93(\mathrm{~m}, 1 \mathrm{H}), 0.94(\mathrm{~s}, 3 \mathrm{H}), 0.85(\mathrm{t}, J=6.9 \mathrm{~Hz}, 3 \mathrm{H}), 0.66-0.57(\mathrm{~m}$, $1 \mathrm{H}) .{ }^{13} \mathrm{C}$ NMR $\left(151 \mathrm{MHz}, \mathrm{CD}_{3} \mathrm{OD}\right) \delta=175.9,175.8,175.5,173.7,159.8,159.8,156.8,156.0$, $150.4,145.8,144.9,143.5,143.4,142.6,140.8,139.8,128.5,128.2,128.1,124.0,121.4$, $121.3,118.7,111.8,111.5,105.8,105.6,103.8,103.8,56.2,56.2,55.1,50.7,48.9,49.3,49.3$, $45.5,45.5,44.9,44.2,44.1,42.1,41.8,40.2,39.0,38.7,37.1,36.6,32.9,31.1,30.0,29.9$, 29.6, 29.6, 28.4, 27.8, 27.8, 27.8, 27.6, 26.9, 26.9, 26.3, 25.8, 25.1, 24.3, 24.1, 23.7, 21.4, 14.4. IR 2368, 2929, 1571, 1489, 1445, 1385, 1190, 1153, 1116, 1024, 980, 689, 616. ESIHRMS calcd for $\mathrm{C}_{69} \mathrm{H}_{99} \mathrm{~N}_{4} \mathrm{O}_{16} \mathrm{~S}_{4}[\mathrm{M}]^{+}$1367.5933; found 1367.5948 . 


\section{Synthesis of $\mathbf{S 6}$}

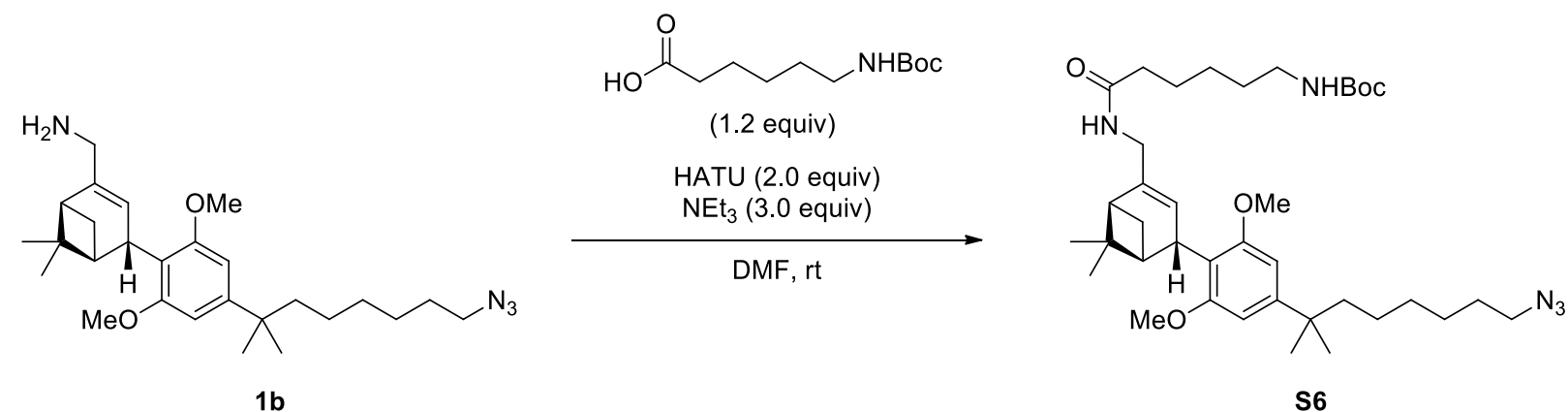

To a solution of $\mathbf{1 b}(0.008 \mathrm{~g}, \quad 0.02 \mathrm{mmol}, 1.0$ equiv) and 6-((tertbutoxycarbonyl)amino)hexanoic acid $(0.006 \mathrm{~g}, 0.03 \mathrm{mmol}, 1.5$ equiv $)$ in anhydrous DMF $(0.18$ $\mathrm{mL}$ ) at $0{ }^{\circ} \mathrm{C}$ was added HATU $\left(0.01 \mathrm{~g}, 0.04 \mathrm{mmol}, 2.0\right.$ equiv) and $\mathrm{NEt}_{3}(0.007 \mathrm{~mL}, 0.05 \mathrm{mmol}$, 3.0 equiv) and the resulting yellow solution was stirred at ambient temperature for $18 \mathrm{~h}$. The reaction was stopped by addition of water $(1 \mathrm{~mL})$ and the aqueous layer was extracted with $\mathrm{Et}_{2} \mathrm{O}(3 \times 5 \mathrm{~mL})$. The combined organic extracts were washed with water and brine, dried over $\mathrm{Na}_{2} \mathrm{SO}_{4}$ and concentrated under reduced pressure. Purification of the crude material by flash column chromatography $\left(\mathrm{SiO}_{2}\right.$; using 30 to $70 \%$ EtOAc in hexanes), followed by further purification by preparative TLC $\left(5 \% \mathrm{MeOH}\right.$ in $\left.\mathrm{CH}_{2} \mathrm{Cl}_{2}\right)$ afforded the product as faintly yellow oil (10 mg, 85\% yield).

${ }^{1} \mathrm{H}$ NMR $\left(500 \mathrm{MHz}, \mathrm{CDCl}_{3}\right) \delta=6.47(\mathrm{~s}, 2 \mathrm{H}), 5.62-5.59(\mathrm{~m}, 1 \mathrm{H}), 5.37-5.31(\mathrm{~m}, 1 \mathrm{H}), 4.53(\mathrm{~s}$, $1 \mathrm{H}), 3.96(\mathrm{t}, J=2.3 \mathrm{~Hz}, 1 \mathrm{H}), 3.91-3.79(\mathrm{~m}, 2 \mathrm{H}), 3.73(\mathrm{~s}, 6 \mathrm{H}), 3.22(\mathrm{t}, J=6.9 \mathrm{~Hz}, 2 \mathrm{H}), 3.10$ (q, $J=6.8 \mathrm{~Hz}, 2 \mathrm{H}), 2.22-2.14(\mathrm{~m}, 3 \mathrm{H}), 2.11-2.03(\mathrm{~m}, 2 \mathrm{H}), 1.72-1.62(\mathrm{~m}, 3 \mathrm{H}), 1.59-1.47$ (m, 9H), $1.43(\mathrm{~s}, 6 \mathrm{H}), 1.39-1.29(\mathrm{~m}, 4 \mathrm{H}), 1.28(\mathrm{~s}, 6 \mathrm{H}), 1.27(\mathrm{~s}, 3 \mathrm{H}), 1.25-1.19(\mathrm{~m}, 2 \mathrm{H}), 1.16$ $-1.07(\mathrm{~m}, 2 \mathrm{H}), 0.95(\mathrm{~s}, 3 \mathrm{H}) .{ }^{13} \mathrm{C}$ NMR $\left(126 \mathrm{MHz}, \mathrm{CDCl}_{3}\right) \delta=172.7,158.5,156.1,149.4,138.6$, 124.0, 117.6, 102.8, 79.2, 55.9, 51.6, 47.4, 44.6, 44.6, 44.5, 40.9, 40.5, 38.1, 37.6, 36.9, 30.0, 29.8, 29.0, 29.0, 28.6, 28.0, 26.7, 26.6, 26.4, 25.6, 24.7, 21.2. IR (neat, $v_{\max } / \mathrm{cm}^{-1}$ ) 3328, 2925, 2855, 2096, 1701, 1650, 1519, 1461, 1365, 1239, 1123. ESI-HRMS calcd for $\mathrm{C}_{38} \mathrm{H}_{61} \mathrm{~N}_{5} \mathrm{NaO}_{5}$ $690.4565[\mathrm{M}+\mathrm{Na}]^{+}$; found 690.4556 


\section{Synthesis of 5}
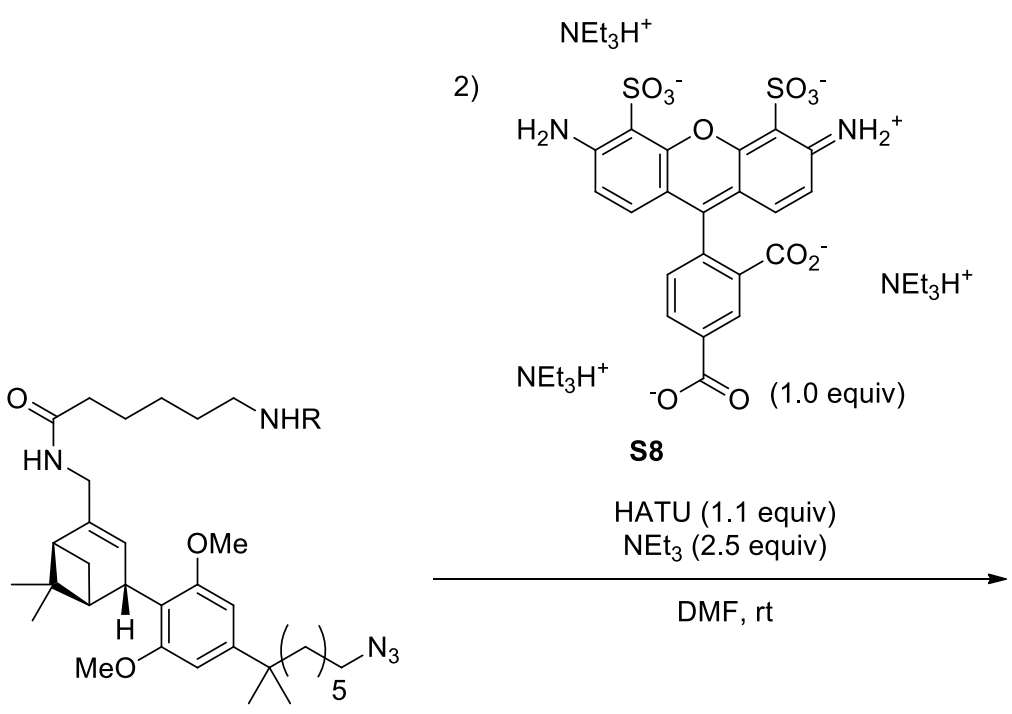

S6 $\mathrm{R}=\mathrm{Boc} \longrightarrow$ 1) $\mathrm{HCl}$, quant.
S7 R $=\mathrm{H}_{2} \mathrm{Cl} \longleftarrow$

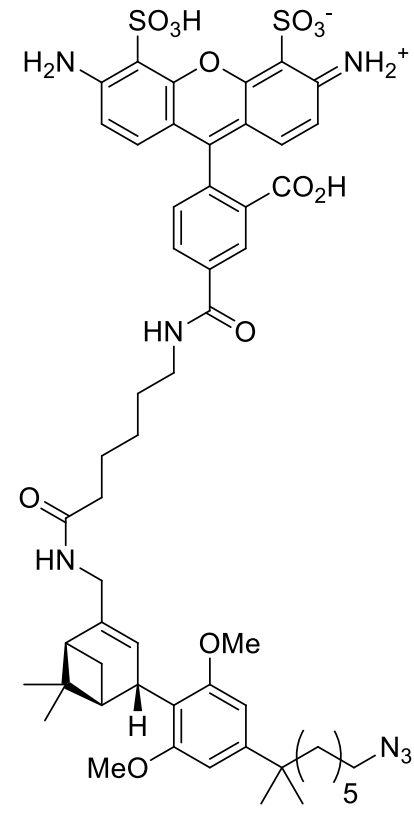

5

To a solution of $\mathbf{S 6}(9.0 \mathrm{mg}, 0.013 \mathrm{mmol}, 2.0$ equiv) in dioxane $(0.14 \mathrm{~mL})$ was added $2.0 \mathrm{M}$ $\mathrm{HCl}$ in ether $(0.051 \mathrm{~mL}, 0.10 \mathrm{mmol}, 17$ equiv) and the mixture was stirred for 1 hour at ambient temperature. The solvent was removed under a stream of nitrogen followed by high vacuum. The obtained hydrochloride was used without further purification in the subsequent step.

A solution of hydrochloride $\mathbf{S} 7(8.0 \mathrm{mg}, 0.013 \mathrm{mmol}, 2.2$ equiv) in DMF $(0.1 \mathrm{~mL})$ was added to the $\mathbf{S} 8\left(5.0 \mathrm{mg}, 6.0 \mu \mathrm{mol}, 1.0\right.$ equiv) $\mathrm{NEt}_{3}(4.2 \mu \mathrm{L}, 0.030 \mathrm{mmol}, 5.0$ equiv) and HATU (2.5 mg, $6.6 \mu \mathrm{mol}, 1.1$ equiv) were added. The reaction mixture was stirred at ambient temperature overnight. Another portion of HATU ( $1.1 \mathrm{mg}, 3.0 \mu \mathrm{mol}, 0.5$ equiv) was added and stirring was continued for 20 hours. Water was added and all volatiles were removed by lyophilization. Purification by preparative TLC (20\% water $40 \%$ PrOH $40 \%$ EtOAc) did not afford pure material. Further purification by preparative reverse-phase HPLC (Reprosil Gold $120 \mathrm{C} 18125$ x $20 \mathrm{~mm}$ column, flow $26.5 \mathrm{~mL} / \mathrm{min}$ ) afforded the product as dark red solid ( $2 \mathrm{mg}, 30 \%$ yield).

ESI-HRMS calcd for $\mathrm{C}_{54} \mathrm{H}_{63} \mathrm{~N}_{7} \mathrm{O}_{13} \mathrm{~S}_{2} 540.6968[\mathrm{M}-\mathrm{H}]^{2-}$; found 540.6982. Preparative HPLC (Reprosil Gold $120 \mathrm{C} 18125 \times 20 \mathrm{~mm}$ column, flow $26.5 \mathrm{~mL} / \mathrm{min}) \mathrm{H}_{2} \mathrm{O}(+0.1 \% \mathrm{HCOOH}): \mathrm{MeCN}$ $(+0.1 \% \mathrm{HCOOH})=30: 70(\mathrm{t}=0.0 \mathrm{~min}) \rightarrow 10: 90(\mathrm{t}=8.0 \mathrm{~min}) \rightarrow 10: 90(\mathrm{t}=9.0 \mathrm{~min}) \rightarrow 10: 90(\mathrm{t}$ 
$=12.0 \mathrm{~min}), t_{R}=4.55 \mathrm{~min}$. Analytical HPLC (Dr. Maisch Reprosphere C12, $5 \mu \mathrm{m}, 125 \times 4.6$ $\mathrm{mm}$, flow $1.0 \mathrm{~mL} / \mathrm{min}): \mathrm{H}_{2} \mathrm{O}(+0.1 \% \mathrm{HCOOH}): \mathrm{MeCN}(+0.1 \% \mathrm{HCOOH})=40: 60(\mathrm{t}=0.0 \mathrm{~min})$ $\rightarrow 10: 90(\mathrm{t}=10.0 \mathrm{~min}), t_{R}=4.62 \mathrm{~min}$.
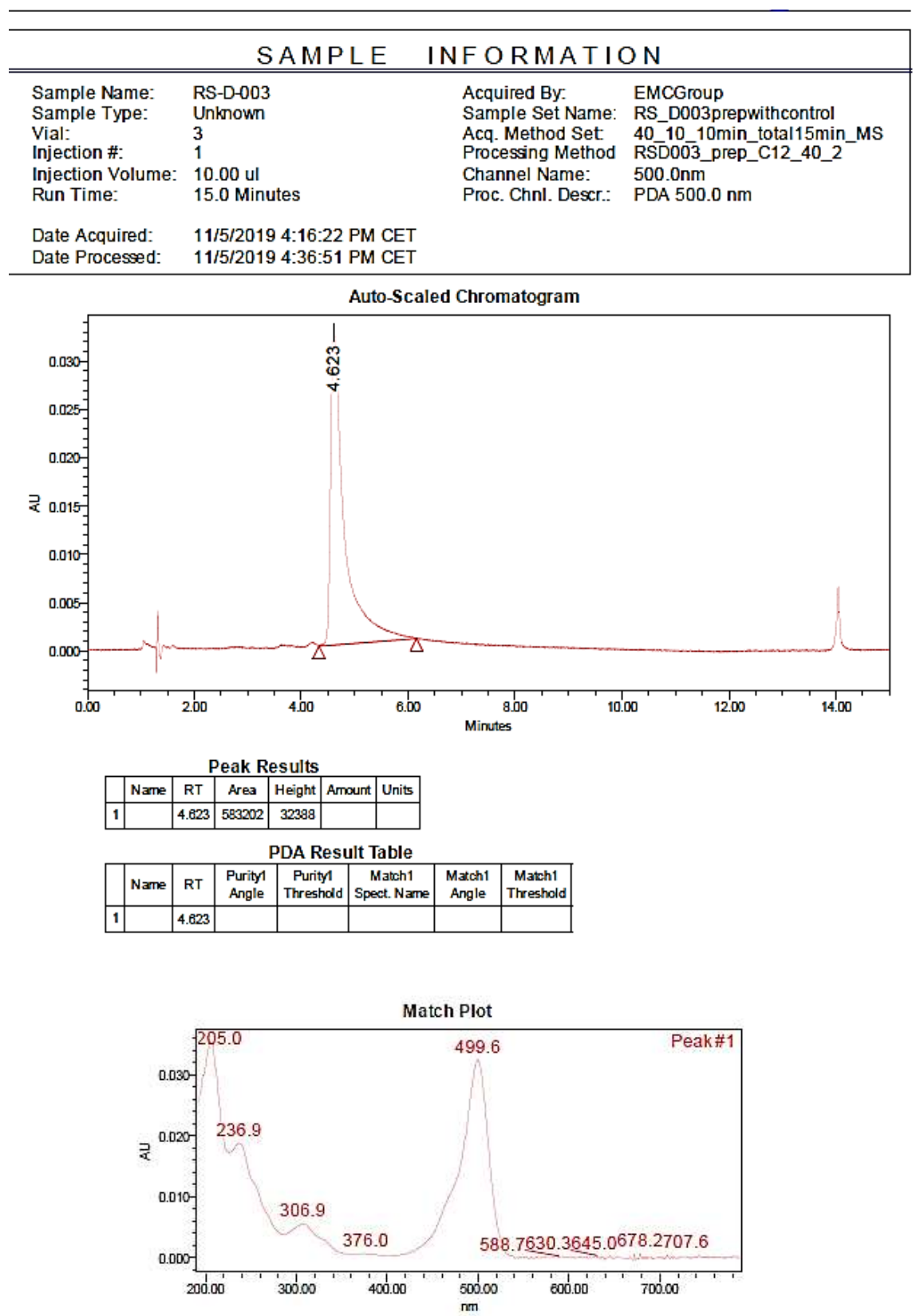


\section{Synthesis of 6}

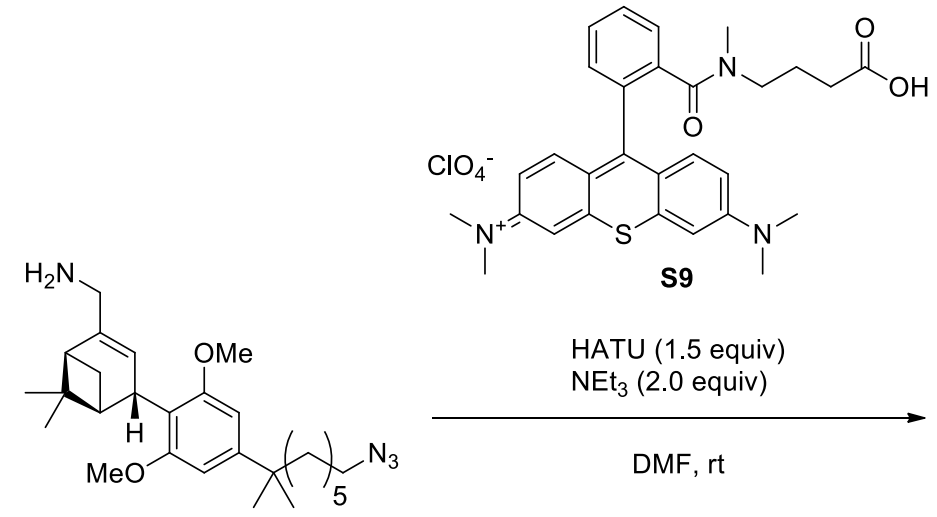

$1 \mathrm{~b}$

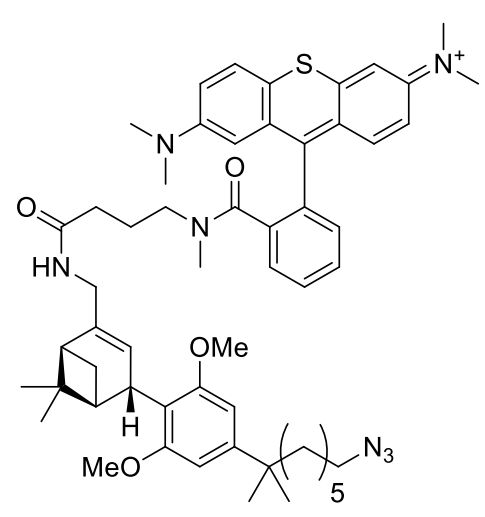

6

ATTO Thio12 carboxy S9 $(5.0 \mathrm{mg}, 0.0083 \mathrm{mmol}, 1.0$ equiv) was combined with a solution of amine 1b (5.7 mg, 0.012 mmol, 1.5 equiv) in DMF (0.17 mL). NEt 3 (2.3 mL, 0.017 mmol, 2.0 equiv) and HATU (4.7 mg, $0.012 \mathrm{mmol}, 1.5$ equiv) were added and the purple solution was stirred at ambient temperature under exclusion of light until LCMS analysis indicated full conversion of the dye $(<10 \mathrm{~h})$. After concentration by lyophilization the crude, purification by flash chromatography (superneutral silica, $2-3 \% \mathrm{MeOH}$ in $\mathrm{DCM}$ ) afforded the product as deep purple oil (6.0 mg, $0.0064 \mathrm{mmol}, 70 \%)$.

$\mathbf{R}_{\mathbf{f}}=0.53\left(10 \% \mathrm{MeOH}\right.$ in $\mathrm{CH}_{2} \mathrm{Cl}_{2}$; purple spot, UV, Seebach). ${ }^{1} \mathbf{H} \mathbf{N M R}(500 \mathrm{MHz}$, MeOD) $\delta=7.77-7.72(\mathrm{~m}, 2 \mathrm{H}), 7.68$-ff $7.63(\mathrm{~m}, 1 \mathrm{H}), 7.50-7.45(\mathrm{~m}, 1 \mathrm{H}), 7.39(\mathrm{dd}, J=9.7$, $1.0 \mathrm{~Hz}, 2 \mathrm{H}), 7.20$ (dd, $J=15.1,2.6 \mathrm{~Hz}, 2 \mathrm{H}), 7.11-7.07(\mathrm{~m}, 2 \mathrm{H}), 6.56(\mathrm{~s}, 2 \mathrm{H}), 5.51(\mathrm{~m}, 1 \mathrm{H})$, $4.02-3.95(\mathrm{~m}, 1 \mathrm{H}), 3.80-3.74(\mathrm{~m}, 1 \mathrm{H}), 3.73(\mathrm{~s}, 6 \mathrm{H}), 3.66-3.60(\mathrm{~m}, 1 \mathrm{H}), 3.29-3.26(\mathrm{~m}$, $12 \mathrm{H}), 3.23-3.16(\mathrm{~m}, 4 \mathrm{H}), 2.87(\mathrm{~s}, 3 \mathrm{H}), 2.13-2.09(\mathrm{~m}, 1 \mathrm{H}), 2.05-1.97(\mathrm{~m}, 2 \mathrm{H}), 1.70(\mathrm{~d}, J=$ $8.4 \mathrm{~Hz}, 1 \mathrm{H}), 1.68-1.59(\mathrm{~m}, 4 \mathrm{H}), 1.48(\mathrm{q}, J=7.1 \mathrm{~Hz}, 2 \mathrm{H}), 1.42-1.35(\mathrm{~m}, 2 \mathrm{H}), 1.30-1.26(\mathrm{~m}$, $13 \mathrm{H}), 1.15-1.07(\mathrm{~m}, 2 \mathrm{H}), 0.92(\mathrm{~s}, 3 \mathrm{H}) .{ }^{13} \mathrm{C}$ NMR (126 MHz, MeOD) $\delta=174.7,170.6,159.9$, 159.2 , 155.2, 155.2, 150.5, 145.4, 145.4, 139.8, 137.7, 137.4, 135.4, 131.6, 130.7, 130.7, $128.4,123.6,120.3,120.3,118.7,116.5,116.4,106.6,103.9,103.8,56.3,52.4,47.3,45.5$, $45.4,44.9,41.9,40.8,39.1,38.7,37.8,33.9,33.1,30.8,30.5,29.8,29.6,29.5,28.4,27.6$, 26.8, 25.8, 23.9, 23.7, 21.4. IR 2931, 2862, 2094, 1620, 1593, 1498, 1449, 1391, 1363, 1343, 1251, 1179, 1157, 1122, 842. ESI-HRMS calcd for $\mathrm{C}_{56} \mathrm{H}_{72} \mathrm{~N}_{7} \mathrm{O}_{4} \mathrm{~S}[\mathrm{M}]^{+}$938.5361, found 938.5357. 
NMR SPECTRA
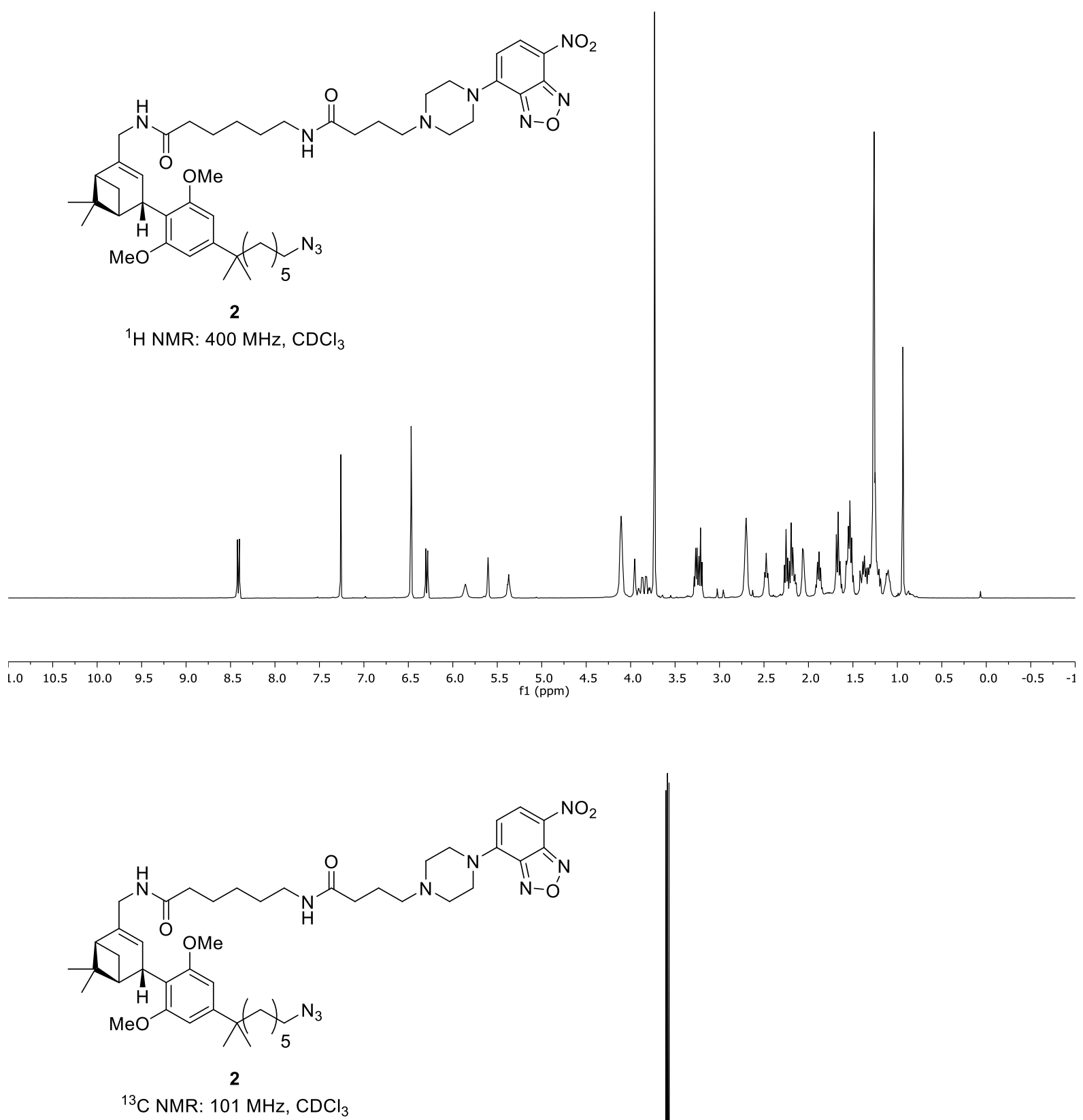

${ }^{13} \mathrm{C}$ NMR: $101 \mathrm{MHz}, \mathrm{CDCl}_{3}$
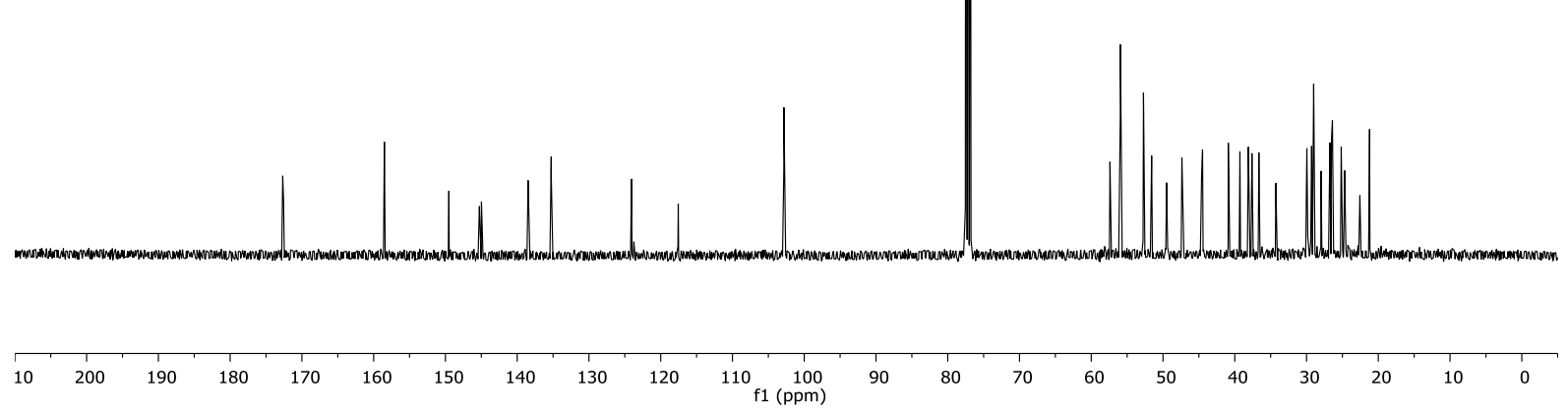

39 

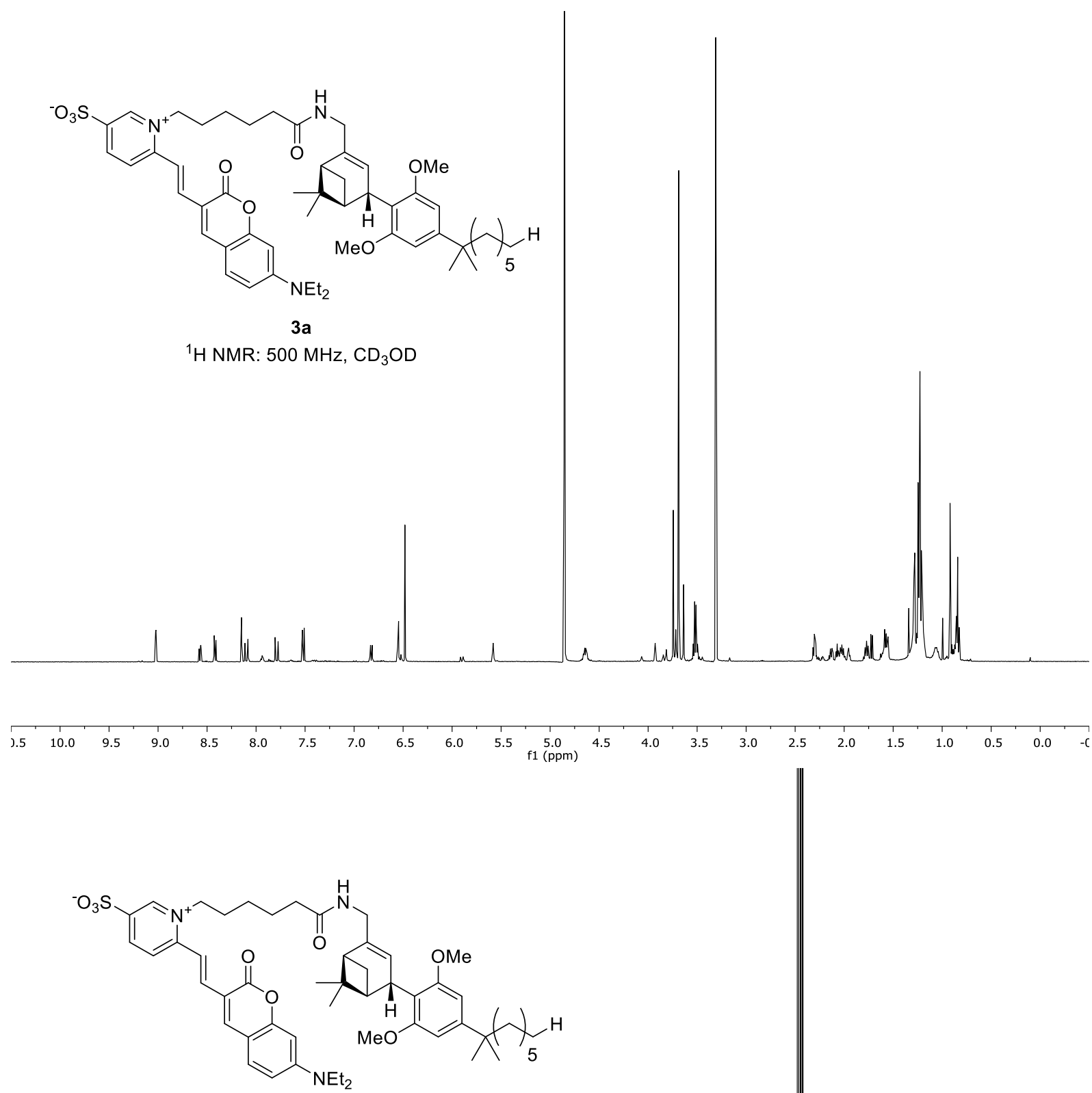

$3 a$

${ }^{13} \mathrm{C}$ NMR: $126 \mathrm{MHz}, \mathrm{CD}_{3} \mathrm{OD}$

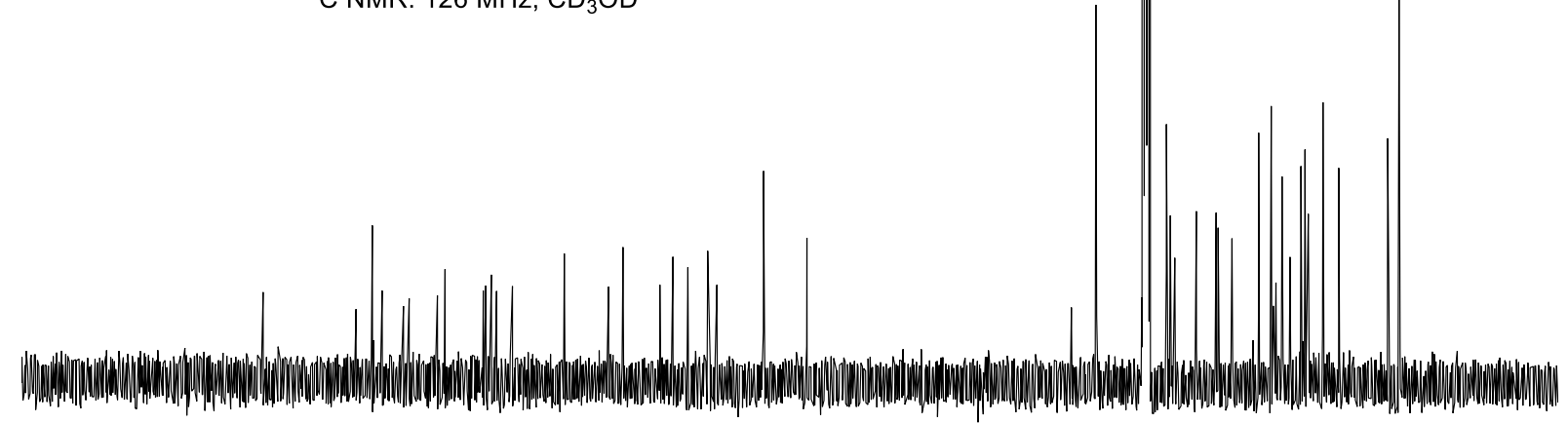

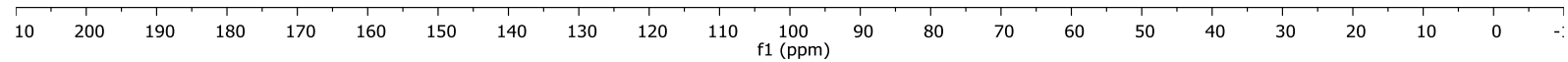




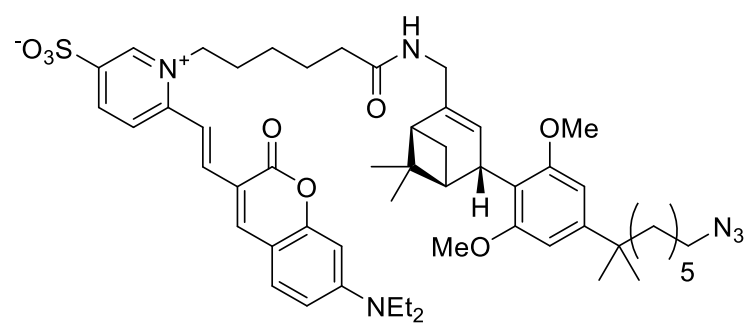

3b

${ }^{1} \mathrm{H}$ NMR: $500 \mathrm{MHz}, \mathrm{CD}_{2} \mathrm{Cl}_{2}$

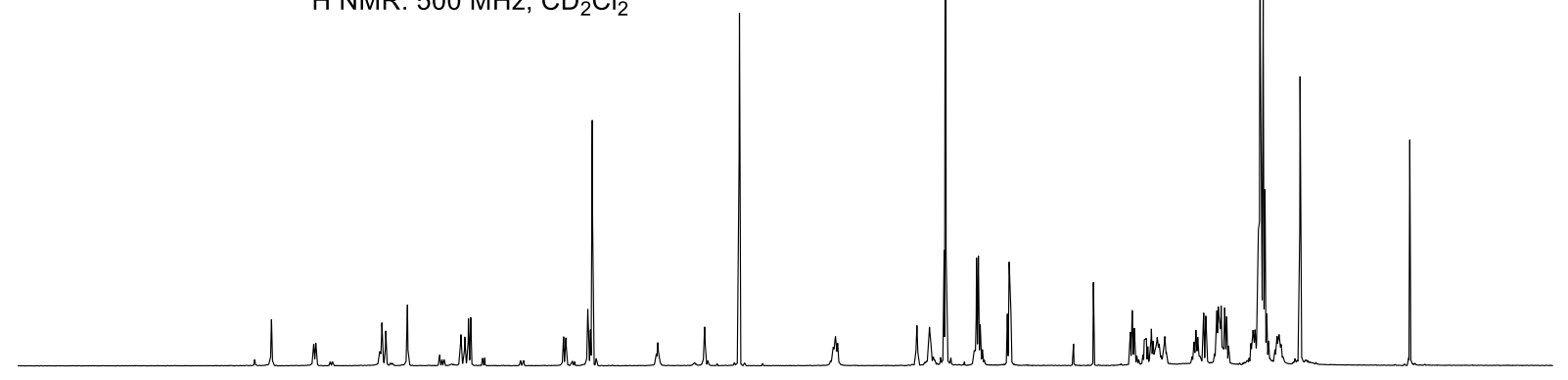

\begin{tabular}{llllllllllllllllllllllllllllll}
\hline 1.0 & 10.5 & 10.0 & 9.5 & 9.0 & 8.5 & 8.0 & 7.5 & 7.0 & 6.5 & 6.0 & 5.5 & 5.0 & 4.5 & 4.0 & 3.5 & 3.0 & 2.5 & 2.0 & 1.5 & 1.0 & 0.5 & 0.0 & -0.5 & -1
\end{tabular}

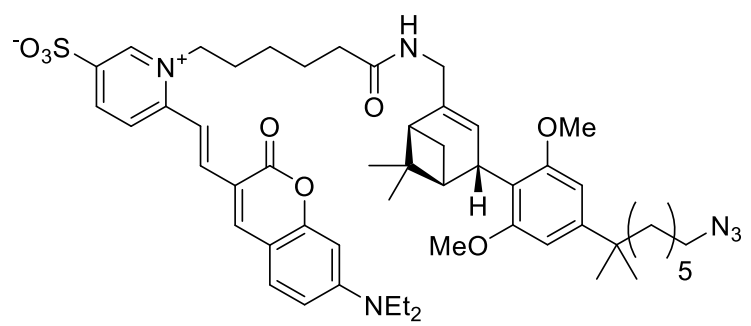

$3 \mathbf{b}$

${ }^{13} \mathrm{C}$ NMR: $126 \mathrm{MHz}, \mathrm{CD}_{2} \mathrm{Cl}_{2}$

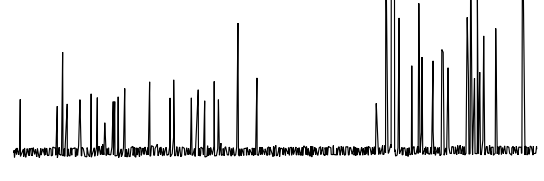

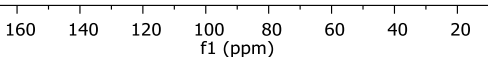

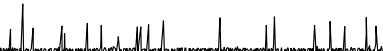

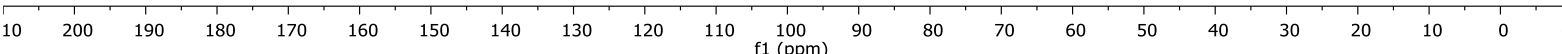



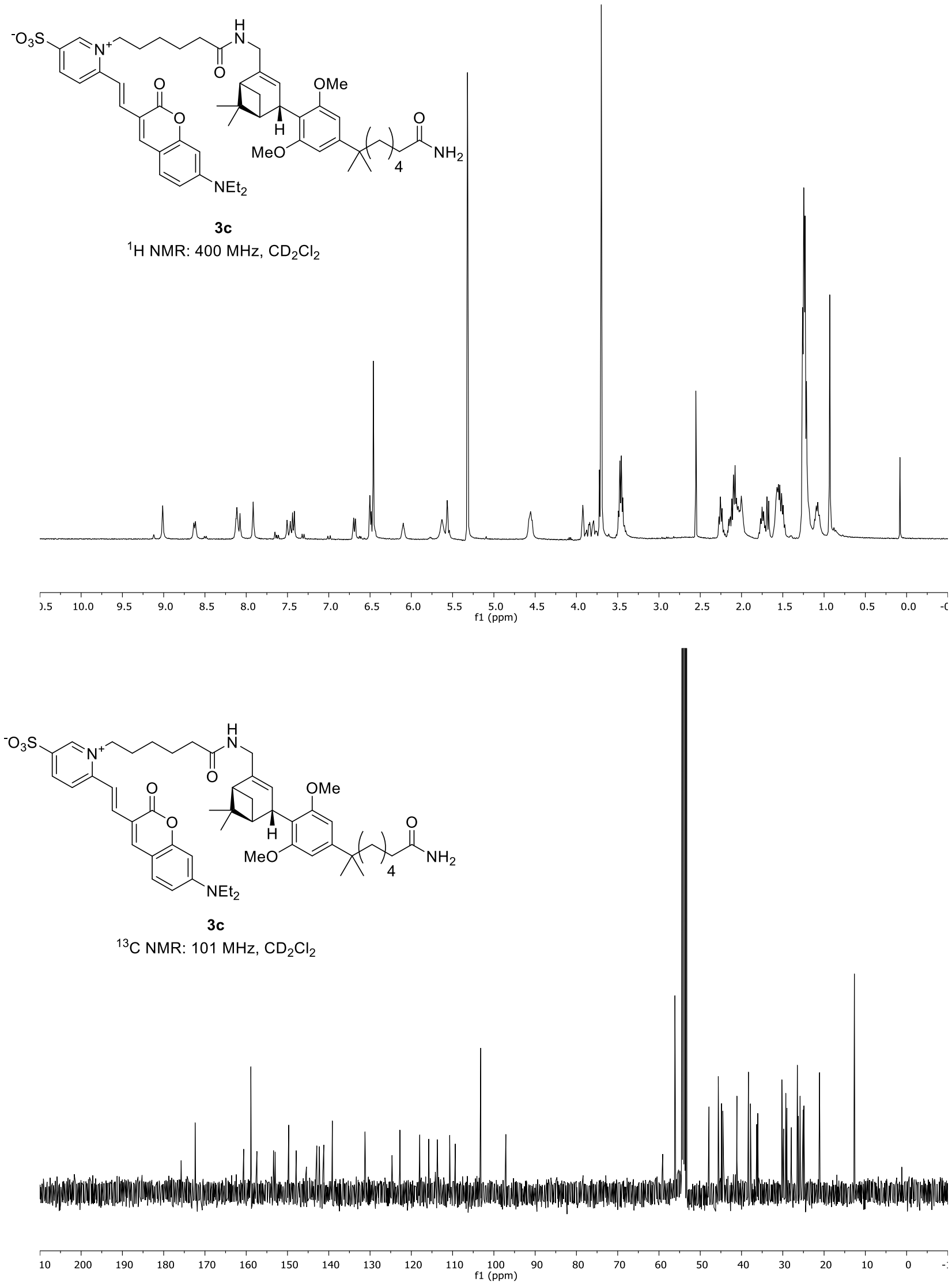

42 


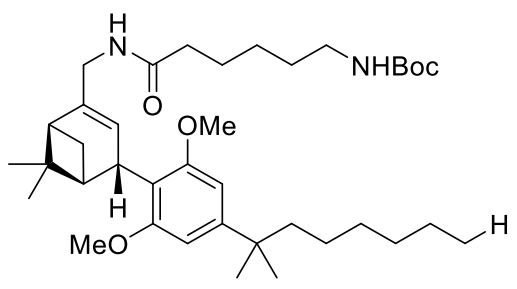

S3

${ }^{1} \mathrm{H}$ NMR: $400 \mathrm{MHz}, \mathrm{CDCl}_{3}$

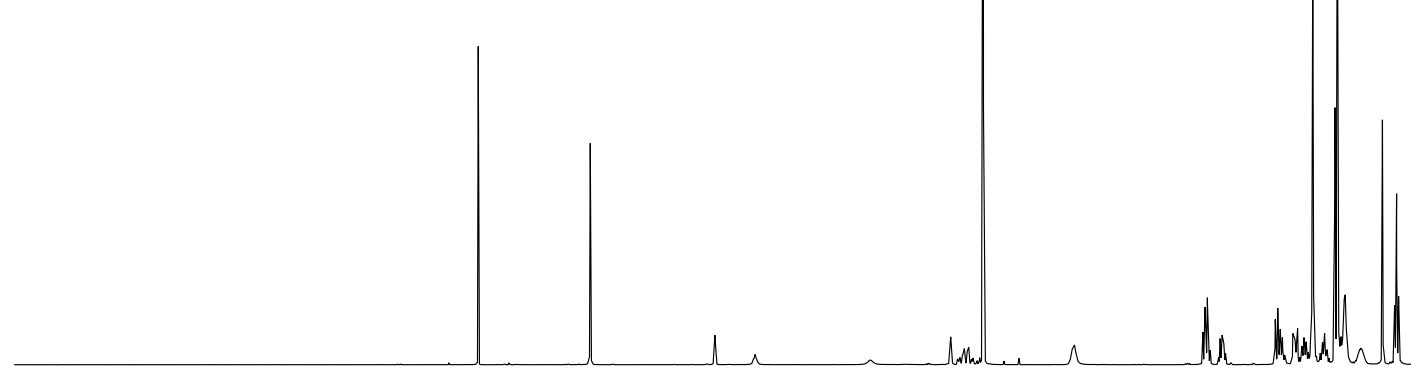

\begin{tabular}{lllllllllllllllllllllllllllll}
\hline .5 & 10.0 & 9.5 & 9.0 & 8.5 & 8.0 & 7.5 & 7.0 & 6.5 & 6.0 & 5.5 & 5.0 & 4.5 & 4.0 & 3.5 & 3.0 & 2.5 & 2.0 & 1.5 & 1.0 & 0.5 & 0.0 & $-c$
\end{tabular}

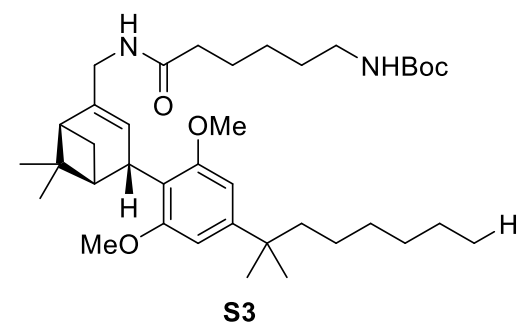

${ }^{13} \mathrm{C}$ NMR: $101 \mathrm{MHz}, \mathrm{CDCl}_{3}$

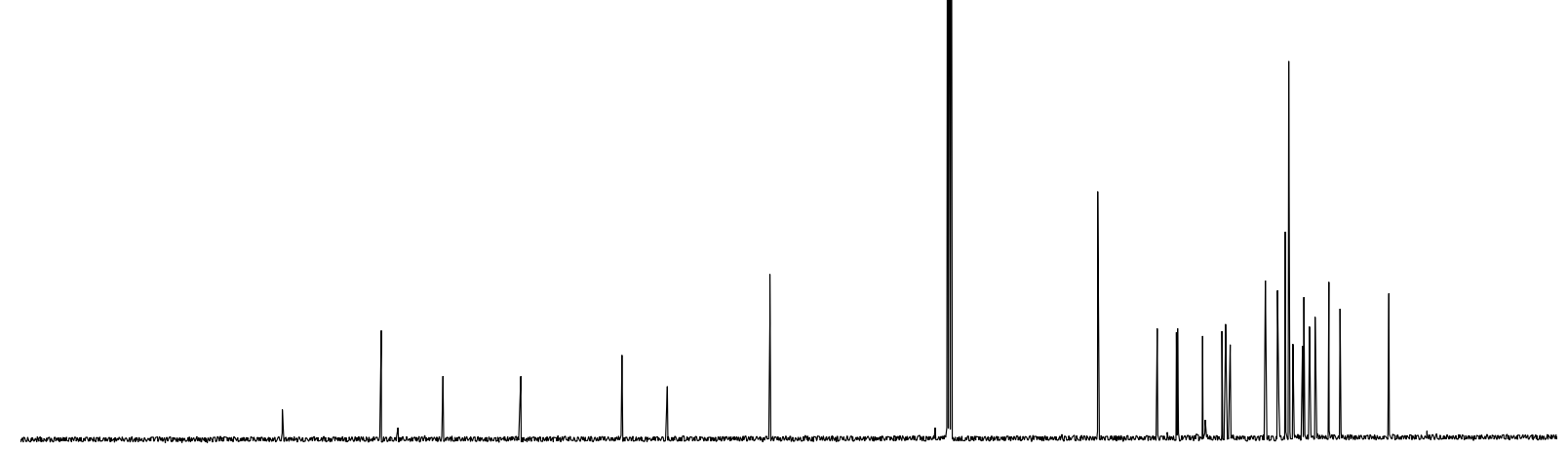

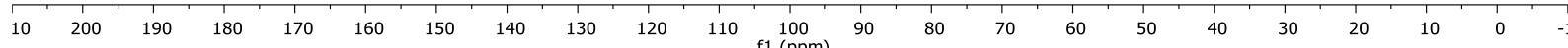



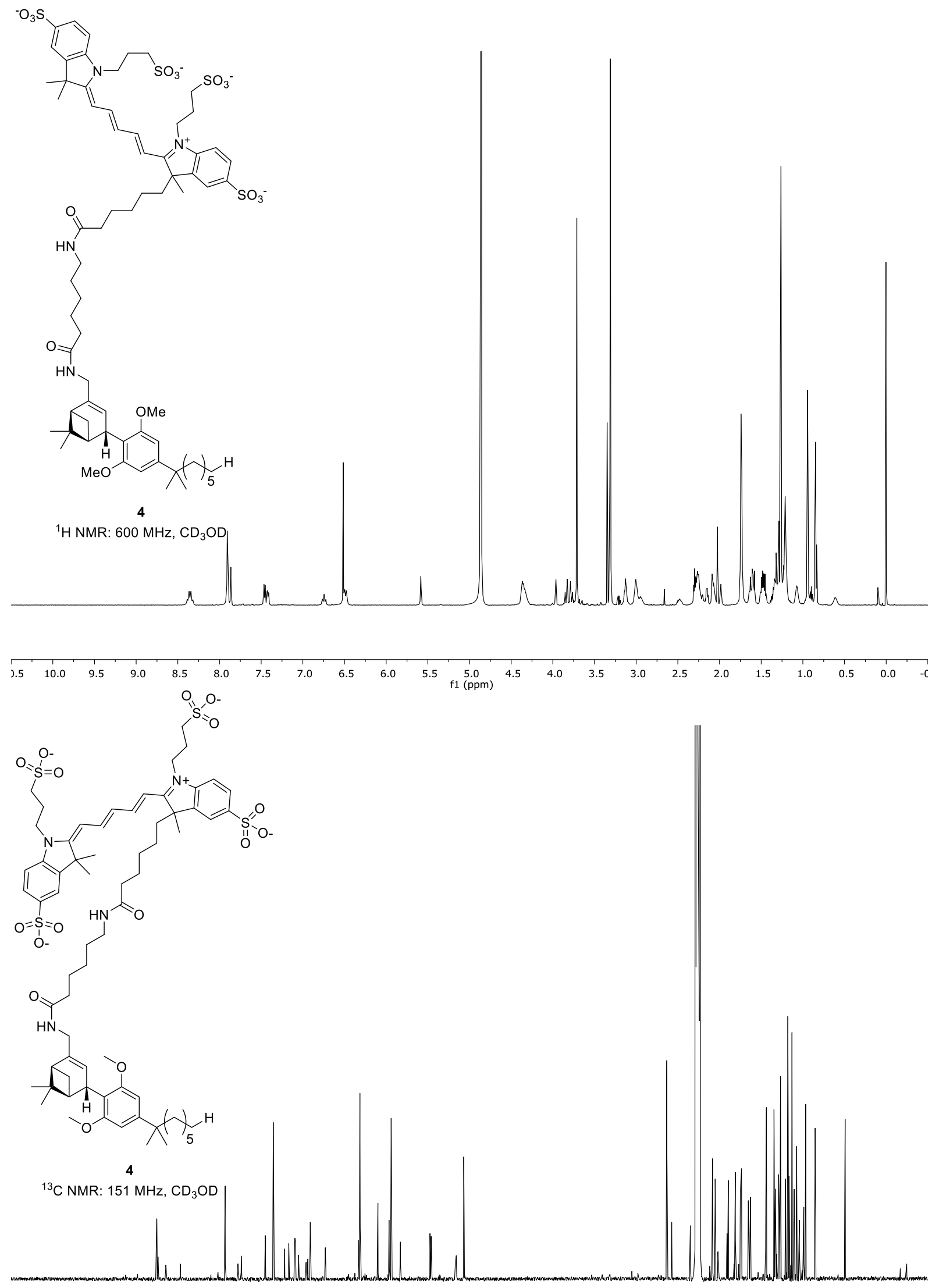

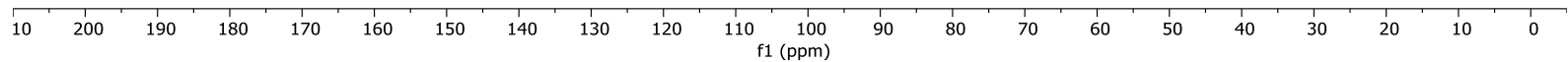




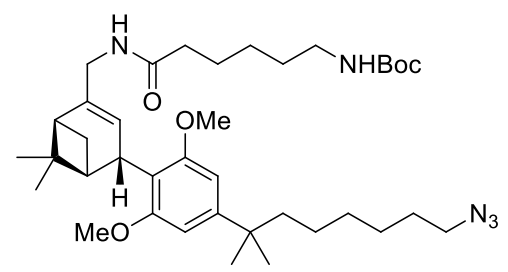

56

${ }^{1} \mathrm{H}$ NMR: $500 \mathrm{MHz}, \mathrm{CDCl}_{3}$
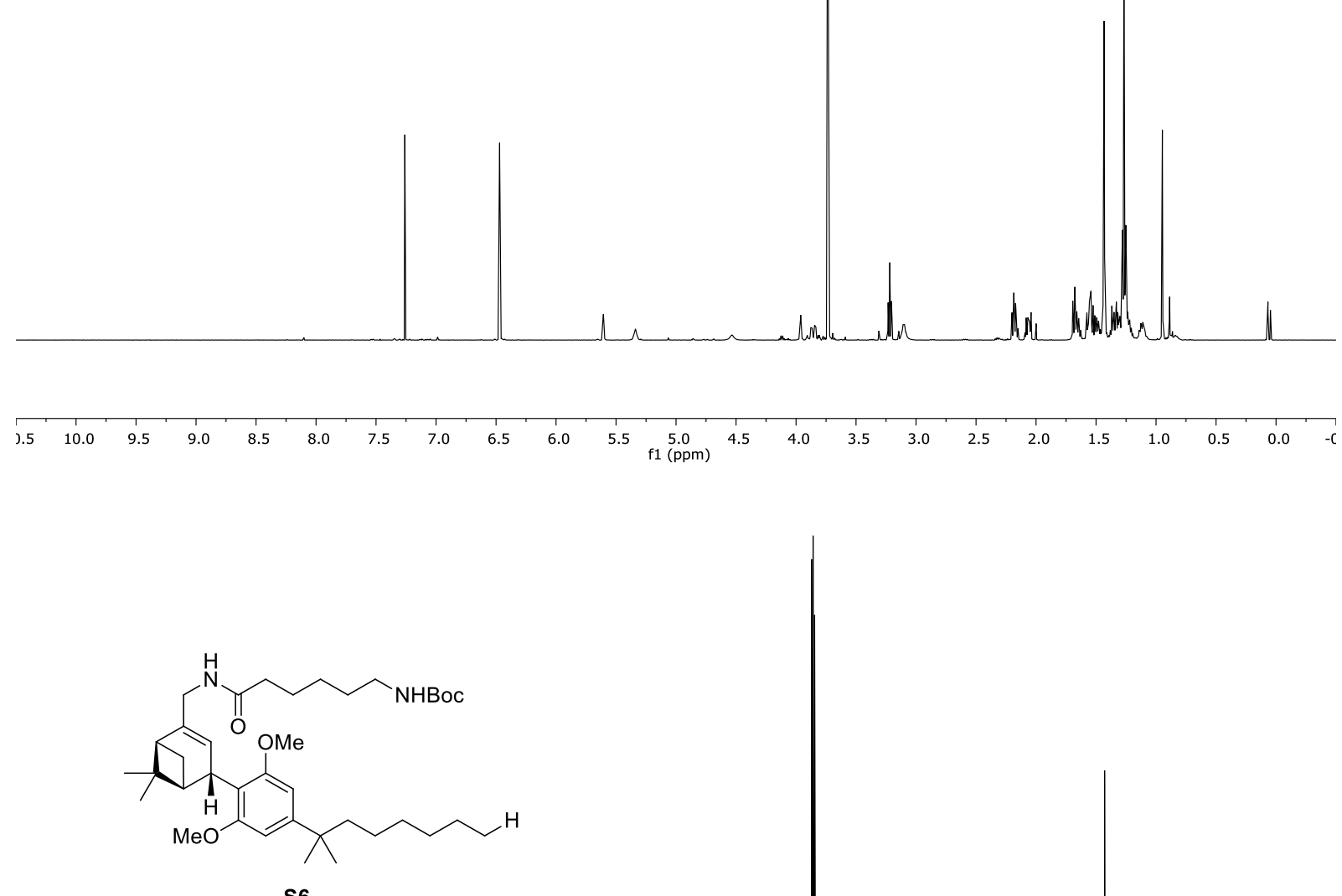

${ }^{13} \mathrm{C}$ NMR: $126 \mathrm{MHz}, \mathrm{CDCl}_{3}$

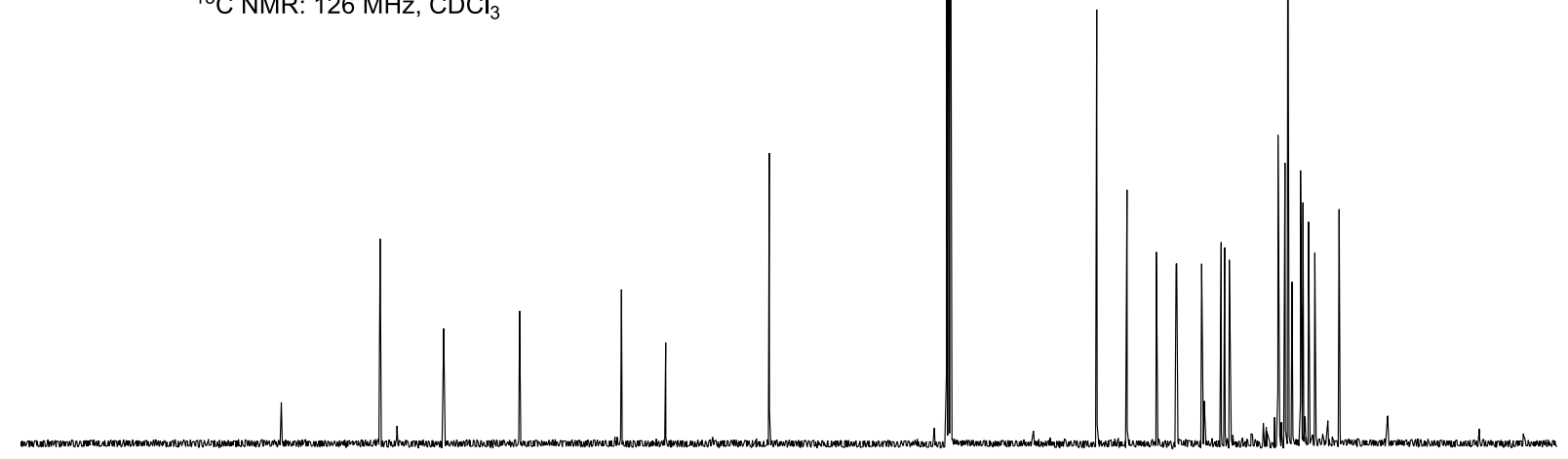

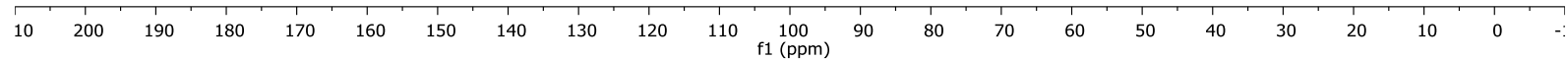




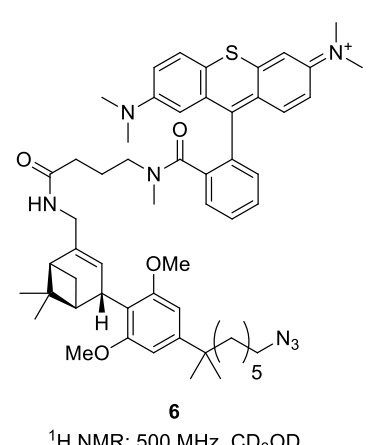

${ }^{1} \mathrm{H}$ NMR: $500 \mathrm{MHz}, \mathrm{CD}_{3} \mathrm{OD}$

buldull

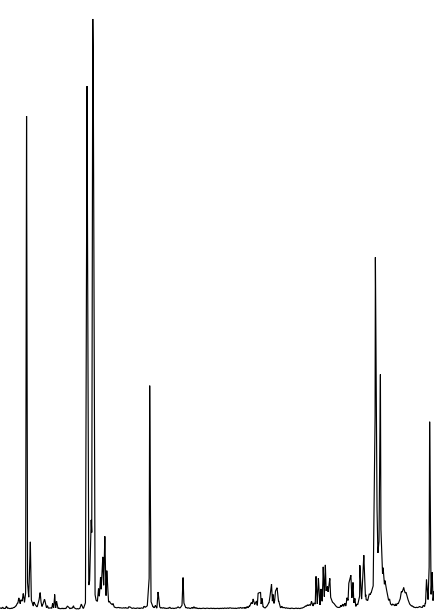

\begin{tabular}{llllllllllllllllllllllllll}
\hline .5 & 10.0 & 9.5 & 9.0 & 8.5 & 8.0 & 7.5 & 7.0 & 6.5 & 6.0 & 5.5 & 5.0 & 4.5 & 4.0 & 3.5 & 3.0 & 2.5 & 2.0 & 1.5 & 1.0 & 0.5 & 0.0 & $-c$
\end{tabular}

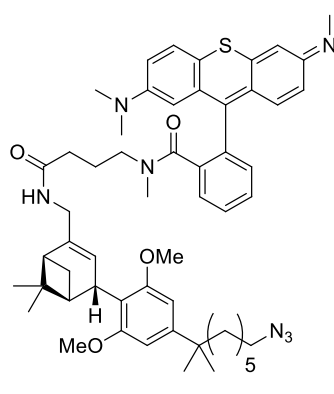

${ }^{13} \mathrm{C}$ NMR: $126 \mathrm{MHz}, \mathrm{CD}_{3} \mathrm{OD}$

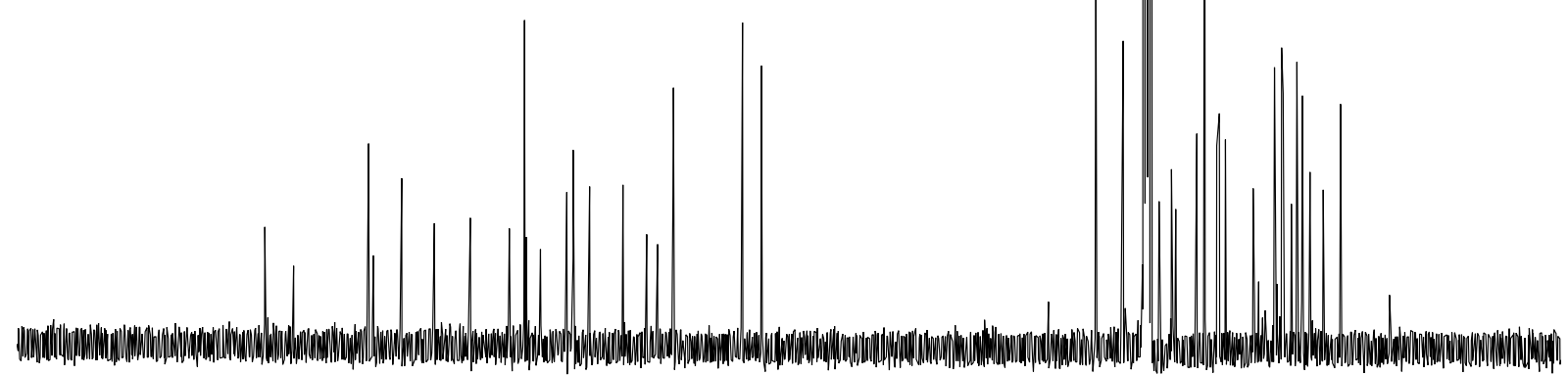

$\begin{array}{lllllllllllllllllllllllll}10 & 200 & 190 & 180 & 170 & 160 & 150 & 140 & 130 & 120 & 110 & \begin{array}{c}100 \\ \mathrm{f} 1(\mathrm{ppm})\end{array} & 90 & 80 & 70 & 60 & 50 & 40 & 30 & 20 & 10 & 0 & -\end{array}$ 


\section{N-TERMINAL SNAP-hCB 2 R SEQUENCE}

\section{pcDNA4TO_SNAP-hCB ${ }_{2} R-T w i n S t r e p-1 D 4$ plasmid DNA sequence}

GACGGATCGGGAGATCTCCCGATCCCCTATGGTGCACTCTCAGTACAATCTGCT CTGATGCCGCATAGTTAAGCCAGTATCTGCTCCCTGCTTGTGTGTTGGAGGTCG CTGAGTAGTGCGCGAGCAAAATTTAAGCTACAACAAGGCAAGGCTTGACCGACA ATTGCATGAAGAATCTGCTTAGGGTTAGGCGTTTTGCGCTGCTTCGCGATGTAC GGGCCAGATATACGCGTTGACATTGATTATTGACTAGTTATTAATAGTAATCAAT TACGGGGTCATTAGTTCATAGCCCATATATGGAGTTCCGCGTTACATAACTTACG GTAAATGGCCCGCCTGGCTGACCGCCCAACGACCCCCGCCCATTGACGTCAAT AATGACGTATGTTCCCATAGTAACGCCAATAGGGACTTTCCATTGACGTCAATG GGTGGAGTATTTACGGTAAACTGCCCACTTGGCAGTACATCAAGTGTATCATAT GCCAAGTACGCCCCCTATTGACGTCAATGACGGTAAATGGCCCGCCTGGCATTA TGCCCAGTACATGACCTTATGGGACTTTCCTACTTGGCAGTACATCTACGTATTA GTCATCGCTATTACCATGGTGATGCGGTTTTGGCAGTACATCAATGGGCGTGGA TAGCGGTTTGACTCACGGGGATTTCCAAGTCTCCACCCCATTGACGTCAATGGG AGTTTGTTTTGGAACCAAAATCAACGGGACTTTCCAAAATGTCGTAACAACTCCG CCCCATTGACGCAAATGGGCGGTAGGCGTGTACGGTGGGAGGTCTATATAAGC AGAGCTCTCCCTATCAGTGATAGAGATCTCCCTATCAGTGATAGAGATCGTCGA CGAGCTCGTTTAGTGAACCGTCAGATCGCCTGGAGACGCCATCCACGCTGTTTT GACCTCCATAGAAGACACCGGGACCGATCCAGCCTCCGGACTCTAGGCTAGCG CCACCATGCGGCTCTGCATCCCGCAGGTGCTGTTGGCCTTGTTCCTTTCCATGC TGACAGGGCCGGGAGAAGGCAGCGCTAGCGATATCGGCGCGCCAGCATTTAAA TCTGTACAGACCGGTGAATTCACCATGGACAAAGACTGCGAAATGAAGCGCACC ACCCTGGATAGCCCTCTGGGCAAGCTGGAACTGTCTGGGTGCGAACAGGGCCT GCACCGTATCATCTTCCTGGGCAAAGGAACATCTGCCGCCGACGCCGTGGAAG TGCCTGCCCCAGCCGCCGTGCTGGGCGGACCAGAGCCACTGATGCAGGCCAC CGCCTGGCTCAACGCCTACTTTCACCAGCCTGAGGCCATCGAGGAGTTCCCTG TGCCAGCCCTGCACCACCCAGTGTTCCAGCAGGAGAGCTTTACCCGCCAGGTG CTGTGGAAACTGCTGAAAGTGGTGAAGTTCGGAGAGGTCATCAGCTACAGCCA CCTGGCCGCCCTGGCCGGCAATCCCGCCGCCACCGCCGCCGTGAAAACCGCC CTGAGCGGAAATCCCGTGCCCATTCTGATCCCCTGCCACCGGGTGGTGCAGGG CGACCTGGACGTGGGGGGCTACGAGGGCGGGCTCGCCGTGAAAGAGTGGCTG CTGGCCCACGAGGGCCACAGACTGGGCAAGCCTGGGCTGGGTCCTGCAGGTA CCATGGAGGAGTGCTGGGTGACTGAGATCGCCAATGGCTCCAAGGACGGTCTG GACAGCAACCCCATGAAGGACTACATGATCCTCTCCGGCCCTCAGAAAACTGCC GTCGCCGTGCTGTGTACTCTCCTGGGCCTGCTCTCCGCCCTGGAAAACGTGGC CGTCCTCTACCTCATCCTGTCCAGCCATCAGCTGCGCCGCAAGCCTTCCTACCT GTTCATTGGCTCCCTGGCCGGCGCTGACTTTCTCGCTTCCGTCGTCTTCGCCTG CAGCTTCGTGAACTTTCACGTGTTCCACGGCGTCGATAGCAAGGCCGTCTTCCT CCTCAAGATCGGTAGCGTGACCATGACCTTCACTGCCAGCGTGGGCTCCCTGC TGCTGACTGCTATCGATCGCTACCTGTGTCTCCGCTACCCCCCCAGCTACAAGG CCCTGCTGACTCGTGGTCGTGCCCTCGTCACCCTGGGCATCATGTGGGTGCTG AGCGCCCTCGTGTCCTACCTGCCTCTCATGGGCTGGACCTGCTGCCCTCGCCC TTGTAGCGAGCTGTTCCCCCTCATTCCTAACGACTACCTCCTGAGCTGGCTGCT CTTCATTGCCTTCCTCTTCTCCGGCATCATCTACACCTACGGCCATGTCCTCTGG AAGGCCCACCAACATGTCGCCAGCCTCTCCGGTCACCAAGACCGCCAAGTGCC CGGTATGGCTCGTATGCGCCTGGACGTCCGTCTCGCCAAGACTCTGGGTCTCG TCCTCGCTGTGCTGCTGATCTGCTGGTTCCCCGTCCTGGCTCTCATGGCTCACA GCCTGGCCACCACCCTCTCCGATCAAGTCAAGAAGGCCTTCGCCTTCTGTAGCA 


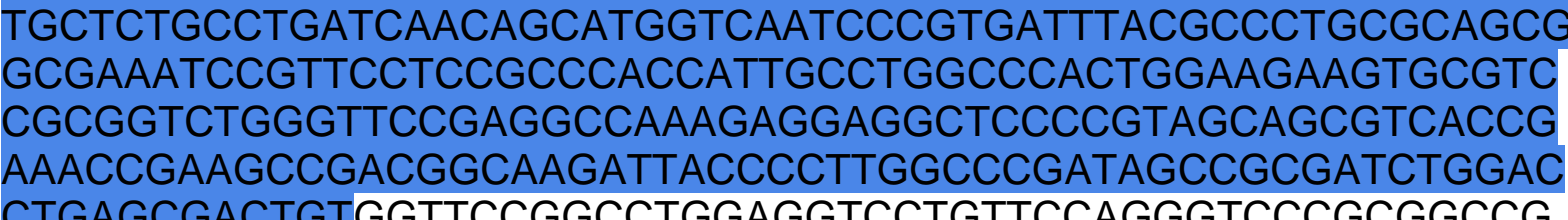
CTGAGCGACTGTGGTTCCGGCCTGGAGGTCCTGTTCCAGGGTCCCGCGGCCG CAGGATCCGCGTGGAGCCACCCACAGTTCGAGAAGGGAGGTGGAAGCGGTGG AGGCTCAGGAGGCAGCGCATGGTCCCACCCCCAGTTTGAAAAGGGCTCAGGAG GTAGCGAAGATCTGACCGAGACCAGCCAGGTGGCCCCCGCCTAAAAGCTTAAG TTTAAAAAGGCTCGAGTCTAGAGGGCCCGTTTAAACCCGCTGATCAGCCTCGAC TGTGCCTTCTAGTTGCCAGCCATCTGTTGTTTGCCCCTCCCCCGTGCCTTCCTT GACCCTGGAAGGTGCCACTCCCACTGTCCTTTCCTAATAAAATGAGGAAATTGC ATCGCATTGTCTGAGTAGGTGTCATTCTATTCTGGGGGGTGGGGTGGGGCAGG ACAGCAAGGGGGAGGATTGGGAAGACAATAGCAGGCATGCTGGGGATGCGGT GGGCTCTATGGCTTCTGAGGCGGAAAGAACCAGCTGGGGCTCTAGGGGGTATC CCCACGCGCCCTGTAGCGGCGCATTAAGCGCGGCGGGTGTGGTGGTTACGCG CAGCGTGACCGCTACACTTGCCAGCGCCCTAGCGCCCGCTCCTTTCGCTTTCTT CCCTTCCTTTCTCGCCACGTTCGCCGGCTTTCCCCGTCAAGCTCTAAATCGGGG GCTCCCTTTAGGGTTCCGATTTAGTGCTTTACGGCACCTCGACCCCAAAAAACT TGATTAGGGTGATGGTTCACGTAGTGGGCCATCGCCCTGATAGACGGTTTTTCG CCCTTTGACGTTGGAGTCCACGTTCTTTAATAGTGGACTCTTGTTCCAAACTGGA ACAACACTCAACCCTATCTCGGTCTATTCTTTTGATTTATAAGGGATTTTGCCGAT TTCGGCCTATTGGTTAAAAAATGAGCTGATTTAACAAAAATTTAACGCGAATTAAT TCTGTGGAATGTGTGTCAGTTAGGGTGTGGAAAGTCCCCAGGCTCCCCAGCAG GCAGAAGTATGCAAAGCATGCATCTCAATTAGTCAGCAACCAGGTGTGGAAAGT CCCCAGGCTCCCCAGCAGGCAGAAGTATGCAAAGCATGCATCTCAATTAGTCAG CAACCATAGTCCCGCCCCTAACTCCGCCCATCCCGCCCCTAACTCCGCCCAGTT CCGCCCATTCTCCGCCCCATGGCTGACTAATTTTTTTTATTTATGCAGAGGCCGA GGCCGCCTCTGCCTCTGAGCTATTCCAGAAGTAGTGAGGAGGCTTTTTTGGAG GCCTAGGCTTTTGCAAAAAGCTCCCGGGAGCTTGTATATCCATTTTCGGATCTG ATCAGCACGTGTTGACAATTAATCATCGGCATAGTATATCGGCATAGTATAATAC GACAAGGTGAGGAACTAAACCATGGCCAAGTTGACCAGTGCCGTTCCGGTGCT CACCGCGCGCGACGTCGCCGGAGCGGTCGAGTTCTGGACCGACCGGCTCGGG TTCTCCCGGGACTTCGTGGAGGACGACTTCGCCGGTGTGGTCCGGGACGACGT GACCCTGTTCATCAGCGCGGTCCAGGACCAGGTGGTGCCGGACAACACCCTGG CCTGGGTGTGGGTGCGCGGCCTGGACGAGCTGTACGCCGAGTGGTCGGAGGT CGTGTCCACGAACTTCCGGGACGCCTCCGGGCCGGCCATGACCGAGATCGGC GAGCAGCCGTGGGGGCGGGAGTTCGCCCTGCGCGACCCGGCCGGCAACTGC GTGCACTTCGTGGCCGAGGAGCAGGACTGACACGTGCTACGAGATTTCGATTC CACCGCCGCCTTCTATGAAAGGTTGGGCTTCGGAATCGTTTTCCGGGACGCCG GCTGGATGATCCTCCAGCGCGGGGATCTCATGCTGGAGTTCTTCGCCCACCCC AACTTGTTTATTGCAGCTTATAATGGTTACAAATAAAGCAATAGCATCACAAATTT CACAAATAAAGCATTTTTTTCACTGCATTCTAGTTGTGGTTTGTCCAAACTCATCA ATGTATCTTATCATGTCTGTATACCGTCGACCTCTAGCTAGAGCTTGGCGTAATC ATGGTCATAGCTGTTTCCTGTGTGAAATTGTTATCCGCTCACAATTCCACACAAC ATACGAGCCGGAAGCATAAAGTGTAAAGCCTGGGGTGCCTAATGAGTGAGCTA ACTCACATTAATTGCGTTGCGCTCACTGCCCGCTTTCCAGTCGGGAAACCTGTC GTGCCAGCTGCATTAATGAATCGGCCAACGCGCGGGGAGAGGCGGTTTGCGTA TTGGGCGCTCTTCCGCTTCCTCGCTCACTGACTCGCTGCGCTCGGTCGTTCGG CTGCGGCGAGCGGTATCAGCTCACTCAAAGGCGGTAATACGGTTATCCACAGA ATCAGGGGATAACGCAGGAAAGAACATGTGAGCAAAAGGCCAGCAAAAGGCCA GGAACCGTAAAAAGGCCGCGTTGCTGGCGTTTTTCCATAGGCTCCGCCCCCCG 
ACGAGCATCACAAAAATCGACGCTCAAGTCAGAGGTGGCGAAACCCGACAGGA CTATAAAGATACCAGGCGTTTCCCCCTGGAAGCTCCCTCGTGCGCTCTCCTGTT CCGACCCTGCCGCTTACCGGATACCTGTCCGCCTTTCTCCCTTCGGGAAGCGT GGCGCTTTCTCATAGCTCACGCTGTAGGTATCTCAGTTCGGTGTAGGTCGTTCG CTCCAAGCTGGGCTGTGTGCACGAACCCCCCGTTCAGCCCGACCGCTGCGCCT TATCCGGTAACTATCGTCTTGAGTCCAACCCGGTAAGACACGACTTATCGCCAC TGGCAGCAGCCACTGGTAACAGGATTAGCAGAGCGAGGTATGTAGGCGGTGCT ACAGAGTTCTTGAAGTGGTGGCCTAACTACGGCTACACTAGAAGAACAGTATTT GGTATCTGCGCTCTGCTGAAGCCAGTTACCTTCGGAAAAAGAGTTGGTAGCTCT TGATCCGGCAAACAAACCACCGCTGGTAGCGGTTTTTTTGTTTGCAAGCAGCAG ATTACGCGCAGAAAAAAAGGATCTCAAGAAGATCCTTTGATCTTTTCTACGGGGT CTGACGCTCAGTGGAACGAAAACTCACGTTAAGGGATTTTGGTCATGAGATTAT CAAAAAGGATCTTCACCTAGATCCTTTTAAATTAAAAATGAAGTTTTTAAATCAATC TAAAGTATATATGAGTAAACTTGGTCTGACAGTTACCAATGCTTAATCAGTGAGG CACCTATCTCAGCGATCTGTCTATTTCGTTCATCCATAGTTGCCTGACTCCCCGT CGTGTAGATAACTACGATACGGGAGGGCTTACCATCTGGCCCCAGTGCTGCAAT GATACCGCGAGACCCACGCTCACCGGCTCCAGATTTATCAGCAATAAACCAGCC AGCCGGAAGGGCCGAGCGCAGAAGTGGTCCTGCAACTTTATCCGCCTCCATCC AGTCTATTAATTGTTGCCGGGAAGCTAGAGTAAGTAGTTCGCCAGTTAATAGTTT GCGCAACGTTGTTGCCATTGCTACAGGCATCGTGGTGTCACGCTCGTCGTTTGG TATGGCTTCATTCAGCTCCGGTTCCCAACGATCAAGGCGAGTTACATGATCCCC CATGTTGTGCAAAAAAGCGGTTAGCTCCTTCGGTCCTCCGATCGTTGTCAGAAG TAAGTTGGCCGCAGTGTTATCACTCATGGTTATGGCAGCACTGCATAATTCTCTT ACTGTCATGCCATCCGTAAGATGCTTTTCTGTGACTGGTGAGTACTCAACCAAGT CATTCTGAGAATAGTGTATGCGGCGACCGAGTTGCTCTTGCCCGGCGTCAATAC GGGATAATACCGCGCCACATAGCAGAACTTTAAAAGTGCTCATCATTGGAAAAC GTTCTTCGGGGCGAAAACTCTCAAGGATCTTACCGCTGTTGAGATCCAGTTCGA TGTAACCCACTCGTGCACCCAACTGATCTTCAGCATCTTTTACTTTCACCAGCGT TTCTGGGTGAGCAAAAACAGGAAGGCAAAATGCCGCAAAAAAGGGAATAAGGG CGACACGGAAATGTTGAATACTCATACTCTTCCTTTTTCAATATTATTGAAGCATT TATCAGGGTTATTGTCTCATGAGCGGATACATATTTGAATGTATTTAGAAAAATAA ACAAATAGGGGTTCCGCGCACATTTCCCCGAAAAGTGCCACCTGACGTC

CMV promotor

serotonin 5HT3A receptor signal peptide

SNAP-tag

$\mathrm{CB}_{2} \mathrm{R}$

TwinStrep purification tag

1D4 purification tag 


\section{SNAP-hCB 2 R-TwinStrep-1D4 protein sequence}

MRLCIPQVLLALFLSMLTGPGEGSASDIGAPAFKSVQTGEFTMDKDCEMKRTTLDS PLGKLELSGCEQGLHRIIFLGKGTSAADAVEVPAPAAVLGGPEPLMQATAWLNAYF HQPEAIEEFPVPALHHPVFQQESFTRQVLWKLLKVVKFGEVISYSHLAALAGNPAAT AAVKTALSGNPVPILIPCHRVVQGDLDVGGYEGGLAVKEWLLAHEGHRLGKPGLGP AGTMEECWVTEIANGSKDGLDSNPMKDYMILSGPQKTAVAVLCTLLGLLSALENVA VLYLILSSHQLRRKPSYLFIGSLAGADFLASVVFACSFVNFHVFHGVDSKAVFLLKIG SVTMTFTASVGSLLLTAIDRYLCLRYPPSYKALLTRGRALVTLGIMWVLSALVSYLPL MGWTCCPRPCSELFPLIPNDYLLSWLLFIAFLFSGIIYTYGHVLWKAHQHVASLSGH QDRQVPGMARMRLDVRLAKTLGLVLAVLLICWFPVLALMAHSLATTLSDQVKKAFA FCSMLCLINSMVNPVIYALRSGEIRSSAHHCLAHWKKCVRGLGSEAKEEAPRSSVT ETEADGKITPWPDSRDLDLSDCGSGLEVLFQGPAAAGSAWSHPQFEKGGGSGGG SGGSAWSHPQFEKGSGGSEDLTETSQVAPA

serotonin 5HT3A receptor signal peptide

SNAP-tag

$\mathrm{CB}_{2} \mathrm{R}$

TwinStrep purification tag

1D4 purification tag 


\section{REFERENCES}

[1] D. R. Lide, CRC Handbook of Chemistry and Physics 2009-2010, 90th Edition, 2009.

[2] A. I. Vogel, Vogel's Practical Organic Chemistry 5th Edition, 1989.

[3] S. Bendels, C. Bissantz, B. Fasching, G. Gerebtzoff, W. Guba, et al., Journal of Pharmacological and Toxicological Methods, ASAP July 2019

[4] A. Pyka, M. Babuska, M. Zachariasz, Acta Pol Pharm. 2006, 63, 159-167.

[5] G. Jones, P. Willett, R. C. Glen, A. R. Leach, R. Taylor, J. Mol. Biol. 1997, 267, 727.

[6] Citation MOE: Molecular Operating Environment (MOE) ver. 2014.09, Chemical ComputingGroup Inc., 1010 Sherbooke Street West, Suite \#910, Montreal,QC H3A 2R7 (Canada), 2015

[7] M. Soethoudt, U. Grether, J. Fingerle, T. W. Grim, F. Fezza, L. de Petrocellis, C. Ullmer, B. Rothenhäusler, C. Perret, N. van Gils, et al., Nat. Comm. 2017, 8, 1.

[8] M. Kansy, F. Senner, K. Gubernator, J. Med. Chem. 1998, 41, 1007.

[9] C. Klein Herenbrink, D. A. Sykes, P. Donthamsetti, M. Canals, T. Coudrat, J. Shonberg, P. J. Scammells, B. Capuano, P. M. Sexton, S. J. Charlton, et al., Nat. Comm. 2016, 7, 10842.

[10] H. J. Motulsky, L. C. Mahan, Mol, Pharmacol., 1984, 25, 1.

[11] a) W. Gonsiorek, D. Heske, S. C. Chen, D. Kinsley, J. V. Jackson et al. J. Biol. Chem. 2006, 38, 28143. b) M. Bouaboula, S. Perrachon, L. Milligan, X. Canat, M. Rinaldi/Carmona, et al. J. Biol. Chem, 1997, 35, 22330.

[12] C. Yung-Chi, W. H. Prusoff, Biochem. Pharmacol. 1973, 22, 3099.

[13] A. López, N. Aparicio, M.R. Pazos et al. J. Neuroinflammation 2018, 15, 158.

[14] D. Wu, L. Yang, A. Goschke, R. Stumm, L. Brandenburg, Y. Liang, V. Höllt, T. Koch, J. Neurochem. 2007, 104, 1132.

[15] P. J. Murray, J. E. Allen, S. K. Biswas, E. A. Fisher, D. W. Gilroy et al. Immunity 2014, $41,339$.

[16] M. V. Westphal, R. C. Sarott, E. A. Zirwes, A. Osterwald, W. Guba, C. Ullmer, U. Grether, E. M. Carreira, Chem. Eur. J. Chem. 2019, 26, 1380. 